University of Louisville

ThinkIR: The University of Louisville's Institutional Repository

\title{
The macro-modelling of steel fiber reinforced concrete/mortar flexural tensile behavior and mix optimization for flexural strength.
}

Li Liu

University of Louisville

Follow this and additional works at: https://ir.library.louisville.edu/etd

Part of the Civil Engineering Commons

\section{Recommended Citation}

$\mathrm{Liu}, \mathrm{Li}$, "The macro-modelling of steel fiber reinforced concrete/mortar flexural tensile behavior and mix optimization for flexural strength." (2017). Electronic Theses and Dissertations. Paper 2809.

https://doi.org/10.18297/etd/2809

This Master's Thesis is brought to you for free and open access by ThinkIR: The University of Louisville's Institutional Repository. It has been accepted for inclusion in Electronic Theses and Dissertations by an authorized administrator of ThinkIR: The University of Louisville's Institutional Repository. This title appears here courtesy of the author, who has retained all other copyrights. For more information, please contact thinkir@louisville.edu. 
THE MACRO-MODELLING OF STEEL FIBER REINFORCED CONCRETE/MORTAR FLEXURAL TENSILE BEHAVIOR AND MIX OPTIMIZATION FOR FLEXURAL STRENGTH

\author{
By \\ Li Liu

\begin{abstract}
A Thesis
Submitted to the Faculty of the

University of Louisville

J.B. Speed School of Engineering

as Partial Fulfillment of the Requirements

for the Degree of
\end{abstract}

Master of Science

in Civil Engineering

Department of Civil \& Environmental Engineering

University of Louisville

Louisville, Kentucky

August 2017 
Copyright 2017 by Li Liu

All rights reserved 

THE MACRO-MODELLING OF STEEL FIBER REINFORCED CONCRETE/MORTAR FLEXURAL TENSILE BEHAVIOR AND MIX OPTIMIZATION FOR FLEXURAL STRENGTH

Submitted By:

\author{
Li Liu
}

A Thesis Approved on

July 272017

(Date)

by the Following Thesis Committee:

Dr. W. Mark McGinley, Thesis Director

Dr. Young Hoon Kim

Dr. Li Yang 


\section{ACKNOWLEDGEMENT}

I would first like to thank my advisor, Dr. W. Mark McGinley, for his guidance and patience. The door to Dr. McGinley's office was always open whenever I ran into a trouble spot or had a question about my research, my writing or anything that an advisor can help to the greatest extent possible. He always encouraged me, pushed me, guided me, during this very first year of overseas study.

I would like to thank my fiancée, Han Qiu, for her concern and encouragement, too. I am gratefully indebted to her support and understanding, especially at this moment of my life, when I determined to chase my dreams and my career from the bottom of my heart. I would like to thank my parents for their spiritual and financial support. They are the best parents in the world.

I would also like to thank my dearest friends, Yan $\mathrm{Wu}$ and Allison Chou, for their accommodation and their help during this whole year. I had more time focusing on my study because of their help and support. Thank Dr. Sun for her concern and reminder. 


\section{ABSTRACT \\ THE MACRO-MODELLING OF STEEL FIBER REINFORCED CONCRETE/MORTAR FLEXURAL TENSILE BEHAVIOR AND MIX OPTIMIZATION FOR FLEXURAL STRENGTH

\author{
Li Liu
}

July 27,2017

With the continuous advances in materials' technology, the performance of the commonly used concrete building material has continued to improve. Compressive strengths exceeding $75 \mathrm{MPa}$ are now being used in applications throughout the world. However, the concrete becomes less ductile and more susceptible to sudden failures with increases in its compressive strength. Although the behavior of concrete is generally governed by its compressive strength, its tensile strength, although much lower, is also important. This tensile strength impacts appearance, the serviceability and durability of concrete elements. In addition, minimum levels of tensile strength are required for many concrete applications including, earthquake resistant structures, tanks and other fluid containment structures, runways, slabs and pavement

The addition of steel fibers also improves the tensile strength of the composite, a significant structural weakness of concrete. At the micro-level, fibers inhibit the initiation and growth of cracks, and after the micro-cracks coalesce into macro-cracks, fibers abate their unstable propagation, bridging the cracks and improving strength, toughness and ductility.

This investigation extended an analytical developed by other for general flexural behavior of fiber reinforced composite concrete materials. Reasonable agreement was 
found between the model and measured behavior. The model is sufficiently accurate to identify which factors may affect flexural strength and how configurations can be optimized to improve this strength. 


\section{TABLE OF CONTENTS}

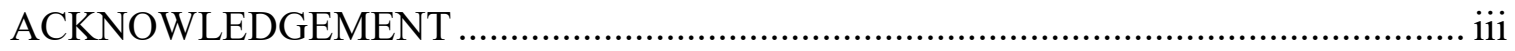

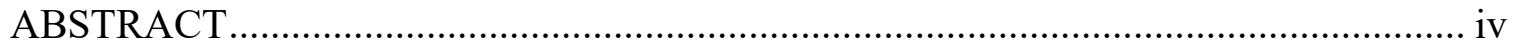

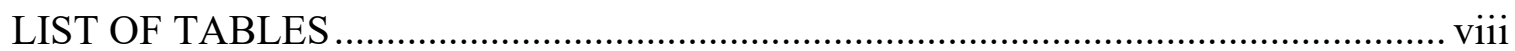

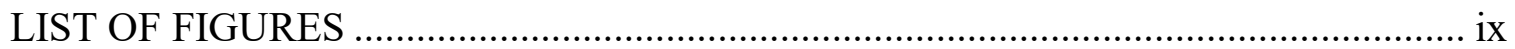

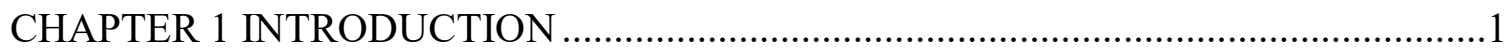

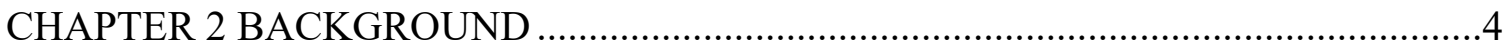

2.1. Fiber Reinforced Concrete ...........................................................................

2.2. Fiber Reinforced Concrete Analytical Models ................................................6

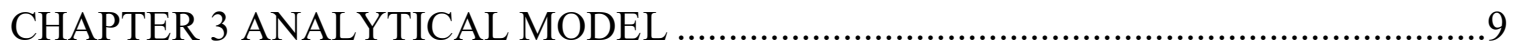

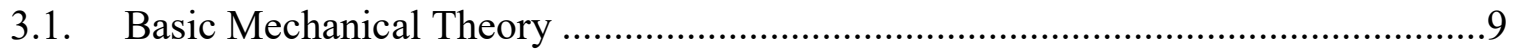

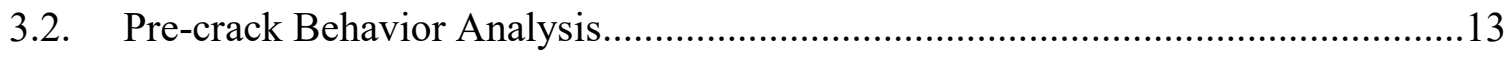

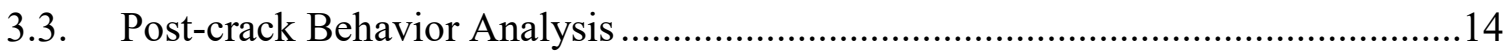

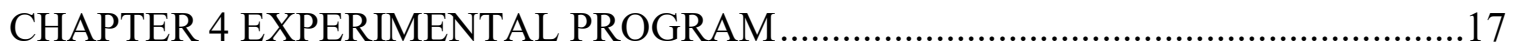

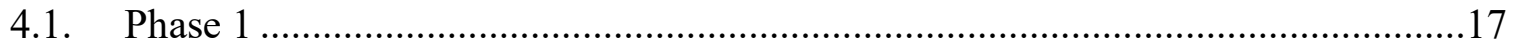

4.1.1. Fiber Direct Tension Tests .......................................................................... 19

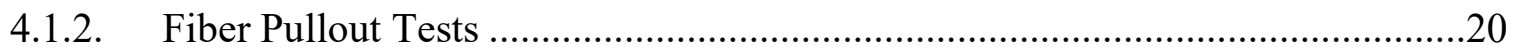


4.2. Phase 2

5.1. Direct Tension Results.

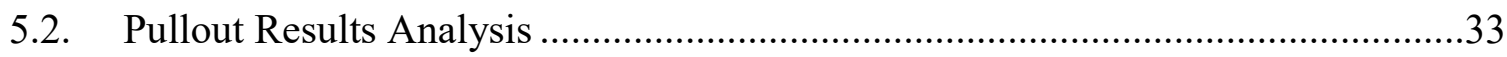

5.3. Beam and Cube Test Results Analysis ........................................................42

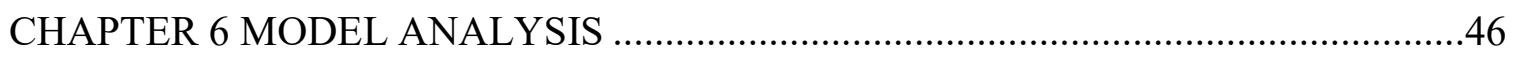

6.1. Preliminary Model Validation - Previous Large Scale Concrete Beam Tests .......46

6.2. Mortar Beam Tests Predicted Measured Behavior ...............................................51

6.2.1. Pre-cracked Behavior .......................................................................... 51

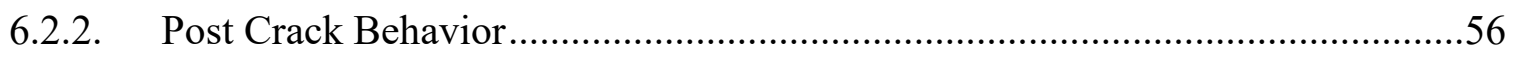

6.3. Model Parametric Study and Optimization.......................................................66

CHAPTER 7 CONCLUSION AND RECOMMENDATIONS ...................................72

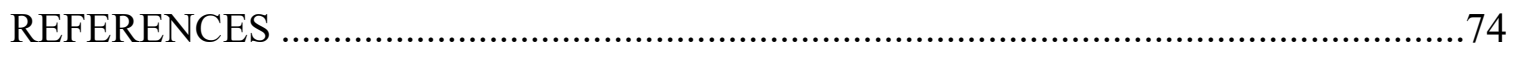

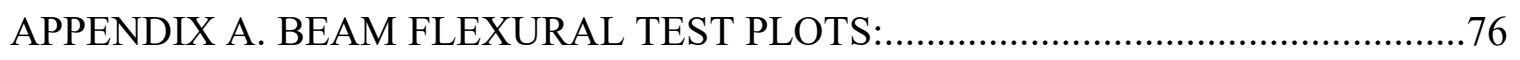

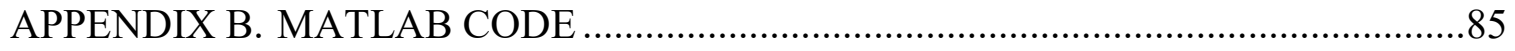

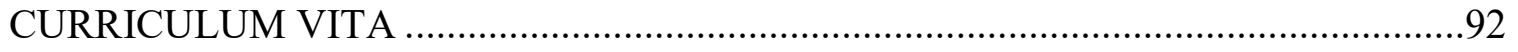




\section{LIST OF TABLES}

Table 4-1: Mass Ratio of Mortar and Concrete Mix...................................................... 17

Table 4-2: Fiber Configuration Used in Mortar Beams and Cubes ................................ 18

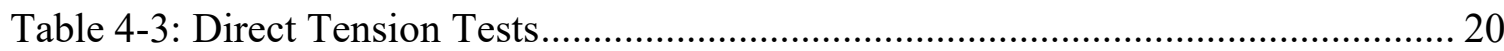

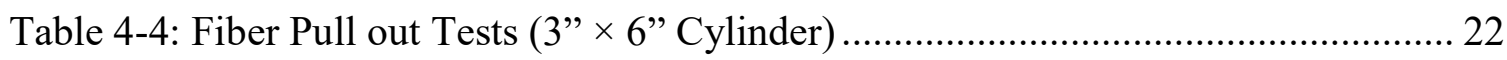

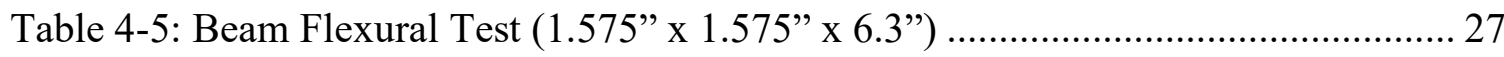

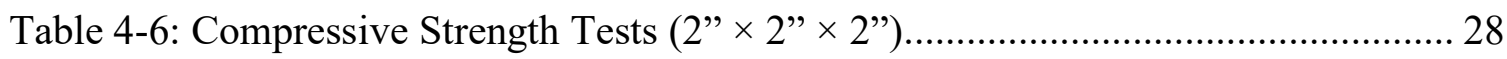

Table 5-1: Direct Tension Test Results (Average of Three Tests) ............................... 30

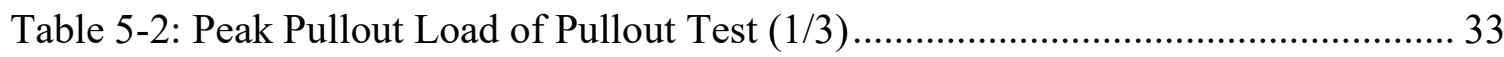

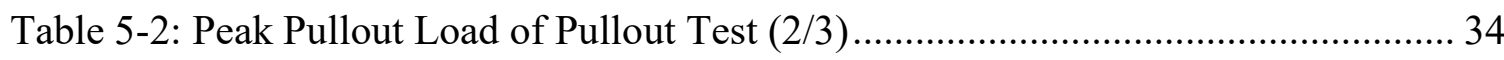

Table 5-2: Peak Pullout Load of Pullout Test (3/3) .................................................... 35

Table 5-3: Concrete Cylinder and Mortar Cube Compression Test Results ................... 38

Table 5-4: Compressive Strength of Cubes Casted with Beams (1/3)......................... 42

Table 5-4: Compressive Strength of Cubes Casted with Beams (2/3).......................... 43

Table 5-4: Compressive Strength of Cubes Casted with Beams (3/3)......................... 44

Table 6-1: Fiber Characteristics assumed for Model Predictions .................................. 46

Table 6-2: Third Point Fiber Reinforced Beam Tests (6" x 6", 18" span beams) ........... 48 


\section{LIST OF FIGURES}

Figure 3-1 Probability of fiber inclination angle using sphere representation...........................................10

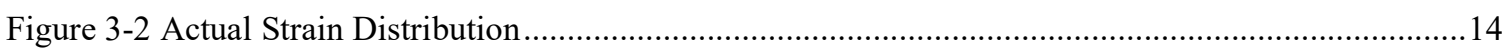

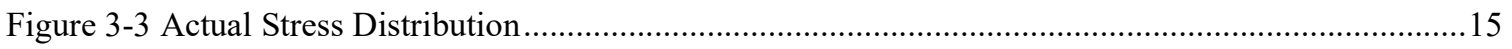

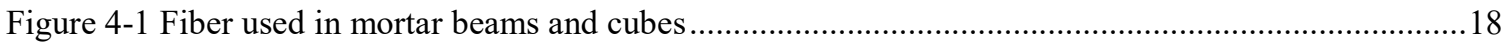

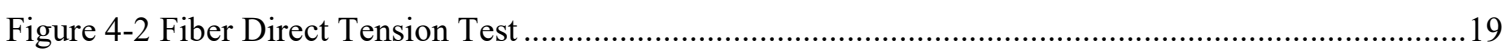

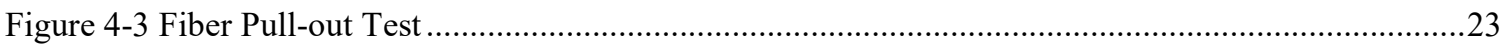

Figure 4-4 Typical Fiber Pull-Out Specimen Just Prior to Test ..................................................................24

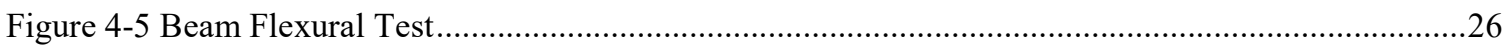

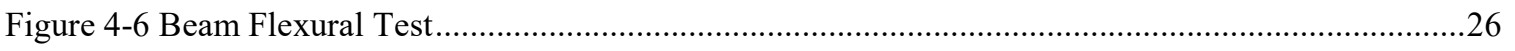

Figure 5-1 Tension Test Results of As Received Fibers (Stress in psi, Strain in microstrain) ......................31

Figure 5-2 Tension Test Results for Heat Treated Fibers (Stress in psi, Strain in microstrain) ....................32

Figure 5-3 Tension Test Results for Coating 2 Fibers (Stress in psi, Strain in microstrain) ........................32

Figure 5-4 Fiber Pullout Load-Displacement Behavior of Bare Fiber at 1.5" Embedment in Concrete ........35

Figure 5-5 Fiber Pullout Load-Displacement Behavior of Bare Fiber at 1.0" Embedment in Concrete ........36

Figure 5-6 Fiber Pullout Load-Displacement Behavior of Bare Fiber at 0.5" Embedment Length in

Concrete .37

Figure 5-7 Fiber Pullout Load-Displacement Behavior of Bare Fiber at 0.75" Embedment Length in Mortar

Figure 5-8 Fiber Pullout Load-Displacement Behavior of CT2 Fiber at 1.5" Embedment Length...............40

Figure 5-9 Fiber Pullout Load-Displacement Behavior of CT2 Fiber at 1.0" Embedment Length...............41

Figure 5-10 Fiber Pullout Load-Displacement Behavior of CT2 Fiber at 0.5” Embedment Length.............41

Figure 5-11 Load Deflection Response of Unreinforced Mortar Beams ......................................................44

Figure 5-12 Typical Load Deflection Response of Reinforced Mortar Beams ............................................45

Figure 6-1 Comparison of Predicted and Measured versus Moment Factor for FRC Beams - Coating B ...49

Figure 6-2 Comparison of Predicted and Measured versus Moment Factor for FRC Beams - Coating C ...50 
Figure 6-3 Fiber Orientation Distribution: Vertical Biased...................................................................52

Figure 6-4 Fiber Orientation Distribution: Uniformly .......................................................................52

Figure 6-5 Fiber Orientation Distribution: Horizontal Biased................................................................52

Figure 6-6 Tested Results and Predictions of Fiber A in Mix 1 ..........................................................53

Figure 6-7 Tested Results and Predictions of Fiber B in Mix 1 ................................................................54

Figure 6-8 Tested Results and Predictions of Fiber C in Mix 1 .........................................................54

Figure 6-9 Tested Results and Predictions of Fiber A in Mix 2 ..............................................................56

Figure 6-10 Symmetric Half of Beam Specimen in Flexural Test ..........................................................57

Figure 6-11 Post-crack Behavior of Fiber A in Mix 1 at 1.3\% volume fraction (2\% Nominally) ...............58

Figure 6-12 Post-crack Behavior of Fiber A in Mix 1 at 1.9\% volume fraction (3\% Nominally) ...............59

Figure 6-13 Post-crack Behavior of Fiber A in Mix 1 at 2.6\% volume fraction (4\% Nominally) ................59

Figure 6-14 Post-crack Behavior of Fiber B in Mix 1 at 1.3\% volume fraction (2\% Nominally)................60

Figure 6-15 Post-crack Behavior of Fiber B in Mix 1 at 2.1\% volume fraction (3\% Nominally)................60

Figure 6-16 Post-crack Behavior of Fiber B in Mix 1 at 2.6\% volume fraction (4\% Nominally).................61

Figure 6-17 Post-crack Behavior of Fiber $\mathrm{C}$ in Mix 1 at 1.2\% volume fraction (2\% Nominally)................61

Figure 6-18 Post-crack Behavior of Fiber C in Mix 1 at 1.7\% volume fraction (3\% Nominally)................62

Figure 6-19 Post-crack Behavior of Fiber $\mathrm{C}$ in Mix 1 at 2.3\% volume fraction (4\% Nominally)................62

Figure 6-20 Post-crack Behavior of Fiber A in Mix 2 at 1.3\% volume fraction (2\% Nominally) ...............63

Figure 6-21 Post-crack Behavior of Fiber A in Mix 2 at 2.0\% volume fraction (3\% Nominally) ...............63

Figure 6-22 Post-crack Behavior of Fiber A in Mix 2 at 2.7\% volume fraction (4\% Nominally) ...............64

Figure 6-23 Post-crack Behavior of Coated Fiber in Mix 2 at 1.4\% volume fraction (2\% Nominally)........64

Figure 6-24 Post-crack Behavior of Coated Fiber in Mix 2 at 2.1\% volume fraction ( $3 \%$ Nominally) ........65

Figure 6-25 Post-crack Behavior of Coated Fiber in Mix 2 at 2.8\% volume fraction (4\% Nominally) ........65

Figure 6-26 Variation of Cracking Moment with Fiber length \& variable volumes for $d_{f}=0.1$ ” fiber ..........67

Figure 6-27 Variation of Cracking Moment with Fiber diameter \& variable volumes for $1_{\mathrm{f}}=0.75$ " fiber .....68

Figure 6-28 Variation of Cracking Moment with Fiber diameter \& variable volumes for $1_{\mathrm{f}}=0.5$ " fiber .......69

Figure 6-29 Variation of Cracking Moment with Fiber diameter \& variable volumes for $1_{\mathrm{f}}=0.25$ " fiber .....70 


\section{CHAPTER 1 INTRODUCTION}

Concrete is one of the most widely used building materials and its use is increasing in all countries and regions in our globe. The reasons for its extensive use include the fact that its components are readily available and inexpensive, its production is relatively simple, and its can be used for a variety of building and civil infrastructure works (Brandt, 2008).

With the continuous advances in materials' technology, the performance of concrete has continued to improve. Compressive strengths exceeding $75 \mathrm{MPa}$ are now being used in applications throughout the world. However, the concrete becomes less ductile and more susceptible to sudden failures with increases in its compressive strength. Although the behavior of concrete is generally governed by its compressive strength, its tensile strength, although much lower, is also important. This tensile strength impacts appearance, the serviceability and durability of concrete elements. In addition, minimum levels of tensile strength are required for many concrete applications including, earthquake resistant structures, tanks and other fluid containment structures, runways, slabs and pavement (Boulekbache, Hamrat, Chemrouk, \& Amziane, 2014).

The addition of steel fibers also improves the tensile strength of the composite, a significant structural weakness of concrete (Boulekbache, Hamrat, Chemrouk, \& Amziane, 2016). At the micro-level, fibers inhibit the initiation and growth of cracks, and 
after the micro-cracks coalesce into macro-cracks, fibers abate their unstable propagation, bridging the cracks (this bridging effect is greatly depends on the bonding between fiber and matrix) and improving strength, toughness and ductility (Banthia \& Sappakittipakorn, 2007).

Steel fibers are generally used as secondary reinforcing and to control cracking in a number of concrete applications where dynamic loading, poor soils or high shrinkage is anticipated. To facilitate this use, the research has been conducted to develop an analytical model for predicting the tensile behavior of the fiber reinforced composite materials (Vellore S. Gopalaratnam \& Surendra P. Shah, 1987) (Lee, Cho, \& Vecchio, 2011). As will be discussed in the following section, researchers have developed analytical models that can be used to predict the impact of the steel fibers on the tension behavior of fiber reinforced concrete composites. However, these methods have generally been confined to the application of concrete under direct tension and have not been applied to prediction of the flexural behavior of the reinforced composite material, especially after cracking. If a reliable analytical model can be developed for this application, it can be used to predict the performance of fiber reinforcement in a wider variety of applications.

The objectives of this investigation will be to develop an analytical model for the prediction of flexural behavior of concrete reinforced with steel fibers. This model will be validated against tested behavior and then used to predict behavior of different fiber reinforced concrete configurations and optimize the flexural strength of fiber reinforced concrete. 
In the following thesis, Chapter II presents the results of previous investigations of fiber reinforced concrete, with a specific emphasis on steel fiber reinforced systems. Chapter III describes the development of the analytical model and Chapter IV the experimental program. Chapter IV presents the result of the experimental program. A discussion of the results, model calibration and optimization of the flexural behavior of fiber reinforced mortar is presented in Chapter V. Conclusions and recommendation are presented in Chapter VII. 


\section{CHAPTER 2}

\section{BACKGROUND}

\section{1. $\quad$ Fiber Reinforced Concrete}

There are many kinds of fiber that are now used in fiber reinforced concrete (FRC). Natural fibers, while are not suitable for high performance structural concrete, are being developed for application with ordinary concretes (Brandt, 2008). Asbestos fiber have also been used but have been completely abandoned in construction because of their detrimental influence on human health and have generally been replaced by other kinds of fibers (Brandt, 2008). Polymeric fibers have also been used with concrete but are primarily effective in reducing plastic shrinkage cracking and do not significantly improve tensile strength (Brandt, 2008). The type of fiber that has the greatest impact on the structural strength of concrete are steel fibers. Hook-ended and various other shapes designed to improve the fiber-matrix bond and thus increase effectiveness of the steel fibers have been used (Brandt, 2008). However, more workable concrete and mortar mixes are obtained with straight steel fibers (Bayasi, Pa, \& Soroushian, July-August 1992), because they are less likely to clump when mixing.

To improve the tensile strength of concrete, steel fibers are added in varying volume percentages (Iqbal, Ali, Holschemacher, \& Bier, 2015). Short steel fibers are one of the most common types of fibers used to improve the tensile capacity of concrete (Iqbal et al., 2015). 
These fibers form a fiber-reinforced concrete composite material with improved ability to absorb energy and deform in a ductile manner. The addition of steel fiber also improves the relatively low tensile strength of the concrete (Boulekbache et al., 2016).

In the absence of main reinforcement bars, addition of high strength steel fibers into concrete results in a material better ductility and higher load carrying capacity compared to concrete with normal steel fibers. Use of steel fiber at an optimal volume percentage in high strength concrete produces high performance bending elements having elasticplastic behavior similar to that of normal strength concrete members with conventional reinforcement (Iqbal et al., 2015), which is concluded from a series of conventional reinforced concrete beam and fiber reinforced concrete beam tests, conducted by Iskhakov et al. (Iskhakov, Ribakov, Holschemacher, \& Mueller, 2014).

At a micro-level, when fibers are present in concrete they inhibit the initiation and growth of cracks, and after micro-cracks coalesce into macro-cracks, the fibers provide mechanisms that abate unstable crack propagation, bridging and restraining crack growth. This bridging effect greatly depends on the bond between fiber and matrix, and improves strength, toughness and ductility (Banthia \& Sappakittipakorn, 2007).

After a period of relative inactivity there appears to be a renewed interest in hybrid fiber (combinations of various types and sizes of fibers) composites and efforts are underway to develop investigate the performance of hybrid fibers in concrete (Banthia \& Sappakittipakorn, 2007). However, although hybridization appears to be a promising concept, hybrid FRCs with a combination of large and small diameter crimped fibers failed to reach the toughness levels demonstrated by FRCs with small diameter fibers alone (Banthia \& Sappakittipakorn, 2007). 
Coated fiber has also been investigated. In, fact an active enamel coating has been developed that greatly improves the bond between the steel and concrete matrix and significantly improves the corrosion resistance of the steel fiber (McGinley, 2016). These active coatings thus improve the efficiency of the fibers by combining the improved workability of straight steel fibers with the higher bond of twisted and hooked fibers.

This investigation will address the performance of straight and coated steel fibers in both mortar and concrete mixes.

\subsection{Fiber Reinforced Concrete Analytical Models}

Several researchers have developed analytical models of the uniaxial tensile behavior of fiber reinforced concrete (FRC). In 1987, Vellore S. Gopalaratnam and Surendra P. Shah proposed a model for the fiber reinforcement mechanism considering fiber aspect ratio $(l / d)$, fiber volume content $\left(\mathrm{V}_{f}\right)$, embedment lengths, fiber orientation, softening behavior, fiber slip and interfacial debonding (Vellore S. Gopalaratnam \& Surendra P. Shah, 1987). However, this model used a fiber pull-out model which is different from what is observed from other investigations (McGinley, 2016). This discrepancy may be caused by the fact that the fiber they used in their investigation was different from what is typical used now. However, this model identified material characteristics that should be taken into consideration when developing a fiber reinforced concrete/mortar model.

Pre and post crack behavior were also described analytically by Vellore S. Gopalaratnam et al. (Vellore S. Gopalaratnam \& Surendra P. Shah, 1987). This investigation proposed that until matrix cracking, the matrix, fibers, and their interface all behave elastically so 
that the composite can be assumed to behave like an elastic material with composite modulus of elasticity given by the law of mixtures (Vellore S. Gopalaratnam \& Surendra P. Shah, 1987).

In research by Marti, P., et al.(Marti, Pfyl, Sigrist, \& Ulaga, 1999), a relationship between crack width and tensile stress for FRC members was derived. In subsequent work by Foster, the distribution of the fibers and their inclination angles normal to the crack (less than $\pi / 3$ ) was considered (Foster, 2001).

Furthermore a variable engagement model (VEM) which addressed the fiber inclination angle, and introduced fiber embedment length was proposed by Jackie Yen Lei Voo and Stephen J. Foster (Voo \& Foster, 2003). In this model, the behavior of the fiber reinforced composite was obtained by a summation of the individual components(fibers), and assuming the geometric centers of the fibers are uniformly distributed in space and all fibers have an equal probability of being oriented in any direction. The model also assumed that all fibers pullout from the shorter embedded side of the crack while the longer side of the fiber remains rigidly embedded in the matrix and displacements due to elastic strain in the fiber and bending stiffness of fiber can be neglected.

In 2011, a diverse embedment model (DEM) was developed (Lee et al., 2011). In this model, the bond stress between steel fibers and concrete matrix and fiber slip at both ends of embedment were considered. In 2016, a modified DEM model that included a fiber efficiency concept was developed. This fiber efficiency factor is taken as the product of the fiber volumetric ratio, fiber aspect ratio and in addition concrete member size and concrete compressive strength (Lee, Oh, \& Cho, 2016). 
It should be noted that all of the models described above are limited to direct tension behavior. Thus, one of the objectives of this investigation will be to extend this basic model in an effort to provide an analytical method to predict flexural behavior of fiber reinforced mortar and concrete. This model will be based on a DEM model and is presented in the following chapter. 


\section{CHAPTER 3}

\section{ANALYTICAL MODEL}

\subsection{Basic Mechanical Theory}

The following chapter describes the development of an analytical model to predict the flexural strength of fiber reinforced concrete based on the DEM model tension model described in the previous chapter (Lee et al., 2016).

In the DEM model (Lee et al., 2016), the tensile stress in the steel fibers was evaluated using a fiber efficiency factor as described by the following equation:

$$
f_{t, f i b e r}=\alpha_{f} V_{f} K_{e} \sigma_{f, c r, a v g}
$$

Where: $\alpha_{f}$ is fiber orientation factor;

$V_{f}$ is fiber volumetric ratio;

$K_{e}$ is fiber efficiency factor;

$\sigma_{f, c r, a v g}$ is the average fiber stress at a given crack considering random

distributions of fiber inclination angle and embedment length.

If an infinite element is considered, $\alpha_{f}=\int_{0}^{\pi / 2} \cos \theta \sin \theta d \theta=0.5$, as derived by Aveston and Kelly(Aveston \& Kelly, 1973). Where $\sin \theta$ is the distribution density function used by Lee et al. and $\cos \theta$ is the projected length of fiber. 
But in this research, we observed that fiber distribution density is not for sure $\sin \theta$, so a $\cos \theta$ and $2 / \pi$ distribution density factor are also assumed, as fiber more horizontal orientated or

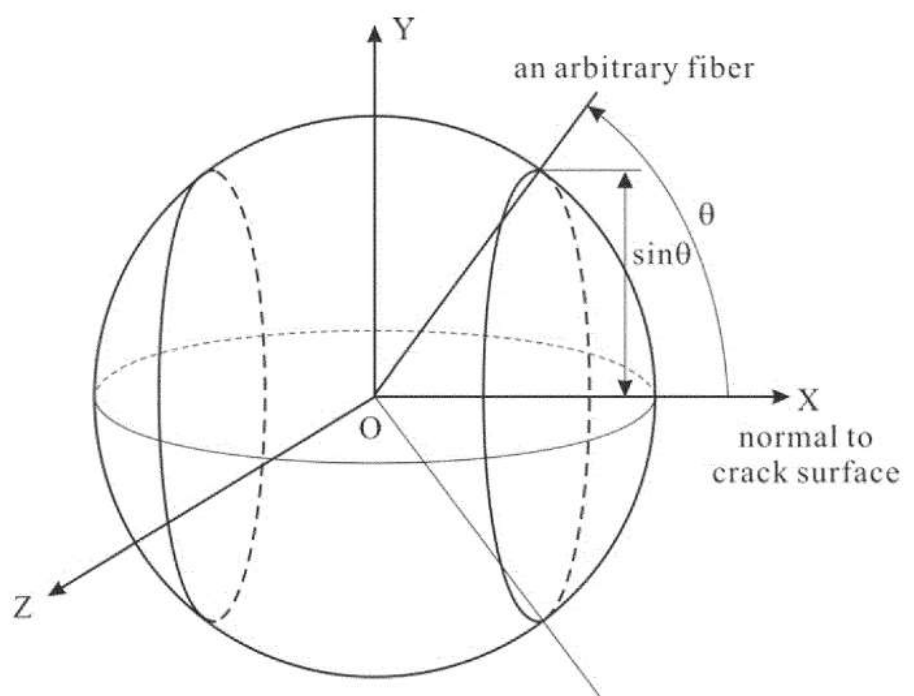
uniformly orientated. Figure 3-1 Probability of fiber inclination angle using sphere representation $K_{e}$, defines the fiber efficiency and is used to explain why the tensile strength of SFRC doesn't linearly vary with fiber volumetric ratio. Lee, S.C., J.H. Oh, and J.Y. Cho (Lee et al., 2016) derived an expression for $K_{e}$ through regression analysis of a series of direct tension tests of steel fiber reinforced concrete samples and this expression is presented below:

$$
K_{e}=\min \left[1,\left(-0.44 V_{f} \frac{l_{f}}{d_{f}}\right) \sqrt{f_{c}}\left(-0.87 /\left(\frac{h}{l_{f}}+0.22\right)^{0.09}+1\right)\right]
$$

Where: $l_{f}$ is fiber length;

$d_{f}$ is fiber diameter;

$f_{c}$ is the concrete compressive strength;

$h$ is the lessor of thickness, the height or width of the concrete specimen. 
$K_{e}$, is the "efficiency factor" of fiber, and was obtained from regression analysis of test data. However, other factors not included in the expression for $K_{e}$ may also affect performance of the fibers and impact the correlation between experimental and analytical results. This factor will be evaluated further during this investigation.

The value of $\sigma_{f, c r, a v g}$ can be calculated following the steps shown below. (Lee et al., 2011). It should be noted that $\tau_{f, \max }$ (frictional pullout strength) and $s_{f}$ (slip at frictional bond strength for fiber with inclination angle of 0 degrees) can be measured for a given type of fiber. For the coated fibers used in previous work by McGinley (McGinley, 2016). tests indicate that not slip occurs and $s_{f}$ is only the strain of steel fiber. The equations for $\sigma_{f, c r, a v g}$ are:

$$
\begin{gathered}
\sigma_{f, c r, a v g}=\frac{1}{l_{f} / 2} \int_{0}^{l_{f} / 2} \sigma_{f, c r, \theta}\left(l_{a}\right) d l_{a} \\
\sigma_{f, c r, \theta}=\int_{0}^{\pi / 2} \sigma_{f, c r}\left(l_{a}, \theta\right) \sin \theta d \theta \\
\sigma_{f, c r}=\frac{4 \tau_{\text {short }}\left(l_{a}-s_{\text {short }}\right)}{d_{f}}
\end{gathered}
$$

Where: $l_{a}$ is fiber embedment length on the shorter side;

$\theta$ is fiber inclination angle from axis that is perpendicular to crack surface;

$s_{\text {short }}$ is slip at crack for the shorter embedded part of the fiber;

$\tau_{\text {short }}$ is frictional bond stress for the shorter embedded part of the fiber at any orientation angle and embedment length. 
$\sigma_{f, c r}$ is calculated using equilibrium and the fact that the stress in the fiber is equal to shear force at the surface of the fiber.

$\sigma_{f, c r, \theta}$ is the integral of the stress for different inclination angles of the fibers. $\sigma_{f, c r, a v g}$ is the integral of different embedment lengths, at the shorter side of the crack.

$\tau_{\text {short }}$ for a fiber with inclination angle of $\theta$ and fiber embedment length on shorter side of $l_{a}$ is determined by the following equations (Lee et al., 2011) derived from their experiments:

$$
\begin{aligned}
& \tau_{\text {short }}=\frac{w_{c r}}{w_{p \theta}} \tau_{f, \max } \text { for } w_{c r} \leq w_{p \theta} \\
& \tau_{\text {short }}=\tau_{f, \max } \text { for } w_{c r}>w_{p \theta} \\
& w_{p \theta}=\frac{s_{f}\left[1+4\left(l_{a} / l_{f}\right)^{2}\right]}{\cos ^{2} \theta}
\end{aligned}
$$

Where: $w_{c r}$ is the crack width;

$w_{p \theta}$ is the crack width at bond strength for fiber with inclination angle of $\theta$;

Using as similar process to that described above $s_{\text {short }}$ is determined using the following equations (Lee et al., 2011):

$$
\begin{aligned}
& s_{\text {short }}=\frac{\left(l_{f}-l_{a}\right) w_{c r}-w_{c r}^{2}}{l_{f}-2 w_{c r}} \text { for } w_{c r} \leq w_{p \theta} \\
& s_{\text {short }}=\frac{-B-\sqrt{B^{2}-4 C}}{2} \text { for } w_{c r}>w_{p \theta}
\end{aligned}
$$

Where: $B=l_{f}-l_{a}-2 w_{c r}-s_{f} / \cos ^{2} \theta, C=l_{a} s_{f} / \cos ^{2} \theta-\left(l_{f}-l_{a}-w_{c r}\right) w_{c r}$. 
As we can see from the equations and expressions above, $\sigma_{f, c r, a v g}$ changes with $w_{c r}$, $f_{t, \text { fiber }}$ changes with $w_{c r}$ and $V_{f}$.

\subsection{Pre-crack Behavior Analysis}

Pre-crack behavior of FRC is dominated by the strength of the concrete (or mortar).

Vellore S. Gopalaratnam et al. found that, prior to concrete cracking, the concrete matrix (cement and aggregates), fibers, and their interface all behave elastically (Vellore S.

Gopalaratnam \& Surendra P. Shah, 1987). From the equations above, we can get a $\sigma_{f, c r, a v g}$ (stress) expressed by $w_{c r}$ and $V_{f}$. Thus, an equivalent elastic modulus $E_{e q}=$ $K_{e} \sigma_{f, c r, a v g} / w_{c r}$, (the elastic modulus of steel fibers), can be calculated as a function of $w_{c r}$ and $V_{f}$. The pre-crack equivalent stress of the steel fibers and concrete $\left(\sigma_{e q}\right)$, can be determined as follows.

$$
\sigma_{e q}=E_{e q} \varepsilon_{\max } V_{f} \alpha_{f}+\left(1-V_{f}\right) f_{r}
$$

In which $f_{r}$ is the tensile strength of concrete matrix, $\varepsilon_{\max }$ is the maximum strain before concrete begins to crack.

From simple mechanics and using the modulus of rupture described by the US concrete design code, ACI 318-14 (ACICommittee318, 2014), the maximum cracking moment in a plain concrete flexural element can be determined as:

$$
M_{\text {plainmax }}=\frac{b h^{2}}{6} \times f_{r}=M_{c r}
$$

Thus, as the modulus of rupture of the concrete is impacted the fiber, the maximum cracking moment a FRC can be determined as: 


$$
M_{\max }=\frac{b h^{2}}{6} \times \sigma_{e q}
$$

The ratio of flexural cracking strength of FRC concrete relative to that of plain concrete (MF) can then be determined as:

$$
M F=M_{\text {max }} / M_{\text {plainmax }}=\sigma_{e q} / f_{r}
$$

\subsection{Post-crack Behavior Analysis}

Post-crack behavior of the FRC is significantly different than pre-pre-crack behavior. As post-cracking behavior defines the ductility of the FRC it is critical accurately to predict this behavior.

The post-crack DEM tension model for fiber reinforced concrete (Lee et al., 2016) can be modified to predict the post cracking flexural behavior of fiber reinforced concrete/mortar. This is accomplished by assuming that the steel fiber is mixed uniformly with the concrete, the concrete is cracked in tension and the fiber provides all the resistance to tension stresses. Based on

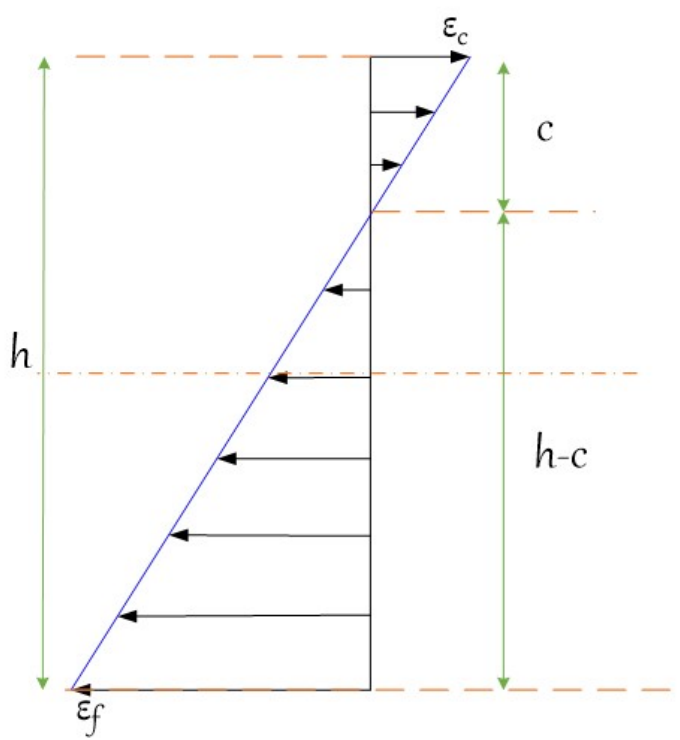

Figure 3-2 Actual Strain Distribution these assumptions, the section stress and strain distribution can be idealized as shown in Figures 3.2 and 3.3. 
It is also assumed that the fiber reinforced concrete/mortar linear elastically in compression, as shown in Figure 3.3.

For a given type of fiber and fiber/concrete matrix condition, the fiber stress model developed by Lee et al. would produce the fiber tension stress distribution shown in lower section (below the neutral axis) of Figure 3.3.

Using this $f_{t, f i b e r}$ expression, (which shows that fiber stress depends on crack width $w_{c r}$ and $V_{f}$ ), the tension stress distribution, $\operatorname{SFRCT} \_\operatorname{stress}_{(w c r, c, V f)}$ along the crack surface from the neutral axis to the bottom of specimen can be determined. The length of the fiber tension zone, $h-c$, varies with a number of parameters. Using this stress distribution,

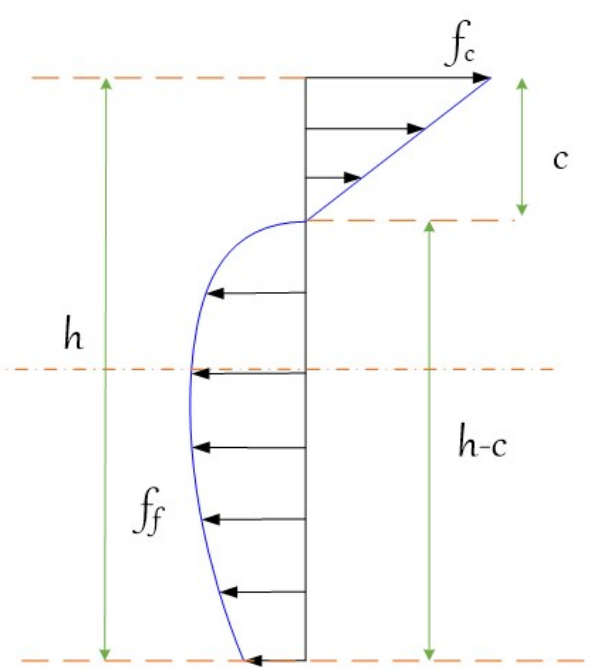

Figure 3-3 Actual Stress Distribution the total tension force $\left(S F R C T_{-} F_{(w c r, c, V f)}\right)$ and the total internal moment about the neutral axis $\left(S F R C T_{-} M_{(w c r, c, V f)}\right)$ produced by fiber tension forces can be determined using simple statics. Similarly, $S F R C C_{-} F_{(f c, c)}$, the total compression force and SFRCC_M $M_{(f c, c)}$, the total internal moment about neutral axis produced this compression force, and can also be determined by simple statics.

Examination of these equations show that $S F R C C_{-} F_{(f c, c)}$ and $S F R C C_{-} M_{(f c, c)}$ are functions of $f_{c}$ and $c, S F R C T_{-} F_{(w c r, c, V f)}$ and $S F R C T_{-} M_{(w c r, c, V f)}$ are function of $w_{c r}, c$ and $V_{f}$.

Using equilibrium, we know the total force in tension and in compression are equal: 


$$
S F R C C_{-} F_{(f c, c)}=S F R C T_{-} F_{(w c r, c, V f)}
$$

And:

$$
S F R C C_{-} F_{(f c, c)}=0.5 f_{c} c b
$$

Thus it can be shown that:

$$
f_{c}=f_{c\left(w_{c r}, c, V f\right)}
$$

The moment resisted by the section after cracking is:

$$
\begin{array}{r}
\operatorname{Moment}_{(w c r, c, V f)}=\operatorname{SFRCC}_{M_{(f c, c)}}+\operatorname{SFRCT}_{M_{(w c r, c, V f)}} \\
=S F R C C_{-} M_{(c)}+S F R C T_{-} M_{(w c r, c, V f)}
\end{array}
$$

Because the maximum bending capacity of this section is critical, different neutral axis locations, $c$, can be used to determine the maximum internal moment for a given fiber distribution. By iteration, the maximum internal moment function $M_{\max (w c r, V f)}$ can be related to crack width $w_{c r}$ and fiber volume fraction $V_{f}$ as shown below.

$$
M F_{(w c r, V f)}=M_{\max (w c r, V f)} / M_{\text {plainmax }}
$$




\section{CHAPTER 4}

\section{EXPERIMENTAL PROGRAM}

The experimental program was conducted in two phases. In the first phase, direct tension tests of selected steel fibers and pullout tests in sand cement mixtures and sand cement gravel mixtures were conducted. The second phase of the experimental program conducted flexural and compressive tests of fiber reinforced sand cements (including coated fiber composites).

\subsection{Phase 1}

Table 4.1 defines the weight proportions of cement, sand and water for the concrete and mortar mixes used in the following tests in both Phase $1 \& 2$. Glenium 7511 were added in a proper amount, shown in Table 4-1. Standard 20-30 sand was used for the mortar mixes and local aggregates were used for the concrete.

\section{Table 4-1: Mass Ratio of Mortar and Concrete Mix}

\begin{tabular}{|c|c|c|c|c|c|}
\hline & Cement & Sand & Water & Corse Aggregates & Glenium 7511 \\
\hline Mortar Mix 1 & 1 & 3 & 0.45 & N.A. & N.A. \\
\hline Mortar Mix 2 & 1 & 3 & 0.5 & N.A. & N.A. \\
\hline Concrete Mix & 1 & 2.369 & 0.514 & 3.236 & 0.418 oz/CUF \\
\hline
\end{tabular}

Typical mixing procedure of plain mortar is mixing sand and cement for 1 minute, then add water and mix for 3 minute, after 2 minutes' rest, mixing last 3 minutes. Typical 
mixing procedure of fiber reinforced mortar is mixing sand and cement for 1 minute first, then add fiber for another 1 minute's mixing, add water and mix for 3 minutes, rest 2 minutes, then mix for another 3 minutes.

Table 4.2 shows the information of fiber we used in the following mortar tests, mainly in Phase 2. Different material types of fiber will be used in pullout tests, too. The results show material type will not affect the pullout load significantly.

\section{Table 4-2: Fiber Configuration Used in Mortar Beams and Cubes}

\begin{tabular}{|c|c|c|c|c|}
\hline & Length & Diameter & $1 / \mathrm{d}$ ratio & Material Type \\
\hline Fiber A & $1 ”$ & $0.029 ”$ & 34.5 & C1060/029 \\
\hline Fiber B & $0.75 ”$ & $0.029 ”$ & 25.9 & C1060/029 \\
\hline Fiber C & $0.75 ”$ & $0.0435^{\prime}$ & 17.2 & $\mathrm{C} 1039 / 047$ \\
\hline CT2/Coated Fiber & 1 & $0.029 ”$ & 34.5 & $\mathrm{C} 1060 / 029$ \\
\hline
\end{tabular}

Figure 4-1 shows the fiber used in mortar beams and cubes. From left to right is CT2/Coated fiber, fiber A, fiber B, fiber C successively.

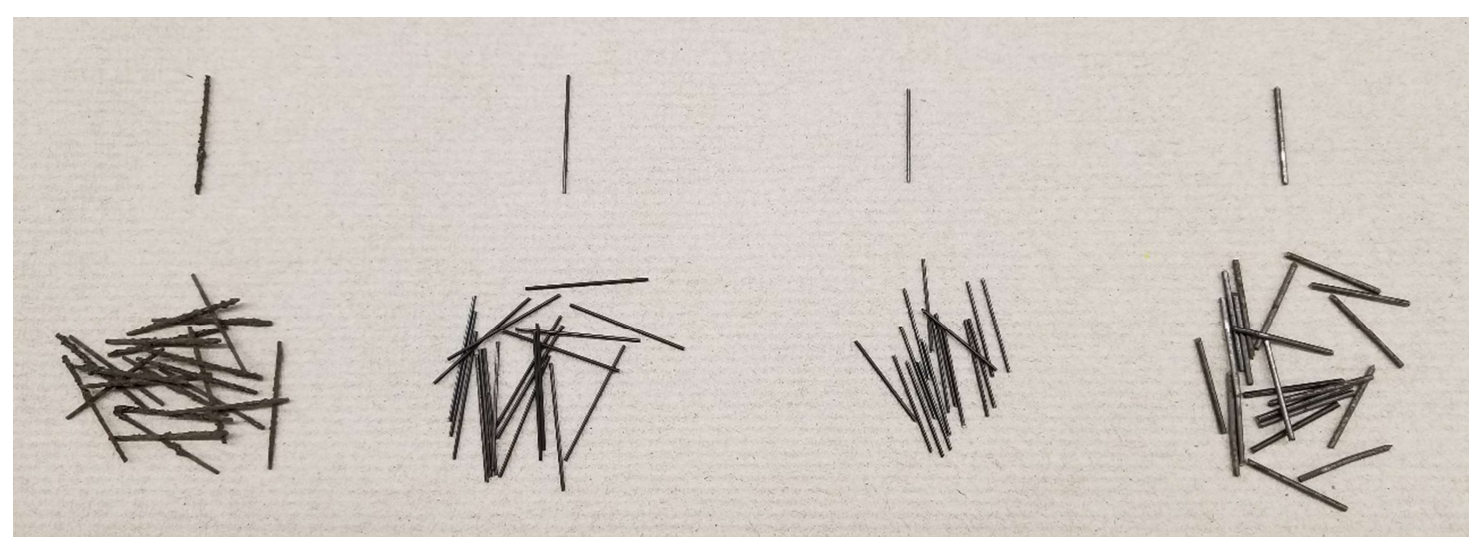

Figure 4-1 Fiber used in mortar beams and cubes 


\subsubsection{Fiber Direct Tension Tests}

For each of fifteen types of fiber, three replicates of each fiber configuration were tested for tensile stress-strain performance using the procedures in ASTM Standard A 307 (ASTM A307, 2014).

Figure 4.2 shows a typical fiber specimen with extensometer ( 2 in gage length) attached just prior to testing. Table 4.3 summarizes the fiber tension test configurations.

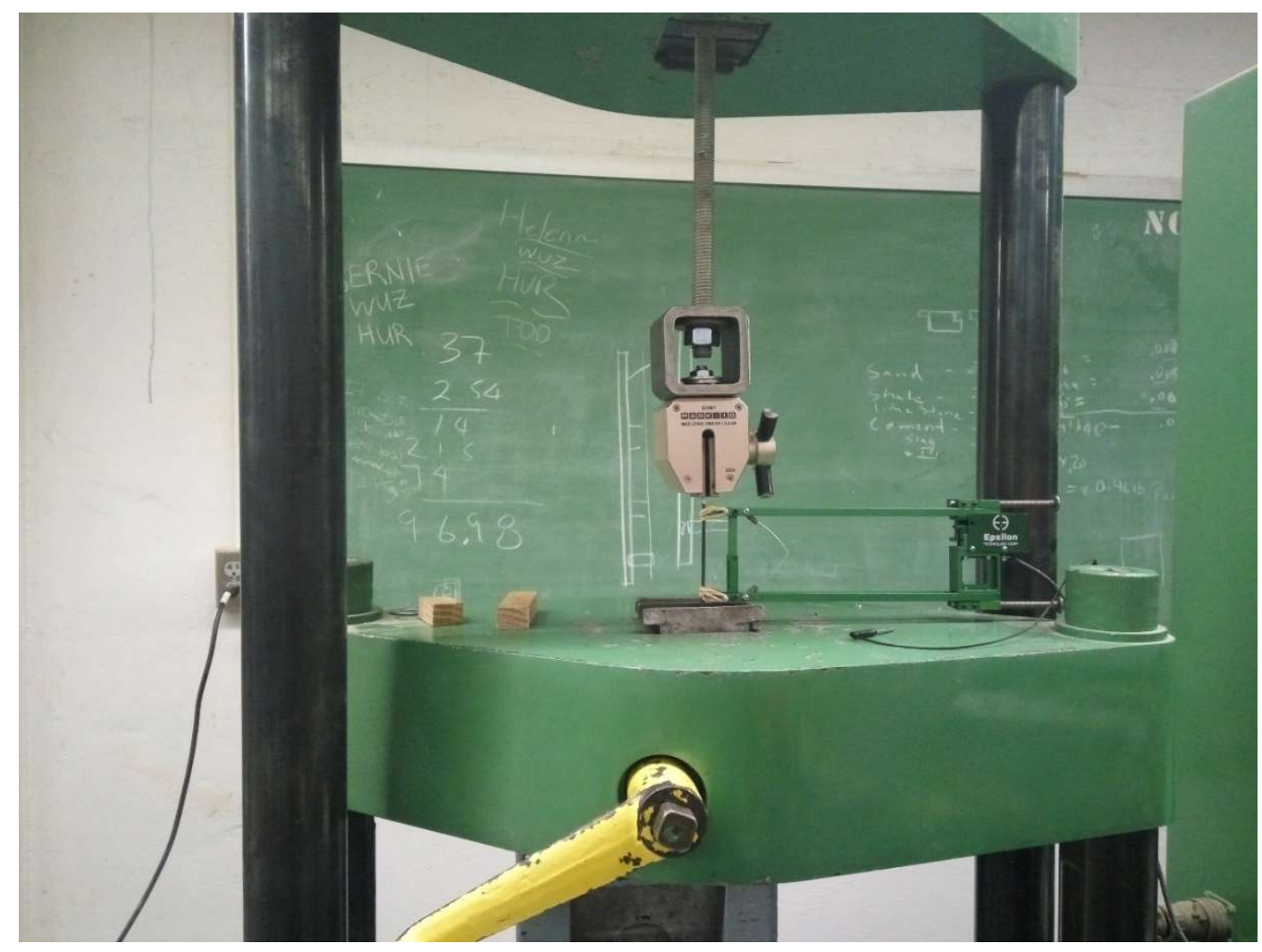

Figure 4-2 Fiber Direct Tension Test 


\begin{tabular}{|c|c|c|c|}
\hline No. & Name & Fiber Type & Diameter (in) \\
\hline 1 & \multirow{5}{*}{$\begin{array}{l}\mathrm{AR}(\mathrm{As} \\
\text { received })\end{array}$} & C1040/080 & $0.077^{\prime \prime}$ \\
\hline 2 & & C1039/080 & $0.077^{\prime \prime}$ \\
\hline 3 & & C1060/080 & $0.077^{\prime \prime}$ \\
\hline 4 & & C1040/047 & $0.0435^{\prime \prime}$ \\
\hline 5 & & C1039/047 & $0.0435^{\prime \prime}$ \\
\hline 6 & \multirow{5}{*}{$\begin{array}{l}\text { HT (Heat } \\
\text { treated) }\end{array}$} & C1040/080 & $0.077^{\prime \prime}$ \\
\hline 7 & & C1039/080 & $0.077^{\prime \prime}$ \\
\hline 8 & & C1060/080 & $0.077^{\prime \prime}$ \\
\hline 9 & & C1040/047 & $0.0435^{\prime \prime}$ \\
\hline 10 & & C1039/047 & $0.0435 "$ \\
\hline 11 & \multirow{5}{*}{$\begin{array}{l}\mathrm{CT} 2 \\
\text { (Coating } \\
\text { 2) }\end{array}$} & C1040/080 & $0.077^{\prime \prime}$ \\
\hline 12 & & C1039/080 & $0.077^{\prime \prime}$ \\
\hline 13 & & C1060/080 & $0.077^{\prime \prime}$ \\
\hline 14 & & C1040/047 & $0.0435^{\prime \prime}$ \\
\hline 15 & & C1039/047 & $0.0435^{\prime \prime}$ \\
\hline
\end{tabular}

\subsubsection{Fiber Pullout Tests}

In an effort to determine $\tau_{\max }$ values (parallel to pull out force) for a range of fiber configurations, a series of fiber pullout specimens were fabricated. Each of the pullout specimens consisted of a steel fiber embedded in the center of a 3" x 6" cylinder mold filled with concrete or mortar. A number of embedment lengths were used. Twelve fiber configurations were embedded in a concrete mix designed to a have a minimum 5000 psi at 28 days. To facilitate testing after seven days of curing, Type III (high early) cement was used in the concrete mix. Three compression strength 4 " x 8 " cylinder specimens 
were cast from each batch of concrete. These cylinders were tested for compression strength at the beginning, middle, and end of the pullout tests of the specimens fabricated from the matching concrete batch.

Two fiber configurations were also tested in 3 in. cylinder molds filed with mortar in an effort to quantify any effect that variations in aggregate size and distribution might have on fiber pullout strength. Three mortar cubes ( 2 in. $x 2$ in. $x 2$ in.) were fabricated for each mortar batch and tested for compression strength at the start, middle and end of the pullout testing.

Three replicates were constructed for each fiber type, embedment and substrate. Pullout and compression specimens were tested after 7 days of curing in a moist room at room temperature $(95 \%+$ relative humidity). All the pullout specimen configurations are summarized in Table 4.4.

After curing, each pullout each specimen was placed in the testing apparatus shown in Figure 4.3. Each specimen was seated in the testing frame. The fiber was then clamped in the vice jaws. The fiber displacement sensor clamp was attached to the fiber and the LVDT’s $( \pm 0.1$ in.) were positioned to measure the displacement of the fiber. Tension load was applied to the fiber monotonically and at a and steady rate until failure, or to the end of the travel sensors. Figure 4.4 shows a typical pullout specimen in the testing apparatus. 
Table 4-4: Fiber Pull out Tests (3" × 6" Cylinder)

\begin{tabular}{|c|c|c|c|c|c|}
\hline No. & Name & Material Type & Diameter & Embedment length & Matrix \\
\hline PC1 & Fiber A & C1060/029 & $0.029 "$ & $0.75 "$ & Mortar \\
\hline $\mathrm{PC} 2$ & Fiber $\mathrm{C}$ & C1039/047 & $0.435 \%$ & $0.75^{\prime \prime}$ & $\operatorname{mix} 1$ \\
\hline PC3 & \multirow{6}{*}{$\begin{array}{l}\text { Bare } \\
\text { Fiber }\end{array}$} & $\mathrm{C} 1039 / \mathrm{C} 1040 / \mathrm{C} 1060$ & \multirow{3}{*}{ 0.077” } & $0.5 \%$ & \multirow{12}{*}{$\begin{array}{l}\text { Concrete } \\
\text { mix }\end{array}$} \\
\hline PC4 & & C1039/C1040/C1060 & & $1 "$ & \\
\hline PC5 & & C1039/C1040/C1060 & & $1.5 "$ & \\
\hline PC6 & & C1039/C1040 & & $0.5 \%$ & \\
\hline PC7 & & C1039/C1040 & $0.435 "$ & $1 "$ & \\
\hline PC8 & & $\mathrm{C} 1039 / \mathrm{C} 1040$ & & $1.5^{\prime \prime}$ & \\
\hline PC9 & \multirow{6}{*}{$\begin{array}{l}\text { Coating } \\
2 \text { Fiber }\end{array}$} & C1040 & \multirow{3}{*}{$0.077^{\prime}$} & $0.5^{\prime \prime}$ & \\
\hline PC10 & & C1040 & & $1 "$ & \\
\hline PC11 & & C1039/C1040/C1060 & & 1.5" & \\
\hline PC12 & & C1040 & \multirow{3}{*}{$0.435 ”$} & $0.5 "$ & \\
\hline PC13 & & C1040 & & $1 "$ & \\
\hline PC14 & & C1039/C1040 & & $1.5 "$ & \\
\hline
\end{tabular}




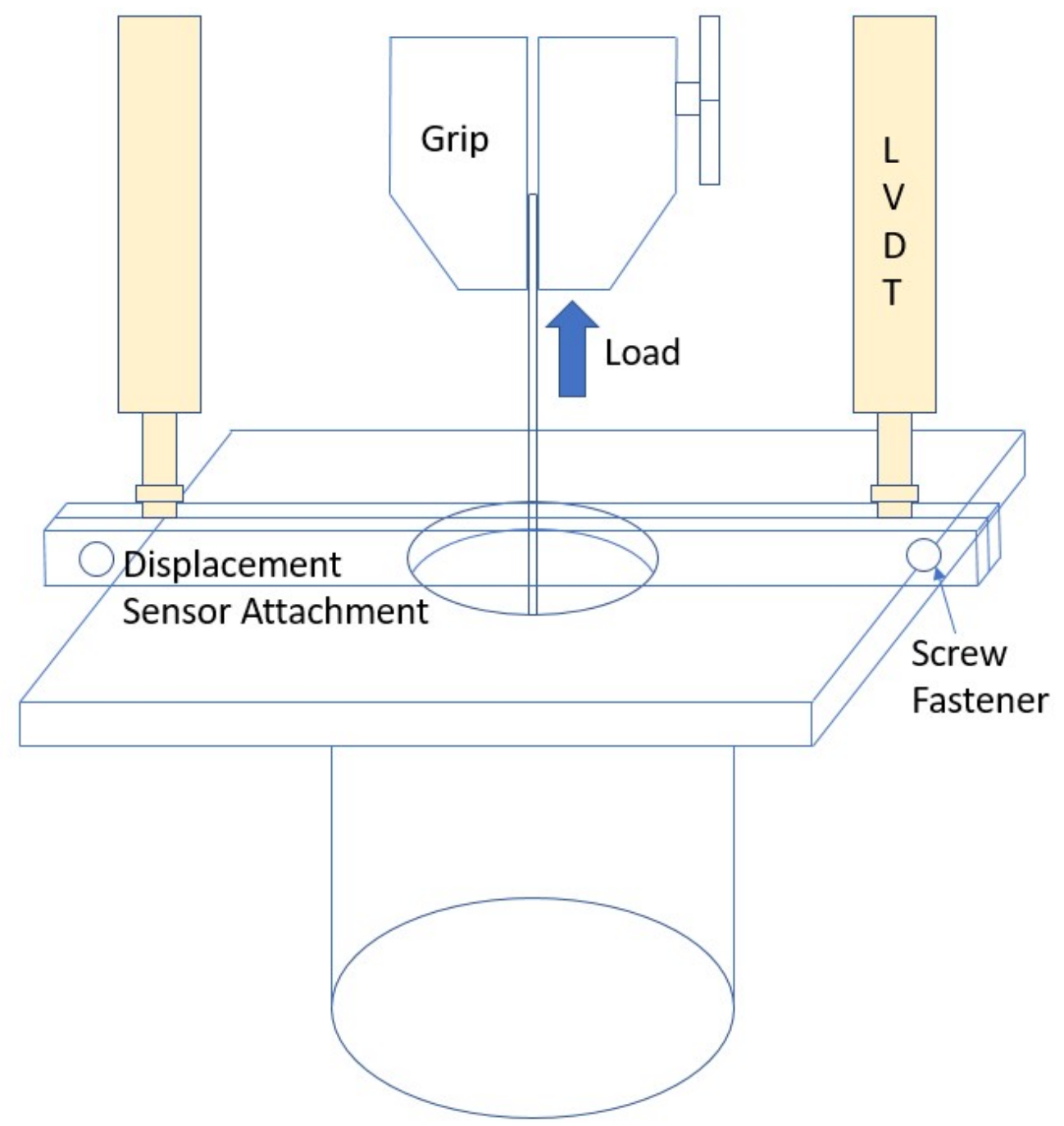

Figure 4-3 Fiber Pull-out Test 


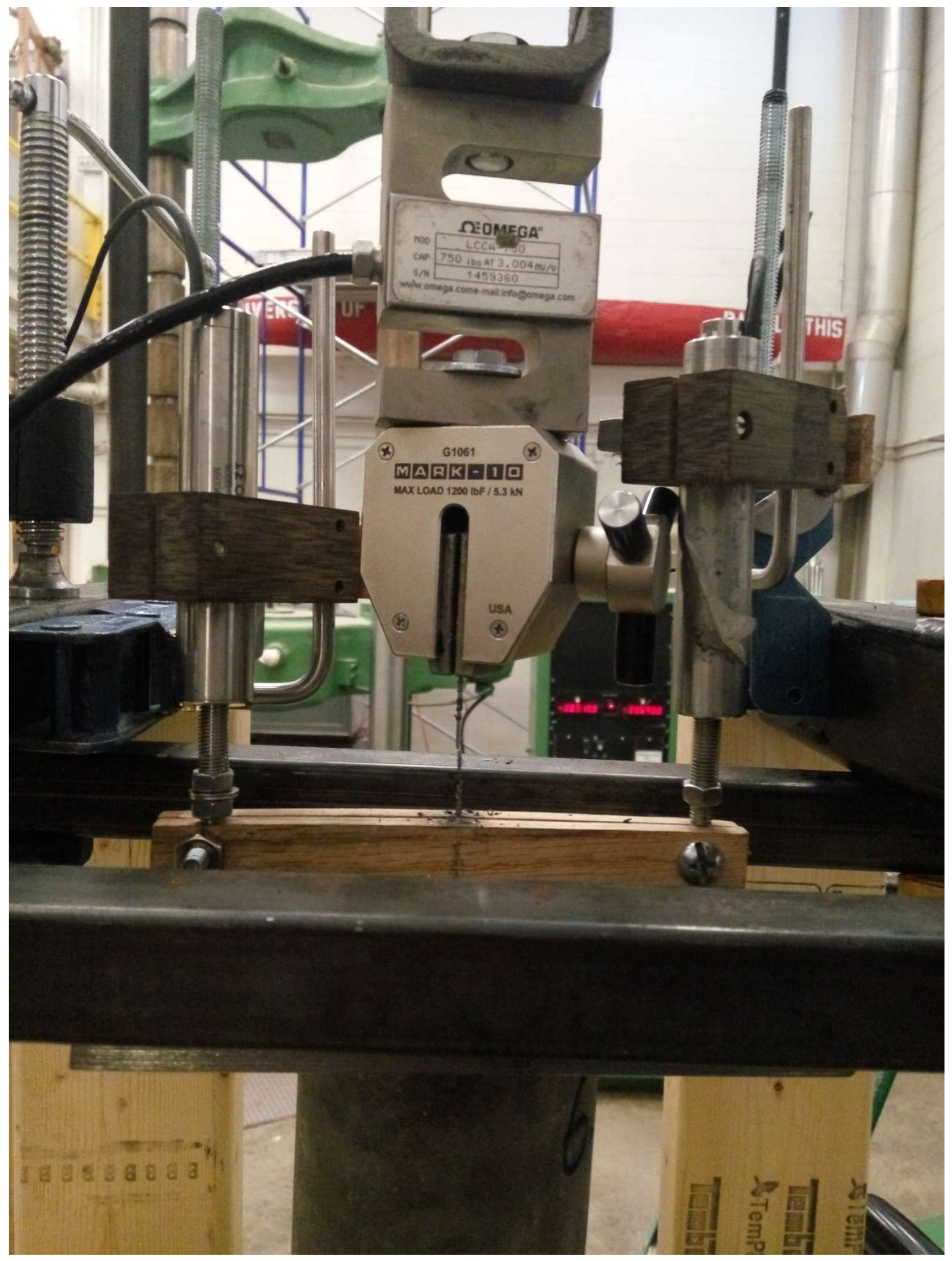

Figure 4-4 Typical Fiber Pull-Out Specimen Just Prior to Test 


\subsection{Phase 2}

A number of $1.575 " \times 1.575 "$ x $6.3 "(40 \mathrm{~mm} \times 40 \mathrm{~mm} \times 160 \mathrm{~mm})$ mortar and fiber beam specimen configuration were constructed and tested under bending loading as described in ASTM C348-14 (ASTM C348-14), with the exception that a vibrating table was used to consolidate the specimens. Two groups of specimens were constructed. The first group used uncoated steel wire and varied the fiber length and fiber diameter, along with fiber volume. The second group of specimens were constructed with coated fiber and three different fiber volumes. For each fiber configuration, three specimens were fabricated and tested after 7 days of curing in a moist room. The beam tests configurations are summarized in Table 4.5. A total of 51 specimens were tested.

In addition, three mortar code compression specimens were fabricated for each of the mortar/fiber batches and tested for compression strength. Each of the cube specimens (2 in. $x 2$ in. $x 2$ in.) were fabricated using the procedures in ASTM Standard C 109/C 109M (ASTM C109, 2016) and these are summarized in Table 4.6.

After curing each beam was placed in the testing apparatus as shown in Figure 4.5 and subjected to a central point load on the simply supported beam. The load was applied monotonically until failure, or to the end of the displacement sensor travel. The displacement was measured at the point of load application. Figure 4.6 shows a typical beam specimen just prior to testing. 


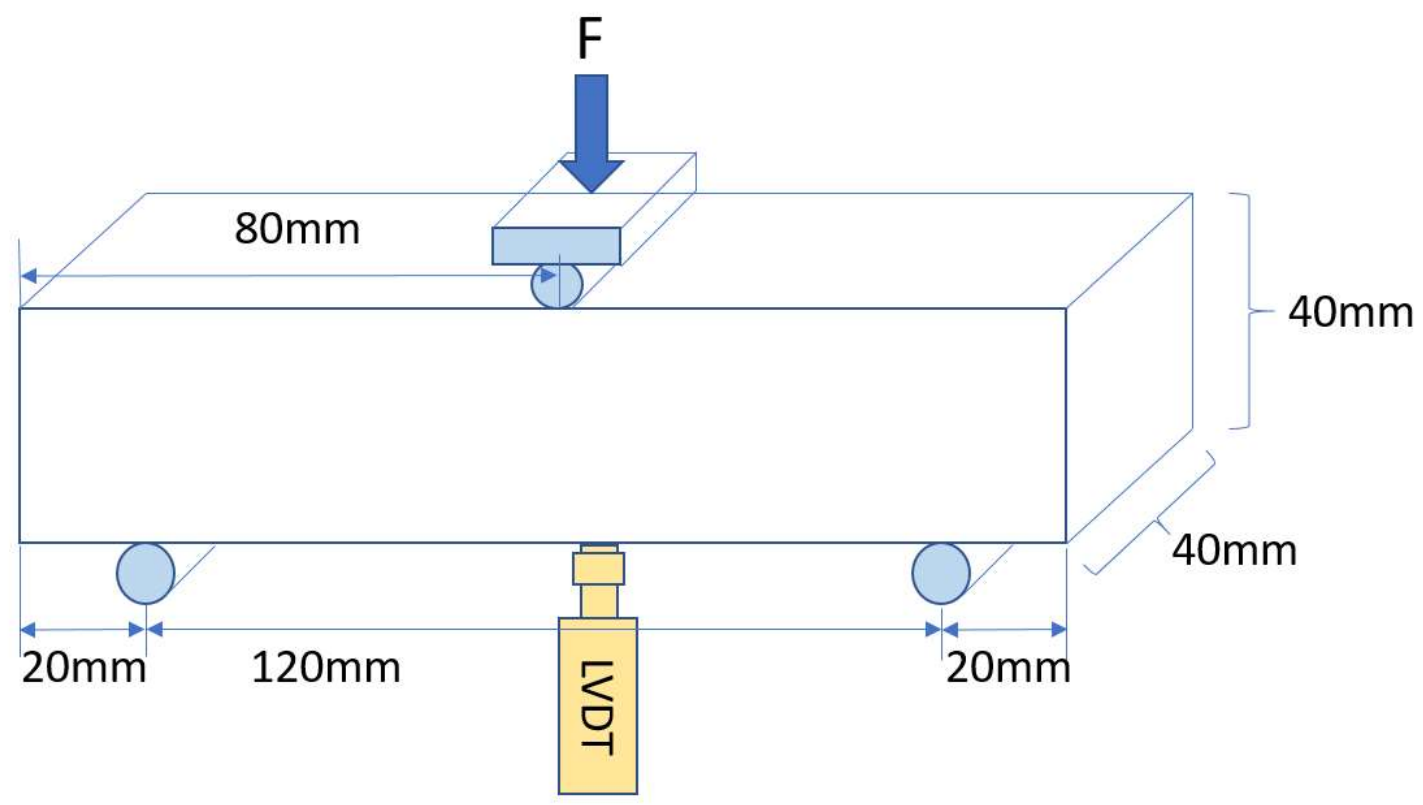

Figure 4-5 Beam Flexural Test

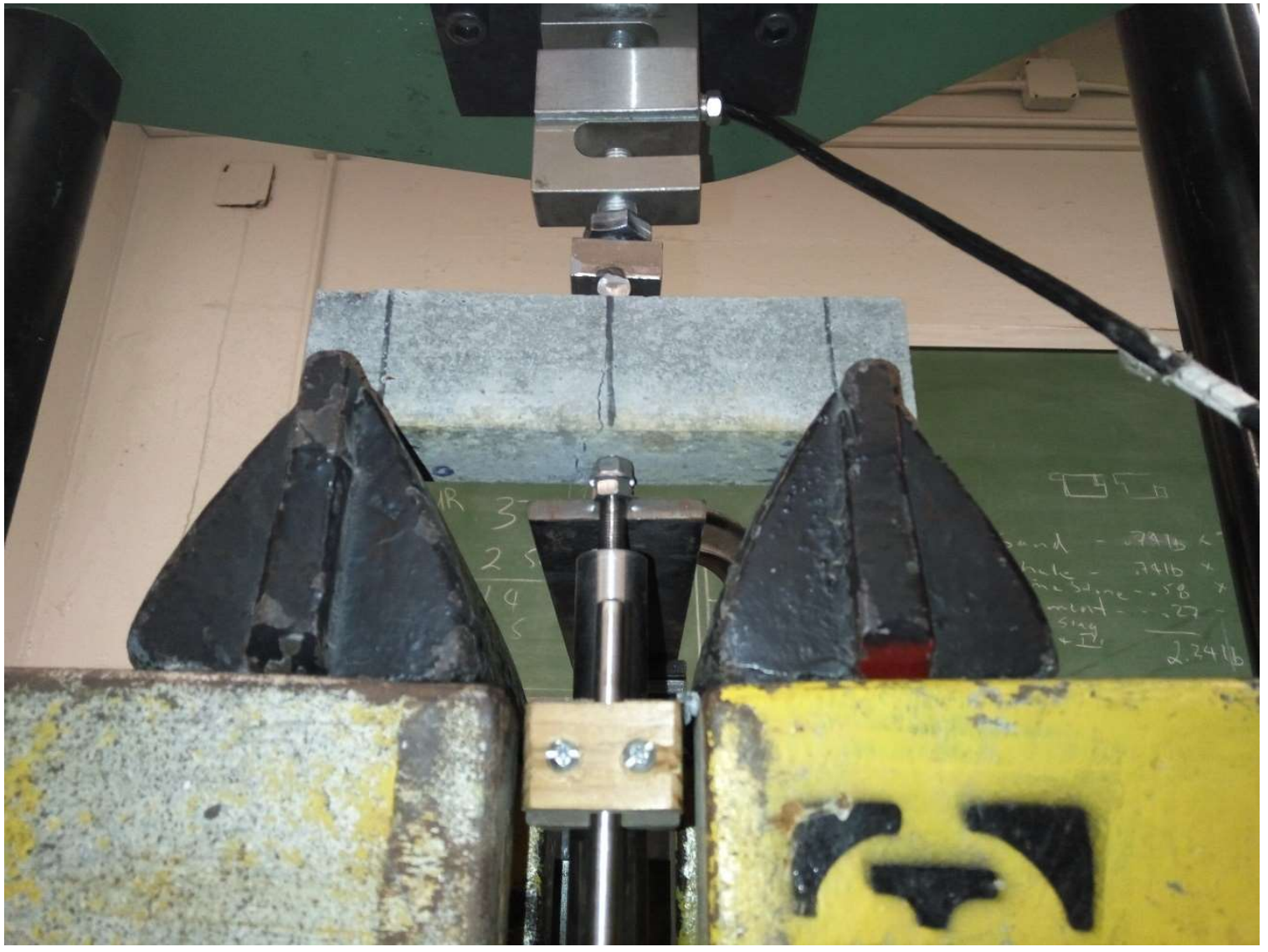

Figure 4-6 Beam Flexural Test 
Table 4-5: Beam Flexural Test (1.575" x 1.575"x 6.3")

\begin{tabular}{|c|c|c|c|}
\hline Specimen Name & Fiber Type & Matrix Type & Volume Fraction (\%) \\
\hline BS1 & \multirow{6}{*}{ Fiber A } & \multirow{3}{*}{ Mortar mix 1} & $V f=2 \%$ \\
\hline BS2 & & & $V f=3 \%$ \\
\hline BS3 & & & $\mathrm{Vf}=4 \%$ \\
\hline BS4 & & \multirow{3}{*}{ Mortar mix 2} & $\mathrm{Vf}=2 \%$ \\
\hline BS5 & & & $\mathrm{Vf}=3 \%$ \\
\hline BS6 & & & $\mathrm{Vf}=4 \%$ \\
\hline BS7 & \multirow{3}{*}{ Fiber B } & \multirow{3}{*}{ Mortar mix 1} & $\mathrm{Vf}=2 \%$ \\
\hline BS8 & & & $\mathrm{Vf}=3 \%$ \\
\hline BS9 & & & $\mathrm{Vf}=4 \%$ \\
\hline BS10 & \multirow{3}{*}{ Fiber C } & \multirow{3}{*}{ Mortar mix 1} & $V f=2 \%$ \\
\hline BS11 & & & $\mathrm{Vf}=3 \%$ \\
\hline BS12 & & & $V f=4 \%$ \\
\hline BS13 & \multirow{3}{*}{ Fiber A coated } & \multirow{3}{*}{ Mortar mix 2} & $\mathrm{Vf}=2 \%$ \\
\hline BS14 & & & $\mathrm{Vf}=3 \%$ \\
\hline BS15 & & & $\mathrm{Vf}=4 \%$ \\
\hline BS16 & \multirow{2}{*}{ No fiber } & Mortar mix 1 & - \\
\hline BS17 & & Mortar mix 2 & - \\
\hline
\end{tabular}


Table 4-6: Compressive Strength Tests (2" $\times 2$ " $\times 2$ ")

\begin{tabular}{|c|c|c|c|}
\hline Specimen Name & Fiber Type & Matrix Type & $\begin{array}{c}\text { Volume Fraction } \\
(\%)\end{array}$ \\
\hline CS1 & \multirow{6}{*}{ Fiber A } & \multirow{3}{*}{ Mortar mix 1} & $\mathrm{Vf}=2 \%$ \\
\hline $\mathrm{CS} 2$ & & & $\mathrm{Vf}=3 \%$ \\
\hline $\mathrm{CS} 3$ & & & $\mathrm{Vf}=4 \%$ \\
\hline CS4 & & \multirow{3}{*}{ Mortar mix 2} & $\mathrm{Vf}=2 \%$ \\
\hline CS5 & & & $\mathrm{Vf}=3 \%$ \\
\hline CS6 & & & $\mathrm{Vf}=4 \%$ \\
\hline CS7 & \multirow{3}{*}{ Fiber B } & \multirow{3}{*}{ Mortar mix 1} & $V f=2 \%$ \\
\hline CS8 & & & $\mathrm{Vf}=3 \%$ \\
\hline CS9 & & & $\mathrm{Vf}=4 \%$ \\
\hline CS10 & \multirow{3}{*}{ Fiber C } & \multirow{3}{*}{ Mortar mix 1} & $\mathrm{Vf}=2 \%$ \\
\hline CS11 & & & $\mathrm{Vf}=3 \%$ \\
\hline CS12 & & & $\mathrm{Vf}=4 \%$ \\
\hline $\mathrm{CS} 13$ & \multirow{3}{*}{$\begin{array}{l}\text { Fiber A } \\
\text { coated }\end{array}$} & \multirow{3}{*}{ Mortar mix 2} & $\mathrm{Vf}=2 \%$ \\
\hline CS14 & & & $\mathrm{Vf}=3 \%$ \\
\hline CS15 & & & $\mathrm{Vf}=4 \%$ \\
\hline CS16 & \multirow{2}{*}{ No fiber } & Mortar mix 1 & - \\
\hline CS17 & & Mortar mix 2 & - \\
\hline
\end{tabular}




\section{CHAPTER 5}

\section{EXPERIMENTAL RESULTS AND DISCUSSION}

\subsection{Direct Tension Results}

Figures 5.1 and 5.2 show the direct tensions stress strain results of the "as received" steel fiber and the fibers that were heat treated to simulate the enameling processes of the coated fiber. In addition, the yield stress and ultimate stress of each fiber are listed in Table 5.1. As received bare fiber (AR) results show that the AR C1040 and C1039 steel fibers exhibited similar stress-strain behavior. Both types of steel fibers show ductile behavior. However, the C1060 steel fibers behave differently than the other two metals. The maximum capacity of these fibers is about three times that of the C1040/1039 steel, has little yielding, and was quite brittle. These fibers broke soon after reaching maximum stress, at about 25000 micro strain. By comparison, the other two types of steel fibers did not fail until after 150000 micro strain (6 times larger). However, heat treated fibers (HT/CT2) of C1060 steel, exhibited ductile behavior similar to the C1040/C1039 steel, with a significant reduction in ultimate strength (although still greater than that exhibited by the C1040/C1039 steel fibers). The ultimate strength of the heat treated C1060 fiber, (115000 psi) was much lower that the AR C1060 fiber (about 260000 psi). Other than a slight more defined yield plateau, there was little difference between the behavior of the AR and HT C1040/1039 fiber.

It is clear that the heat treatment process anneals the fibers and produces a clear yielding plateau and strain hardening regions in the heat-treated fiber. Heat treatment slightly 
improved the ductility of the C1040/C1039 fibers but had only a small effect on ultimate strength.

Table 5-1: Direct Tension Test Results (Average of Three Tests)

\begin{tabular}{|c|c|c|c|c|c|c|c|c|}
\hline No. & Name & Fiber Type & $\begin{array}{l}\text { Diameter } \\
\text { (in) }\end{array}$ & $\begin{array}{l}\text { Yieldin } \\
\text { g Load } \\
\text { (lb) }\end{array}$ & $\begin{array}{c}\text { Ultimate } \\
\text { Capacity } \\
\text { (lb) }\end{array}$ & $\begin{array}{c}\text { Yieldin } \\
\text { g Stess } \\
\text { (psi) }\end{array}$ & $\begin{array}{c}\text { Ultimat } \\
\text { e Stress } \\
\text { (psi) }\end{array}$ & $\operatorname{cov}$ \\
\hline 1 & \multirow{5}{*}{$\begin{array}{l}\mathrm{AR}(\mathrm{As} \\
\text { received, } \\
\text { Bare) }\end{array}$} & $\mathrm{C} 1040 / 080$ & 0.077” & $\begin{array}{c}\text { No } \\
\text { yield } \\
\text { plateau }\end{array}$ & 346 & $\begin{array}{c}\text { No } \\
\text { yield } \\
\text { plateau }\end{array}$ & 73238 & $4.8 \%$ \\
\hline 2 & & $\mathrm{C} 1039 / 080$ & 0.077” & $\begin{array}{c}\text { No } \\
\text { yield } \\
\text { plateau }\end{array}$ & 359 & $\begin{array}{c}\text { No } \\
\text { yield } \\
\text { plateau }\end{array}$ & 74681 & $0.6 \%$ \\
\hline 3 & & $\mathrm{C} 1060 / 080$ & 0.077” & $\begin{array}{c}\text { No } \\
\text { yield } \\
\text { plateau }\end{array}$ & 1221 & $\begin{array}{c}\text { No } \\
\text { yield } \\
\text { plateau }\end{array}$ & 254357 & $0.9 \%$ \\
\hline 4 & & $\mathrm{C} 1040 / 047$ & $0.0435 ”$ & $\begin{array}{c}\text { No } \\
\text { yield } \\
\text { plateau }\end{array}$ & 117 & $\begin{array}{c}\text { No } \\
\text { yield } \\
\text { plateau }\end{array}$ & 70490 & $3.3 \%$ \\
\hline 5 & & $\mathrm{C} 1039 / 047$ & $0.0435 "$ & $\begin{array}{c}\text { No } \\
\text { yield } \\
\text { plateau }\end{array}$ & 140 & $\begin{array}{c}\text { No } \\
\text { yield } \\
\text { plateau }\end{array}$ & 84428 & $2.8 \%$ \\
\hline 6 & \multirow{5}{*}{$\begin{array}{l}\text { HT } \\
\text { (Heat } \\
\text { treated) }\end{array}$} & $\mathrm{C} 1040 / 080$ & $0.077 ”$ & 255 & 406 & 532 & 86749 & $0.8 \%$ \\
\hline 7 & & C1039/080 & $0.077^{\prime \prime}$ & 262 & 404 & 262 & 83828 & $1.4 \%$ \\
\hline 8 & & C1060/080 & $0.077 ”$ & 329 & 543 & 329 & 113306 & $0.6 \%$ \\
\hline 9 & & C1040/047 & $0.0435^{\prime \prime}$ & 84 & 128 & 84 & 78061 & $2.3 \%$ \\
\hline 10 & & C1039/047 & $0.0435^{\prime \prime}$ & 86 & 142 & 86 & 85586 & $0.8 \%$ \\
\hline 11 & \multirow{5}{*}{$\begin{array}{l}\text { CT2 } \\
\text { (Coating } \\
\text { 2) }\end{array}$} & $\mathrm{C} 1040 / 080$ & $0.077 ”$ & 271 & 405 & 53200 & 84486 & $1 \%$ \\
\hline 12 & & C1039/080 & $0.077^{\prime \prime}$ & 277 & 403 & 57500 & 84129 & $0.8 \%$ \\
\hline 13 & & C1060/080 & $0.077 ”$ & 340 & 552 & 71000 & 114965 & $0.1 \%$ \\
\hline 14 & & C1040/047 & $0.0435^{\prime \prime}$ & 91 & 130 & 54000 & 78185 & $2 \%$ \\
\hline 15 & & C1039/047 & $0.0435^{\prime \prime}$ & 91 & 142 & 55000 & 85910 & $0.7 \%$ \\
\hline
\end{tabular}




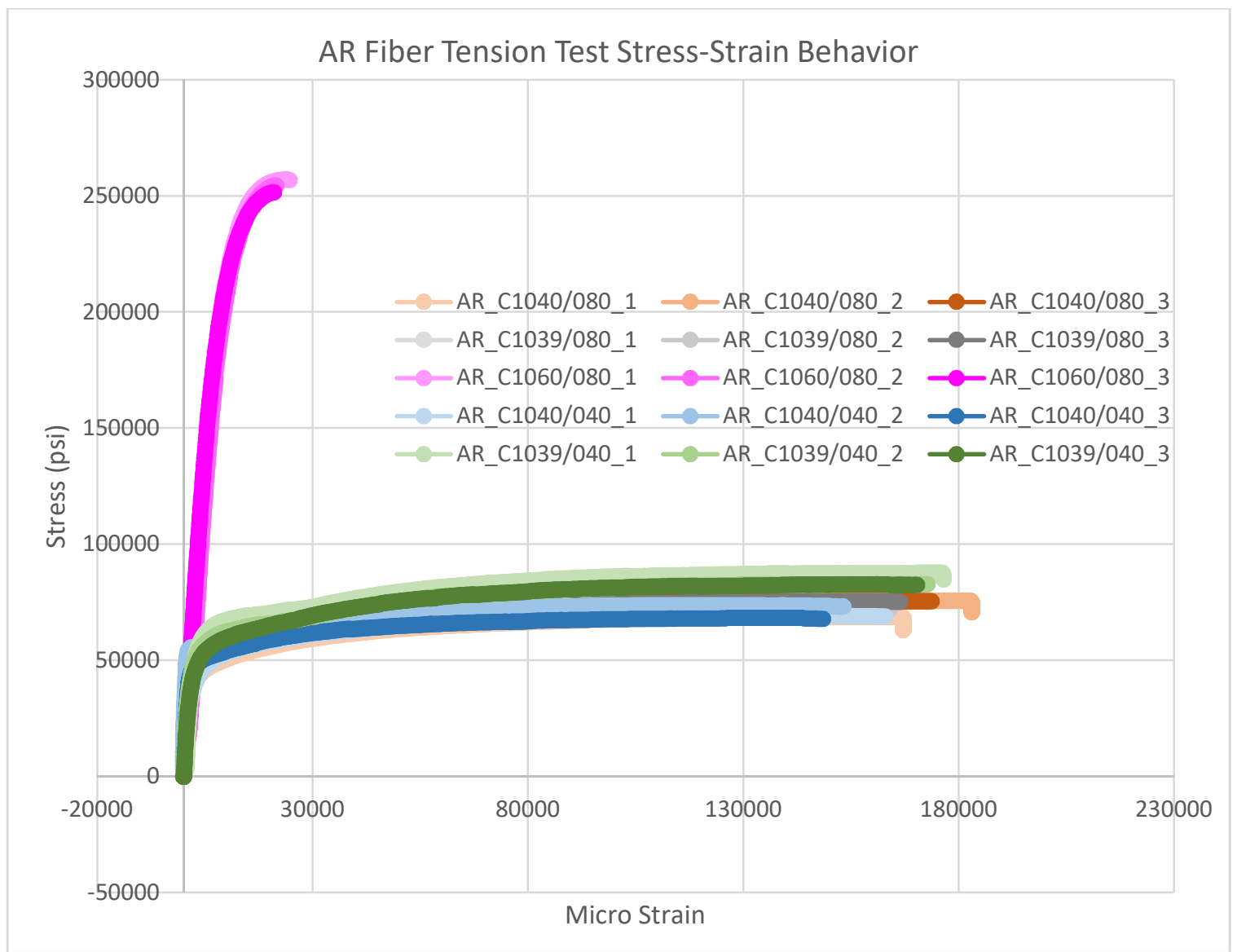

Figure 5-1 Tension Test Results of As Received Fibers (Stress in psi, Strain in microstrain)

Figure 5.3 shows the stress strain behavior of the coated steel fibers. Coated fibers (CT2) exhibited essentially the same behavior as the heat-treated fibers of the same diameter. This means the coating itself almost doesn't affect the stress-strain behavior at all. In other words, the pullout behavior difference is proved caused by bonding effect due to coating process. It should be noted that the coating did not start to flake off until significant inelastic fiber deformations had occurred. 


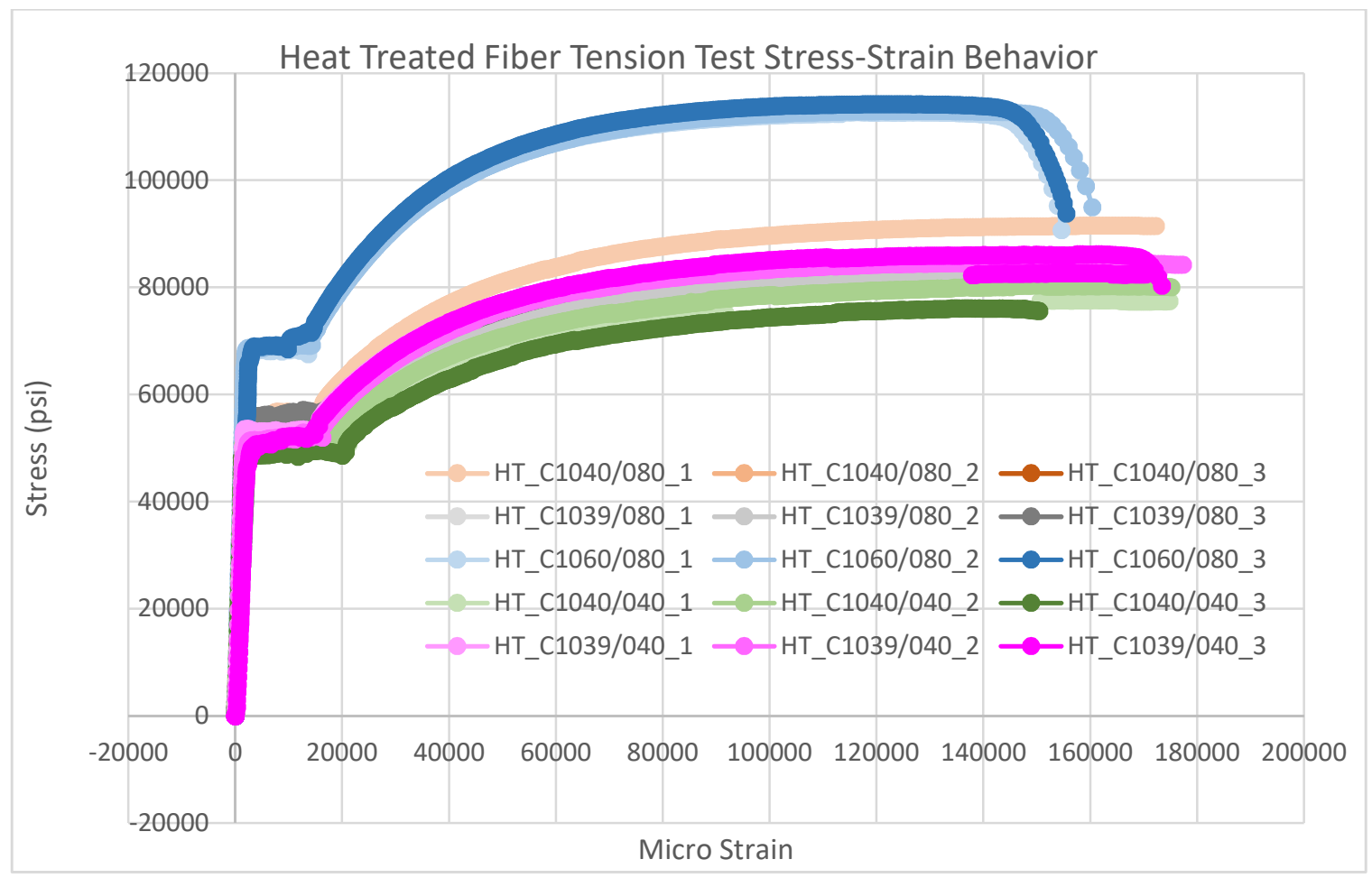

Figure 5-2 Tension Test Results for Heat Treated Fibers (Stress in psi, Strain in microstrain)

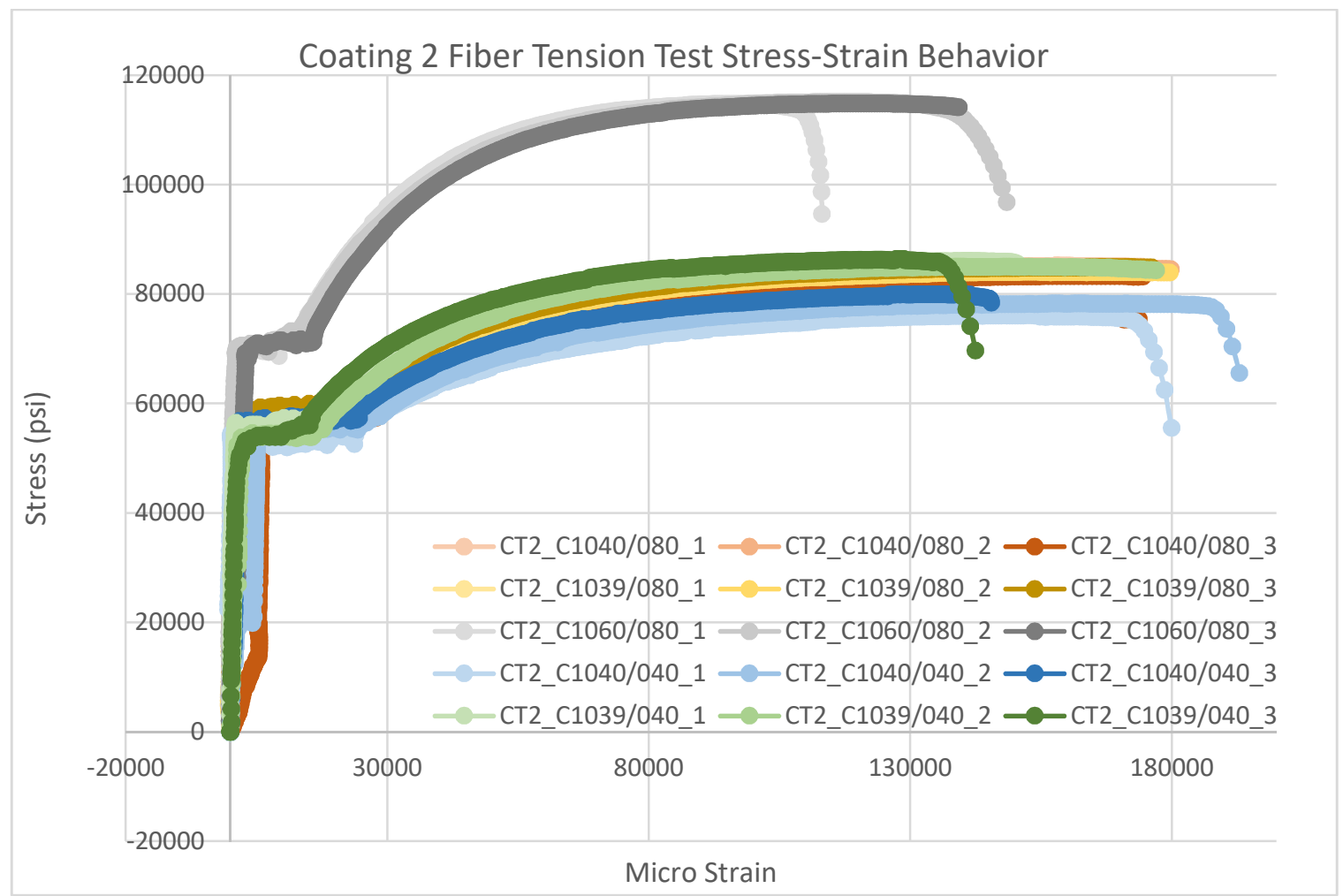

Figure 5-3 Tension Test Results for Coating 2 Fibers (Stress in psi, Strain in microstrain) 


\subsection{Pullout Results Analysis}

Figure 5.4, 5.5 and 5.6, show that the pullout response of the bare fibers is highly variable, and trends are unclear. Peak pullout loads for the C1040/C1039_080 fiber were around 400 lbs. for the C1060_080 fiber and less than 100 lbs. for C1040/C1039_080 fibers. These values were much less than measured fiber ultimate tension capacity of about $1200 \mathrm{lbs}$ for bare C1060_080 fiber fibers and about $400 \mathrm{lb}$ for the C1040/C1039_080 fiber. However, for both steel types, bare fiber showed consistent residual resistance after peak load capacity, and this resistance did not seem to vary consistently with embedment length. For example, this resistance, a combination of friction and cohesion, for the is about $20 \mathrm{lb}$ for the 040 fibers at a $1.5 \%$ embedment length, $17.5 \mathrm{lbs}$. at a 1" embedment length, $15 \mathrm{lbs}$. at 0.5 " embedment length. Embedment length does not seem to have a consistent effect on pullout, likely due to the early loss of cohesion caused by lateral strains.

The peak pullout load is listed below in Table 5.2

\section{Table 5-2: Peak Pullout Load of Pullout Test (1/3)}

\begin{tabular}{|c|c|c|c|c|}
\hline Fiber Type & Material Type & Diameter & Embedment Length & Peak Load (lb) \\
\hline \multirow{9}{*}{ AR } & C1040/080 & \multirow{3}{*}{$0.077 "$} & \multirow{6}{*}{$1.5^{\prime \prime}$} & 26.2 \\
\hline & C1039/080 & & & 78.2 \\
\hline & C1060/080 & & & 98.3 \\
\hline & C1040/040 & \multirow{3}{*}{$0.0435^{\prime \prime}$} & & 44.3 \\
\hline & \multirow{2}{*}{ C1039/040 } & & & 77.2 \\
\hline & & & & 74 \\
\hline & $\mathrm{C} 1040 / 080$ & \multirow{3}{*}{$0.077 "$} & \multirow{3}{*}{$1 "$} & 58.3 \\
\hline & C1039/080 & & & 41.3 \\
\hline & C1060/080 & & & 70.1 \\
\hline
\end{tabular}


Table 5-3: Peak Pullout Load of Pullout Test (2/3)

\begin{tabular}{|c|c|c|c|c|}
\hline Fiber Type & Material Type & Diameter & Embedment Length & Peak Load (lb) \\
\hline & \multirow{2}{*}{$\mathrm{C} 1040 / 040$} & \multirow{3}{*}{$0.0435 "$} & \multirow{3}{*}{$1 "$} & 38.5 \\
\hline & & & & 68.8 \\
\hline & C1039/040 & & & 45.4 \\
\hline & C1040/080 & \multirow{3}{*}{$0.077 "$} & \multirow{6}{*}{0.5} & 48.4 \\
\hline & C1039/080 & & & 18.8 \\
\hline & C1060/080 & & & 42 \\
\hline & C1040/040 & & & 21.5 \\
\hline & (2) & $0.0435^{\prime \prime}$ & & 34.1 \\
\hline & C1039/040 & & & 39.3 \\
\hline & \multirow{3}{*}{ C1039/040 } & \multirow{3}{*}{$0.0435 "$} & \multirow{6}{*}{$0.75^{\prime \prime}$} & 24.2 \\
\hline & & & & 19.9 \\
\hline & & & & 28.4 \\
\hline & \multirow{3}{*}{ C1060/029 } & \multirow{3}{*}{$0.029^{\prime \prime}$} & & 39.6 \\
\hline & & & & 17.3 \\
\hline & & & & 14.4 \\
\hline \multirow{15}{*}{$\mathrm{CT} 2$} & & & \multirow{15}{*}{$1.5^{\prime \prime}$} & 330.1 \\
\hline & $\mathrm{C} 1040 / 080$ & $0.077^{\prime \prime}$ & & 417.1 \\
\hline & & & & 376.4 \\
\hline & & & & 351.2 \\
\hline & $\mathrm{C} 1039 / 080$ & $0.077 "$ & & 413.9 \\
\hline & & & & 338.7 \\
\hline & & & & 545.9 \\
\hline & C1060/080 & $0.077^{\prime \prime}$ & & 463.5 \\
\hline & & & & 532 \\
\hline & & & & 127.3 \\
\hline & $\mathrm{C} 1040 / 040$ & $0.0435^{\prime \prime}$ & & 128.9 \\
\hline & & & & 113 \\
\hline & & & & 125.1 \\
\hline & C1039/040 & $0.0435 "$ & & 127.3 \\
\hline & & & & 121.5 \\
\hline
\end{tabular}


Table 5-4: Peak Pullout Load of Pullout Test (3/3)

\begin{tabular}{|c|c|c|c|c|}
\hline Fiber Type & Material Type & Diameter & Embedment Length & Peak Load (lb) \\
\hline \multirow{12}{*}{$\mathrm{CT} 2$} & \multirow{3}{*}{ C1040/080 } & \multirow{3}{*}{$0.077 "$} & \multirow{6}{*}{$1 "$} & 326.5 \\
\hline & & & & 397.8 \\
\hline & & & & 328.9 \\
\hline & \multirow{3}{*}{ C1040/040 } & \multirow{3}{*}{$0.0435^{\prime \prime}$} & & 132.3 \\
\hline & & & & 112.3 \\
\hline & & & & 138.6 \\
\hline & \multirow{3}{*}{ C1040/080 } & \multirow{3}{*}{$0.077 "$} & \multirow{6}{*}{$0.5^{\prime \prime}$} & 209.1 \\
\hline & & & & 204.3 \\
\hline & & & & 322.6 \\
\hline & \multirow{3}{*}{ C1040/040 } & \multirow{3}{*}{$0.0435 "$} & & 122.2 \\
\hline & & & & 110.9 \\
\hline & & & & 130.1 \\
\hline
\end{tabular}

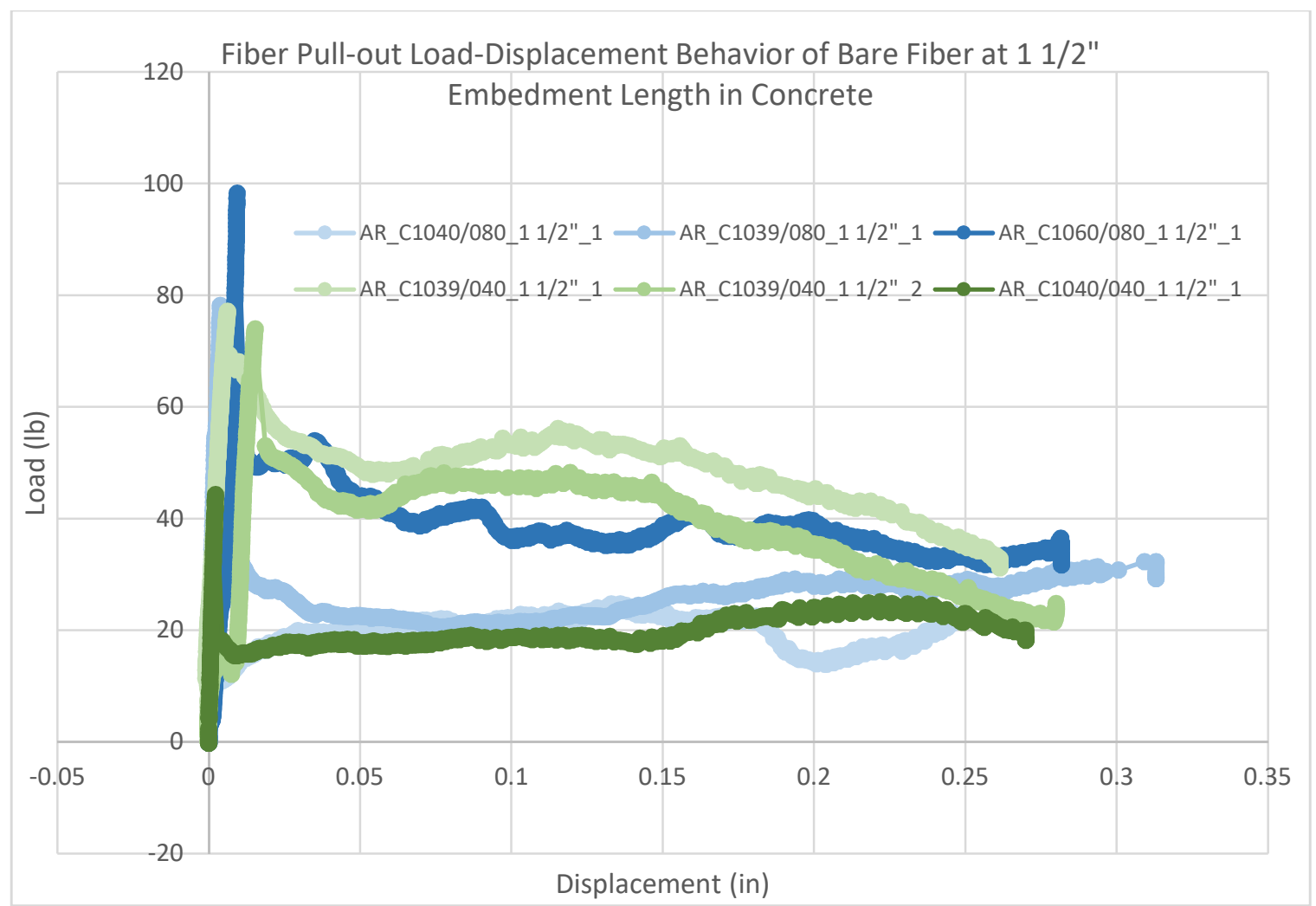

Figure 5-4 Fiber Pullout Load-Displacement Behavior of Bare Fiber at 1.5" Embedment in Concrete 
Figure 5.7 shows the pullout response of bare fiber embedded $3 / 4$ " inch mortar substrate. A comparison of tehis behavior to that shown for the same fiber in Figrire 5.2 As can be seen from this figure and compare it to the previous 2 figures, a conclusion that fiber pullout load of small fiber seems not very sensitive with the change of diameter or embedment length.

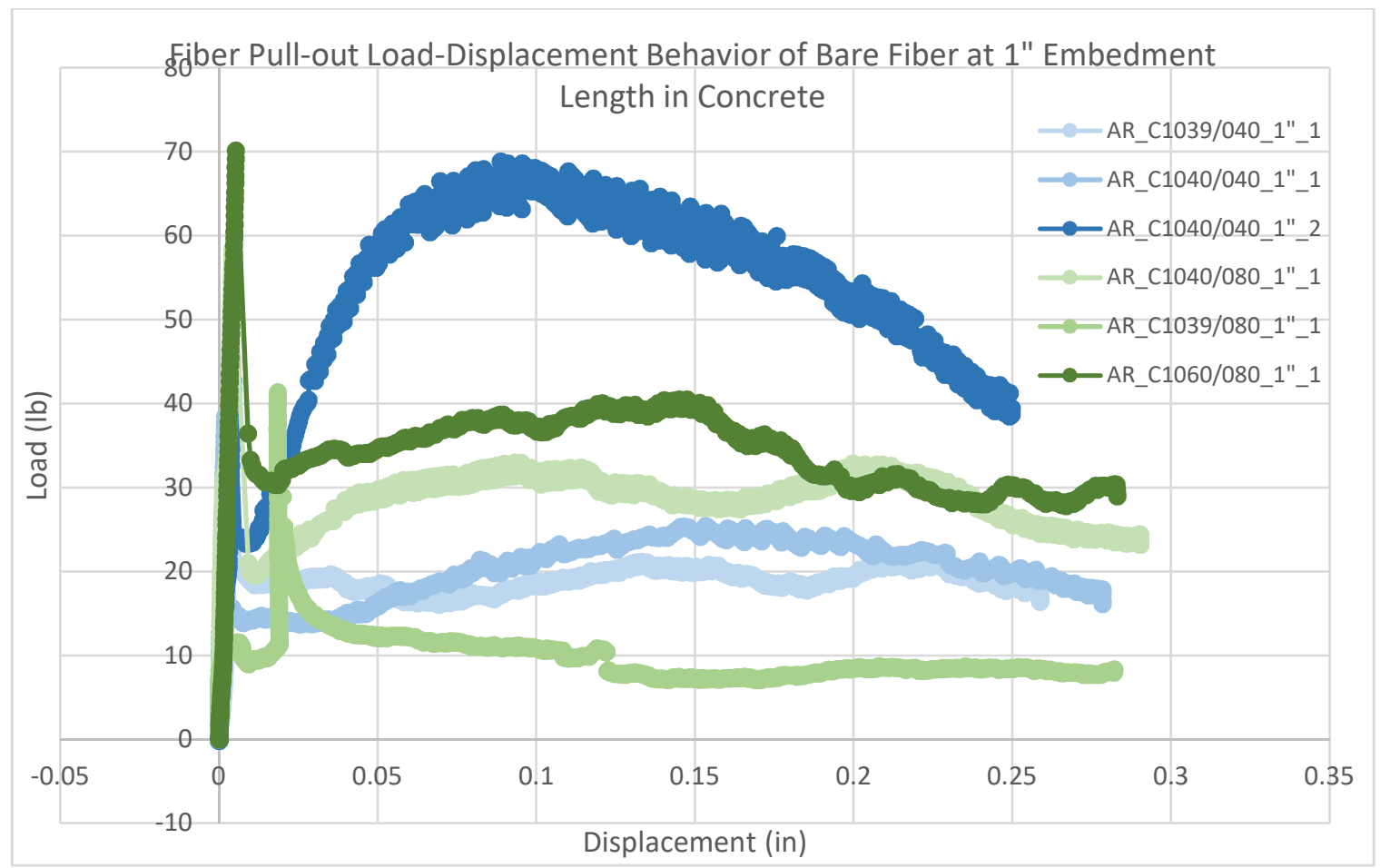

Figure 5-5 Fiber Pullout Load-Displacement Behavior of Bare Fiber at 1.0" Embedment in Concrete 


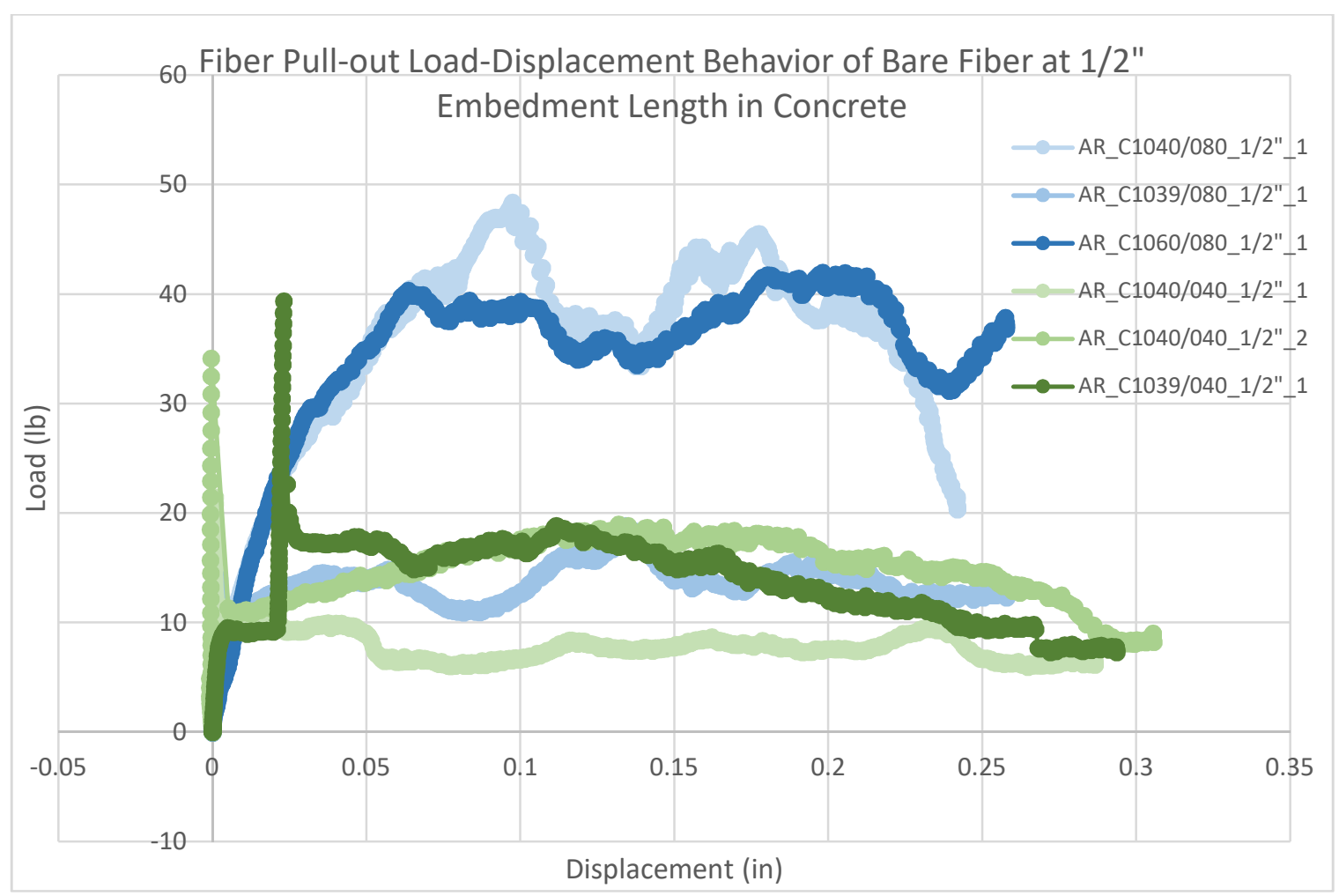

Figure 5-6 Fiber Pullout Load-Displacement Behavior of Bare Fiber at 0.5" Embedment Length in Concrete

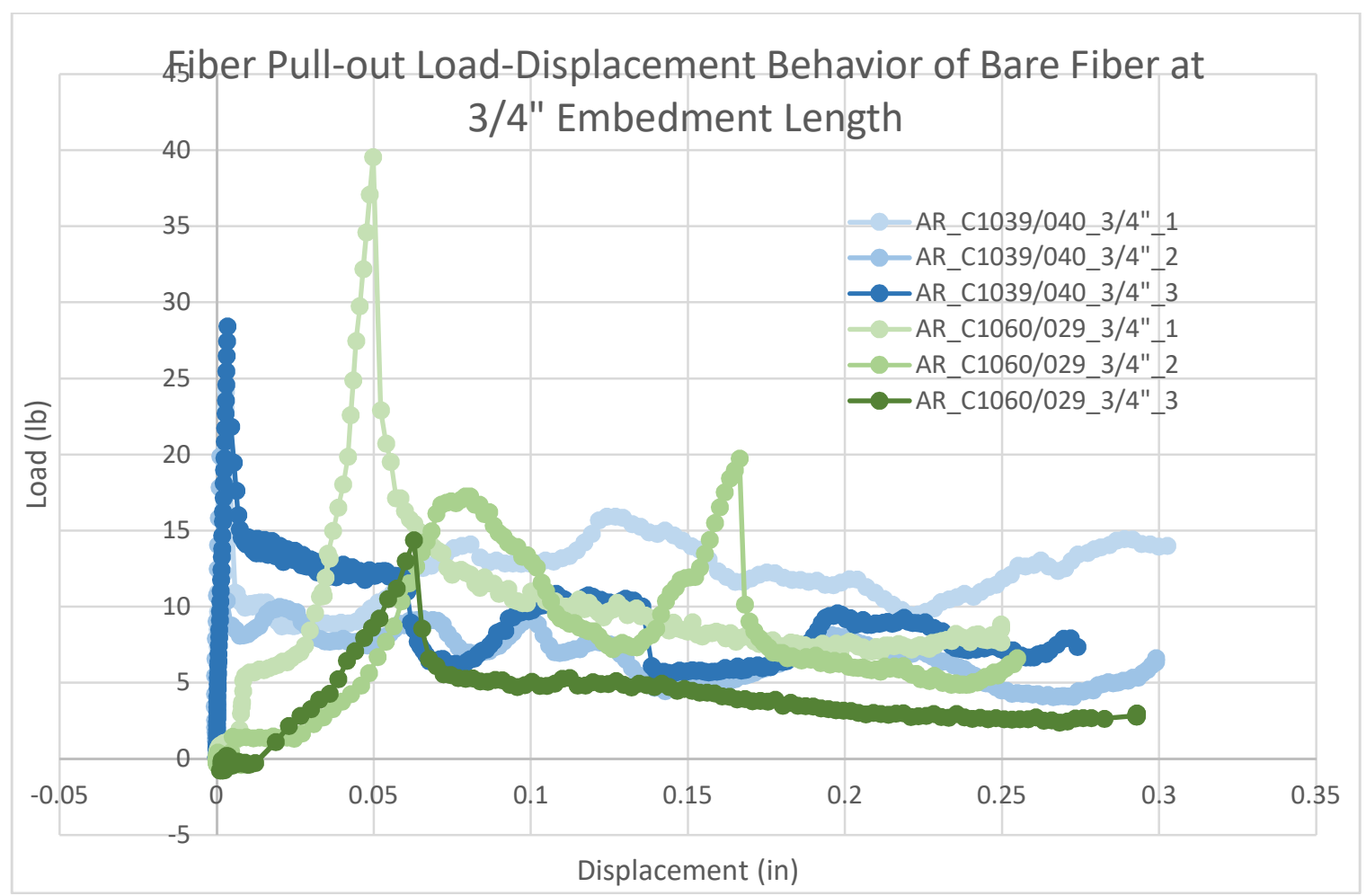

Figure 5-7 Fiber Pullout Load-Displacement Behavior of Bare Fiber at 0.75 "Embedment Length in Mortar 
The concrete cylinder and mortar cube compression test results (related to the pullout tests) were presented as below in Table 5.3.

\section{Table 5-5: Concrete Cylinder and Mortar Cube Compression Test Results}

\begin{tabular}{|c|c|c|}
\hline & Maximum Load (lb) & Compressive Strength (psi) \\
\hline \multirow{2}{*}{$\begin{array}{c}\text { Bare Fiber } \\
\text { Control } \\
\text { (Concrete) }\end{array}$} & 58500 & 4655 \\
\cline { 2 - 3 } & 56500 & 4496 \\
\hline CT2 Fiber & 58700 & 4671 \\
\cline { 2 - 3 } Control & 61500 & 4894 \\
\cline { 2 - 3 }$($ Concrete) & 63300 & 5037 \\
\hline \multirow{3}{*}{$\begin{array}{c}\text { Mix 1 } \\
\text { (Mortar) }\end{array}$} & 61900 & 4925 \\
\cline { 2 - 3 } & 27640 & 6910 \\
\hline
\end{tabular}

In general, the results of the pullout tests appear to show that the fiber peak pullout load and residual strengths do not vary proportionally with embedment length. This phenomenon is not consistent with the DEM model we developed. This model assumes a relationship between pullout load and embedment length. There also appears to be no consistent difference between mortar pullout tests and concrete pullout tests, suggesting aggregate does not have a significant effect on fiber pullout resistance.

Coatings appear to produce more consistent behavior for fiber pullout response. Figures 5.8 and 5.9 show the response of coated fibers (CT2) with 1.5" and 1" embedment lengths pullout results for CT2. Both diameter and material type are designated by the same color. Also shown on the plots are horizontal lines showing the loads (average) for fiber tension yielding and ultimate strength obtained for earlier direct tension test. At the 1.5 and 1.0 embedment length, it is clear that fiber was able to achieve fiber yield and 
significant inelastic deformation prior to pullout of the fiber. In some cases the wire were able to achieve the ultimate strength of the fiber before pullout. It is interesting to point out that the thinner, lower strength fiber does not exhibit as severe drop in residual pullout capacity as thicker fibers. There is likely slipping occurring with the larger diameter fiber at higher strains, possibly because of the higher load levels.

The coated fiber (CT2) (0.5" embedment length) pullout results are shown in Figure 5.10. A concrete/fiber bond failure was observed for all but the lower strength wires, as evidenced by the load drops in the plots. At shorter embedment lengths, fiber/concrete bond appears to govern the capacity of the fiber. There did not appear to be a failure between the steel and coating. 


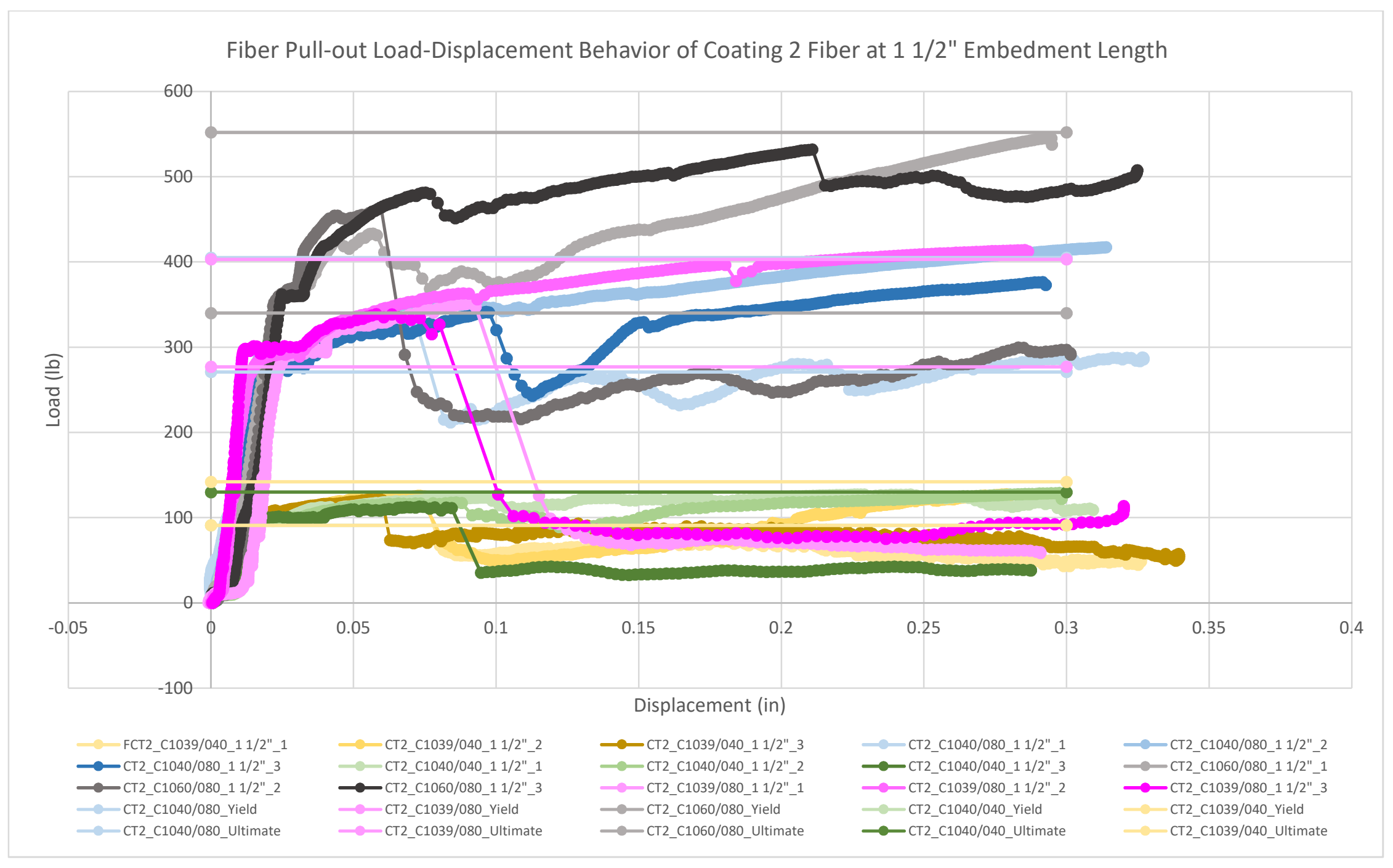

Figure 5-8 Fiber Pullout Load-Displacement Behavior of CT2 Fiber at 1.5" Embedment Length 


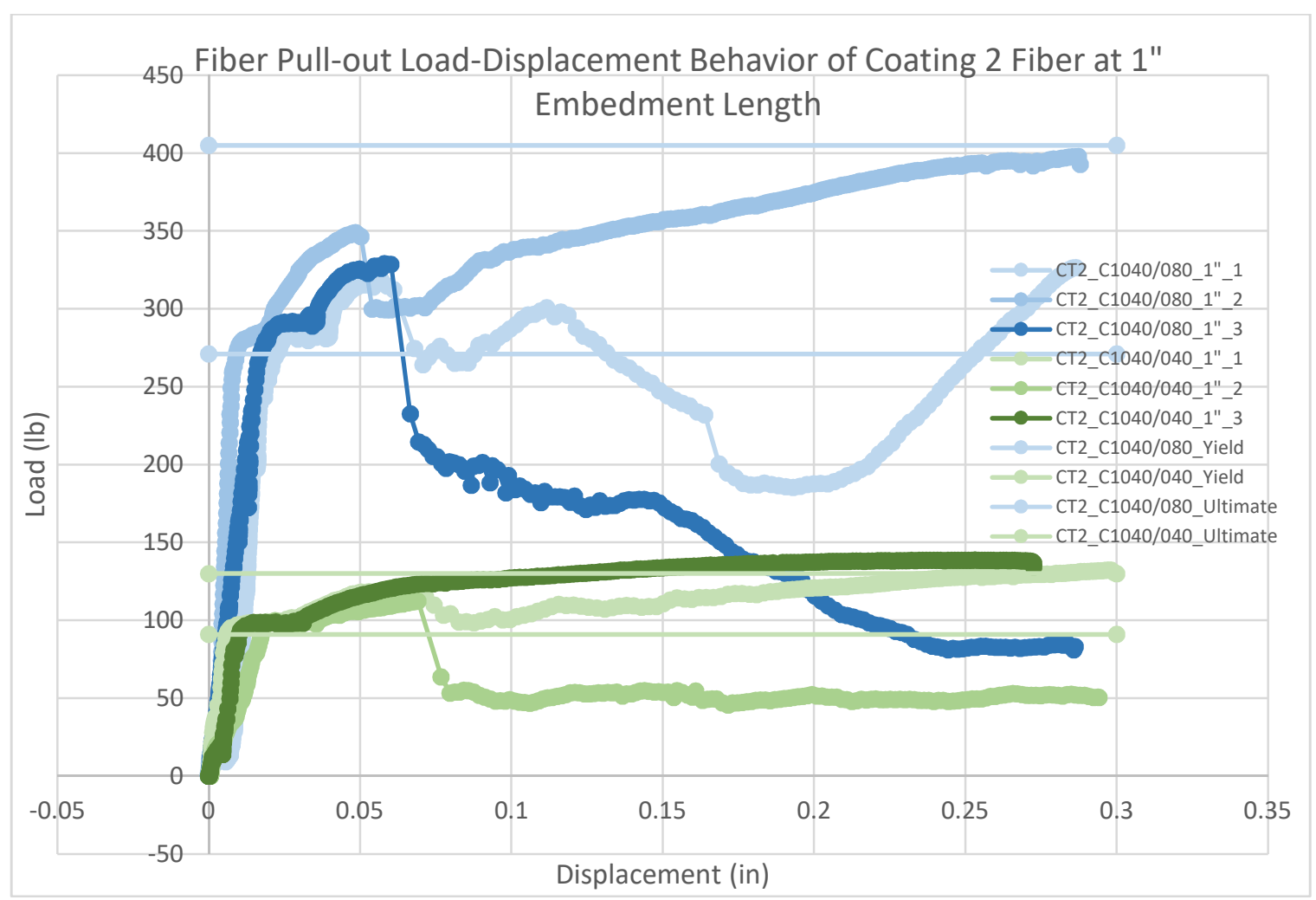

Figure 5-9 Fiber Pullout Load-Displacement Behavior of CT2 Fiber at 1.0” Embedment Length

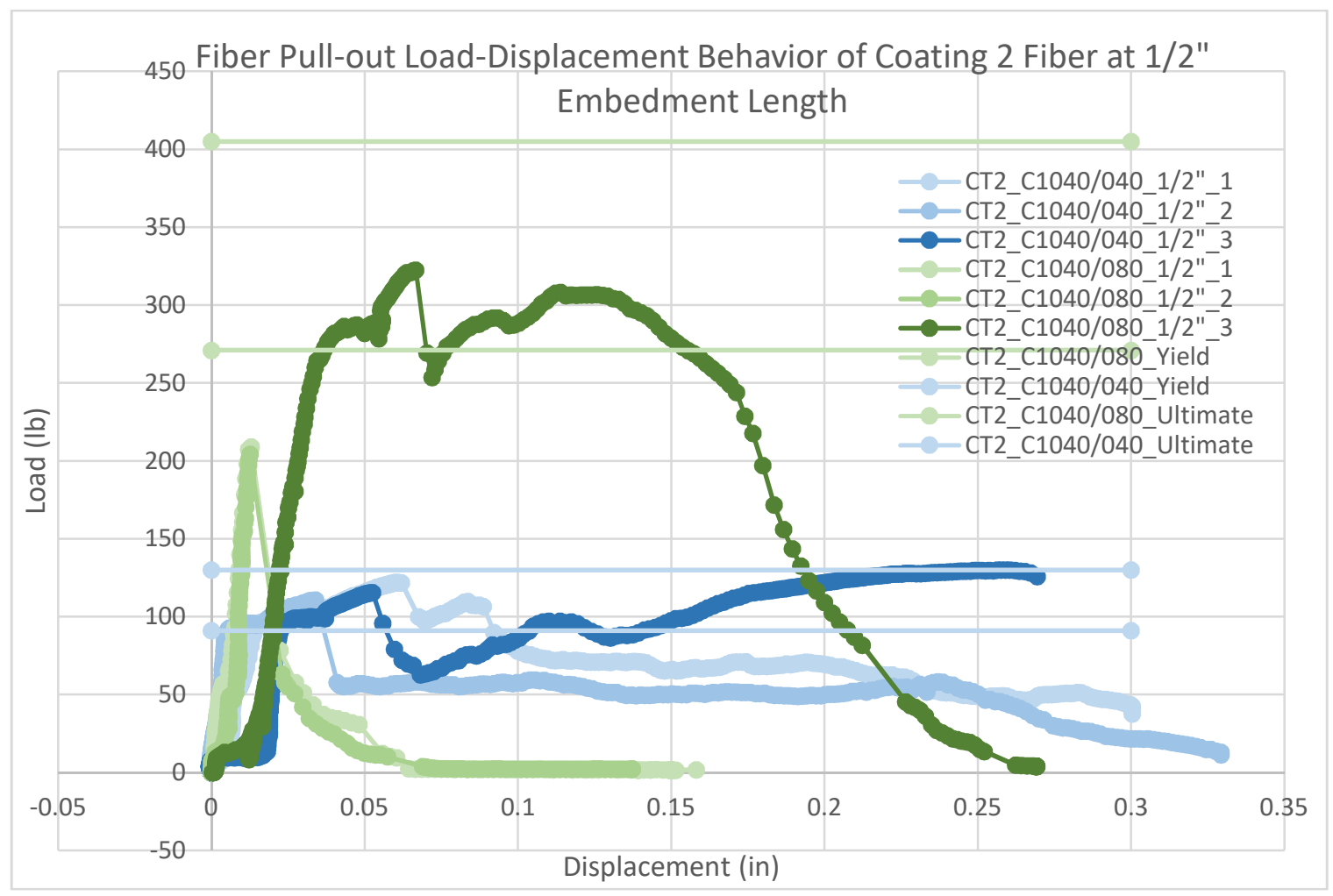

Figure 5-10 Fiber Pullout Load-Displacement Behavior of CT2 Fiber at 0.5 " Embedment Length 


\subsection{Beam and Cube Test Results Analysis}

Compressive strengths obtained from $2 " \times 2 " \times 2 "$ cube tests on the fiber reinforced mortar are listed below. We can see that when fibers are added in mortar, there is generally a small increase in compressive strength (less than 20\%). However, in some conditions, such as when $3 \%$ or $4 \%$ of Fiber $\mathrm{C}$ is added to the mortar, the compressive strength decreases significantly. This decrease may be because of its Fiber C's small 1/d ratio, which is around 17, while other two fibers are 35 and 26. A reasonable surmise is that if $1 / \mathrm{d}$ ratio of a fiber is too small, it will not work to bond the concrete matrix, bridging cracks and strengthening the composite system. If too short, the fibers are more likely to cause planes of weakness and produce a splitting effect. The phenomenon may also explain why some of the flexural test beams did not show increased strength with addition of steel fiber, but actually showed reduction in strength. The splitting effect can override the strengthening effect if the fibers are too short.

Compressive strength results of cubes are listed below, which indicate the compressive strength of beams in flexural test.

Table 5-6: Compressive Strength of Cubes Casted with Beams (1/3)

(Mortar Mix information see Table 4.1)

\begin{tabular}{|c|c|c|c|c|c|}
\hline & \multirow{2}{*}{ Load (lb) } & \multirow{2}{*}{$\begin{array}{c}\text { Avg_Load } \\
\text { (lb) }\end{array}$} & \multicolumn{2}{|c|}{ Compressive strength } & \multirow{2}{*}{ Cov } \\
\hline & & & psi & $\mathrm{MPa}$ & \\
\hline \multirow{3}{*}{ Mortar Mix 1} & 26490 & \multirow{3}{*}{26673} & \multirow{3}{*}{6668} & \multirow{3}{*}{46.0} & \multirow{3}{*}{$1.0 \%$} \\
\hline & 26480 & & & & \\
\hline & 27050 & & & & \\
\hline \multirow{3}{*}{ Mortar Mix $1_{-} 2 \% \mathrm{~A}$} & 30270 & \multirow{3}{*}{31717} & \multirow{3}{*}{7929} & \multirow{3}{*}{54.7} & \multirow{3}{*}{$3.3 \%$} \\
\hline & 32260 & & & & \\
\hline & 32620 & & & & \\
\hline
\end{tabular}


Table 5-7: Compressive Strength of Cubes Casted with Beams (2/3)

\begin{tabular}{|c|c|c|c|c|c|}
\hline & \multirow{2}{*}{ Load (lb) } & \multirow{2}{*}{$\begin{array}{c}\text { Avg_Load } \\
\text { (lb) }\end{array}$} & \multicolumn{2}{|c|}{ Compressive strength } & \multirow{2}{*}{ Cov } \\
\hline & & & psi & $\mathrm{MPa}$ & \\
\hline \multirow{3}{*}{ Mortar Mix $1_{-} 3 \% \mathrm{~A}$} & 30290 & \multirow{3}{*}{29333} & \multirow{3}{*}{7333} & \multirow{3}{*}{50.6} & \multirow{3}{*}{$4.9 \%$} \\
\hline & 27320 & & & & \\
\hline & 30390 & & & & \\
\hline \multirow{3}{*}{ Mortar Mix $1_{-} 4 \% \mathrm{~A}$} & 29130 & \multirow{3}{*}{29830} & \multirow{3}{*}{7458} & \multirow{3}{*}{51.4} & \multirow{3}{*}{$2.7 \%$} \\
\hline & 29400 & & & & \\
\hline & 30960 & & & & \\
\hline \multirow{3}{*}{ Mortar Mix $1 \_2 \% \mathrm{~B}$} & 29480 & \multirow{3}{*}{28300} & \multirow{3}{*}{7075} & \multirow{3}{*}{48.8} & \multirow{3}{*}{$3.7 \%$} \\
\hline & 28470 & & & & \\
\hline & 26950 & & & & \\
\hline \multirow{3}{*}{ Mortar Mix $1_{-} 3 \% \mathrm{~B}$} & 28210 & \multirow{3}{*}{28350} & \multirow{3}{*}{7088} & \multirow{3}{*}{48.9} & \multirow{3}{*}{$1.2 \%$} \\
\hline & 28820 & & & & \\
\hline & 28020 & & & & \\
\hline \multirow{3}{*}{ Mortar Mix $1_{-} 4 \% \mathrm{~B}$} & 28750 & \multirow{3}{*}{28273} & \multirow{3}{*}{7068} & \multirow{3}{*}{48.7} & \multirow{3}{*}{$1.7 \%$} \\
\hline & 28440 & & & & \\
\hline & 27630 & & & & \\
\hline \multirow{3}{*}{ Mortar Mix $1_{-} 2 \% \mathrm{C}$} & 23970 & & & & \\
\hline & 25360 & 21465 & 6166 & 125 & $200 /$ \\
\hline & $\begin{array}{c}3416 \\
\text { (Discard) }\end{array}$ & & & & \\
\hline & 15310 & & & & \\
\hline Mortar Mix $1 \_3 \% \mathrm{C}$ & 15620 & 15577 & 3894 & 26.8 & $1.3 \%$ \\
\hline & 15800 & & & & \\
\hline & 16810 & & & & \\
\hline Mortar Mix $1 \_4 \% \mathrm{C}$ & 17260 & 16520 & 4130 & 28.5 & $4.5 \%$ \\
\hline & 15490 & & & & \\
\hline & 27780 & & & & \\
\hline Mortar Mix 2 & 27430 & 26957 & 6739 & 46.5 & $3.4 \%$ \\
\hline & 25660 & & & & \\
\hline & 29230 & & & & \\
\hline Mortar Mix $2 \_2 \% \mathrm{~A}$ & 29750 & 28833 & 7208 & 49.7 & $3.3 \%$ \\
\hline & 27520 & & & & \\
\hline
\end{tabular}


Table 5-8: Compressive Strength of Cubes Casted with Beams (3/3)

\begin{tabular}{|c|c|c|c|c|c|}
\hline & Load (lb) & \multirow{2}{*}{$\begin{array}{c}\text { Avg_Load } \\
(\mathrm{lb})\end{array}$} & \multicolumn{2}{|c|}{ Compressive strength } & \multirow{2}{*}{ Cov } \\
& & \multirow{2}{*}{30050} & 7513 & 51.8 & \multirow{2}{*}{$1.7 \%$} \\
\hline \multirow{2}{*}{ Mortar Mix 2_3\%A } & 29550 & 29830 & & MPa & \\
\cline { 2 - 2 } & 30770 & & & & \\
\hline \multirow{2}{*}{ Mortar Mix 2_4\%A } & 29240 & \multirow{2}{*}{28520} & 7130 & 49.2 & \multirow{2}{*}{$6.2 \%$} \\
\cline { 2 - 2 } & 30230 & & & & \\
\cline { 2 - 2 } & 26090 & & & \\
\hline
\end{tabular}

The load deflection response of the non-reinforced mortar beam are shown in Figure 5.11. This behavior is very brittle with the beam behaving elastically up to failure and a complete fall off of resistance at cracking.

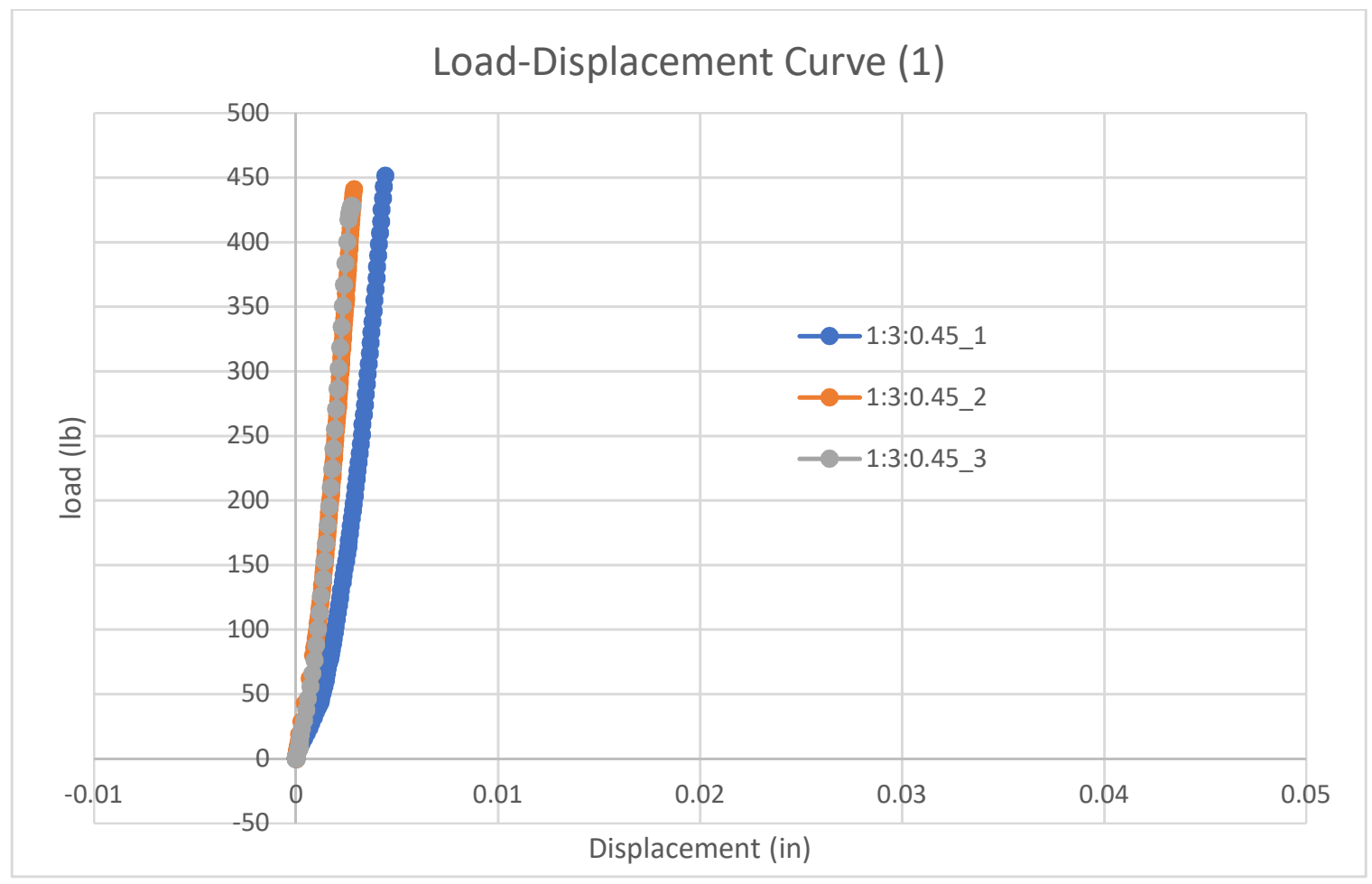

Figure 5-11 Load Deflection Response of Unreinforced Mortar Beams 
Figure 5.12 shows the typical load deflection behavior of the fiber reinforced mortar beams. This behavior was characterized by elastic behavior up to cracking, with a significant increase in deformation with falling load. Typically, the tests were stopped at the end of displacement sensor travel. Al the reinforced beams exhibited similar behavior with varying cracking loads and residual capacities. The measured load deformation response for each of the beams test are shown in Appendix A.

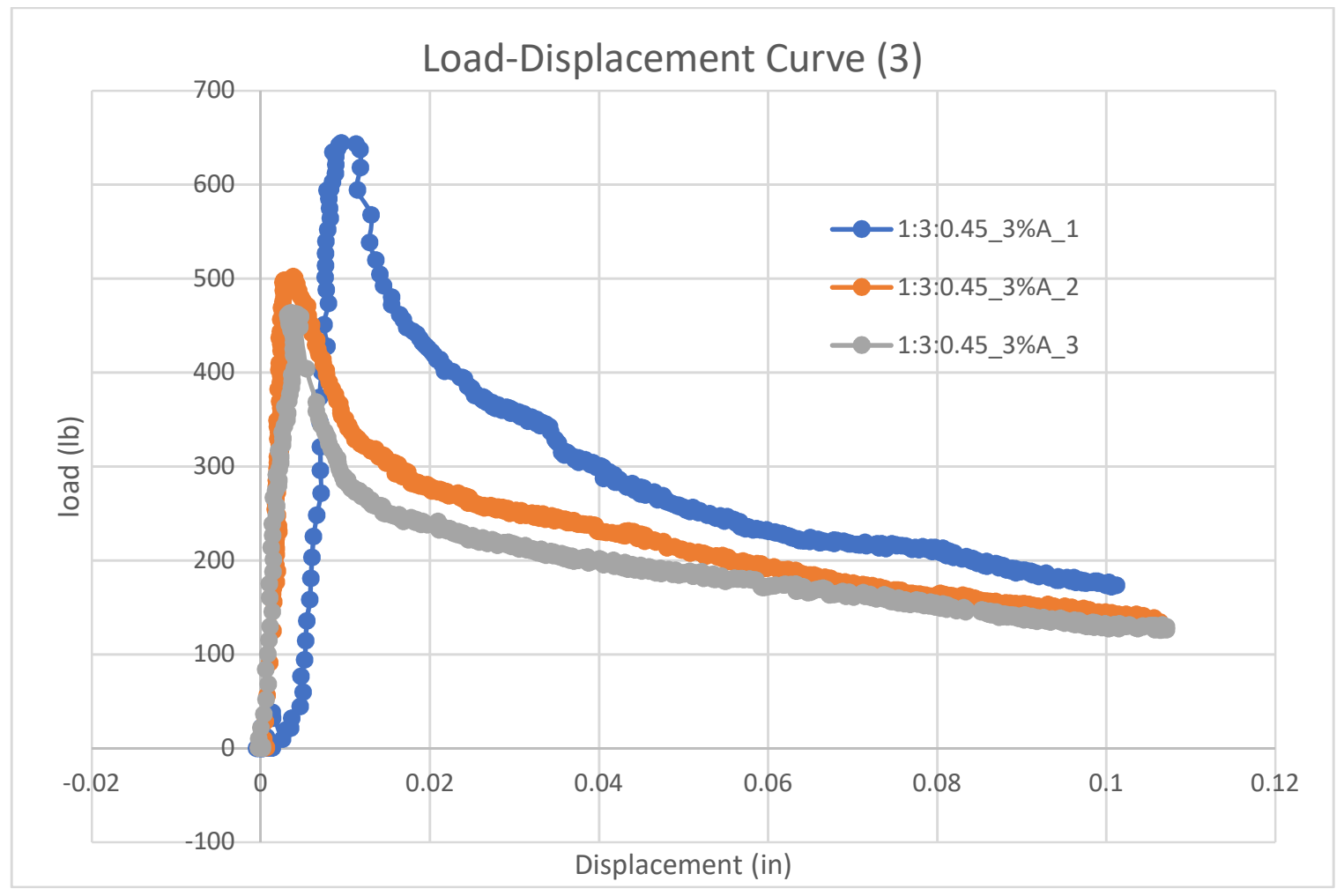

Figure 5-12 Typical Load Deflection Response of Reinforced Mortar Beams 


\section{CHAPTER 6 \\ MODEL ANALYSIS}

\subsection{Preliminary Model Validation - Previous Large Scale Concrete Beam Tests}

The pre-cracking and post-cracking models were applied to FRC beam configurations constructed with coated and uncoated steel fibers (McGinley, 2016). These beams were subjected to $3^{\text {rd }}$ point loading over 18 inch. The MATLAB codes (shown in Appendix A) were used to facilitate numerical integration of the fiber stress in the modified DEM model described in the previous section. These models were then used to predicted the ultimate moment capacity, and then load capacity of FRC $3^{\text {rd }}$ point bending test specimens (18 in. span, 6" x 6" FRC sections) (McGinley, 2016). For Coating B and C fibers, the assumed characteristics for each configuration are shown below in Table 6.1. As can be seen in the table, there are two set of assumptions used for each fiber type. The first one assumes a fiber diameter of 0.043 " (steel alone) to determine the $\tau_{\max }$, and the other accounted for the fiber coating thickness - assumed to be 0.006 ".

\section{Table 6-1: Fiber Characteristics assumed for Model Predictions}

\begin{tabular}{|c|c|c|}
\hline & Coating B Fiber & Coating C Fiber \\
\hline fiber length & $1 "$ & $1 "$ \\
\hline fiber diameter & $0.043 ”$ & $0.043^{\prime \prime}$ \\
\hline modified diameter & $0.043 "+2 \times 0.006 "$ & $0.043 "+2 \times 0.006 "$ \\
\hline slip & $0.00125^{\prime \prime}$ & $0.00125 "$ \\
\hline
\end{tabular}




\begin{tabular}{|l|l|l|}
\hline$\tau_{f, \max }$ & $3.989 \mathrm{MPa}(578.56 \mathrm{psi})$ & $5.319 \mathrm{MPa}$ (771.46 psi) \\
\hline modified $\tau_{f, \max }$ & $3.128 \mathrm{MPa}(453.68 \mathrm{psi})$ & $4.171 \mathrm{MPa}(604.95 \mathrm{psi})$ \\
\hline
\end{tabular}

$\tau_{f, m a}$ is equal to pullout load per unit surface area of fiber:

$$
\tau_{f, \max }=P_{\text {out }} / A_{\text {rea }}
$$

Where: $P_{\text {out }}$ is the maximum pullout load of fiber;

$A_{\text {rea }}$ is the embedded surface area of fiber.

The third point fiber reinforced concrete beam tests conducted by McGinley (McGinley, 2016) are summarized in Table 6.2 . 
Table 6-2: Third Point Fiber Reinforced Beam Tests (6" x 6", 18 " span beams)

\begin{tabular}{|c|c|c|c|c|c|c|}
\hline Beam & $\begin{array}{l}\text { Weight } \\
\text { (lb) }\end{array}$ & Coating & $\begin{array}{l}\text { Fiber } \\
\text { loading (\%) }\end{array}$ & $\begin{array}{l}\text { P load } \\
\text { (lb) }\end{array}$ & $\begin{array}{l}\text { Ave. P } \\
\text { (lb) }\end{array}$ & $\begin{array}{l}\mathrm{COV} \\
(\%)\end{array}$ \\
\hline 1 & 64.50 & None & 0 & 3797 & & \\
\hline 2 & 64.00 & None & 0 & 3812 & & \\
\hline 3 & 64.50 & None & 0 & 3668 & 3759 & $2 \%$ \\
\hline 4 & 60.00 & Bare & 6 & \multicolumn{3}{|c|}{ (Load Cell Malfunction) } \\
\hline 5 & 60.50 & Bare & 6 & 4282 & & \\
\hline 6 & 60.50 & Bare & 6 & 4146 & 4214 & \\
\hline 7 & 59.00 & Bare & 7.5 & 4456 & & \\
\hline 8 & 60.00 & Bare & 7.5 & 3782 & & \\
\hline 9 & 59.90 & Bare & 7.5 & 4313 & 4184 & $9 \%$ \\
\hline 10 & 60.20 & B & 6 & 4444 & & \\
\hline 11 & 60.50 & B & 6 & 4547 & & \\
\hline 12 & 59.85 & B & 6 & 4220 & 4404 & $5 \%$ \\
\hline 13 & 59.90 & B & 7.5 & 4301 & & \\
\hline 14 & 60.20 & B & 7.5 & 3810 & & \\
\hline 15 & 61.70 & B & 7.5 & 4641 & 4250 & $14 \%$ \\
\hline 16 & 61.60 & $\mathrm{C}$ & 6 & 3888 & & \\
\hline 17 & 61.20 & $\mathrm{C}$ & 6 & 3703 & & \\
\hline 18 & 61.50 & $\mathrm{C}$ & 6 & 3681 & 3757 & $3 \%$ \\
\hline 19 & 61.50 & $\mathrm{C}$ & 7.4 & 4351 & & \\
\hline 20 & 62.50 & $\mathrm{C}$ & 7.4 & 4456 & & \\
\hline 21 & 61.50 & $\mathrm{C}$ & 7.4 & 3832 & 4213 & $10 \%$ \\
\hline
\end{tabular}

A comparison of predicted and measured behavior as shown in Figure 6.1 and 6.2. Note that $M F$ was taken as $\sigma_{e q} / f_{r}$. Also, as the coating increased the diameters of the steel 
fibers with respect to the concrete matrix, the coating diameter was also used in the model to bound the possible beam behavior.

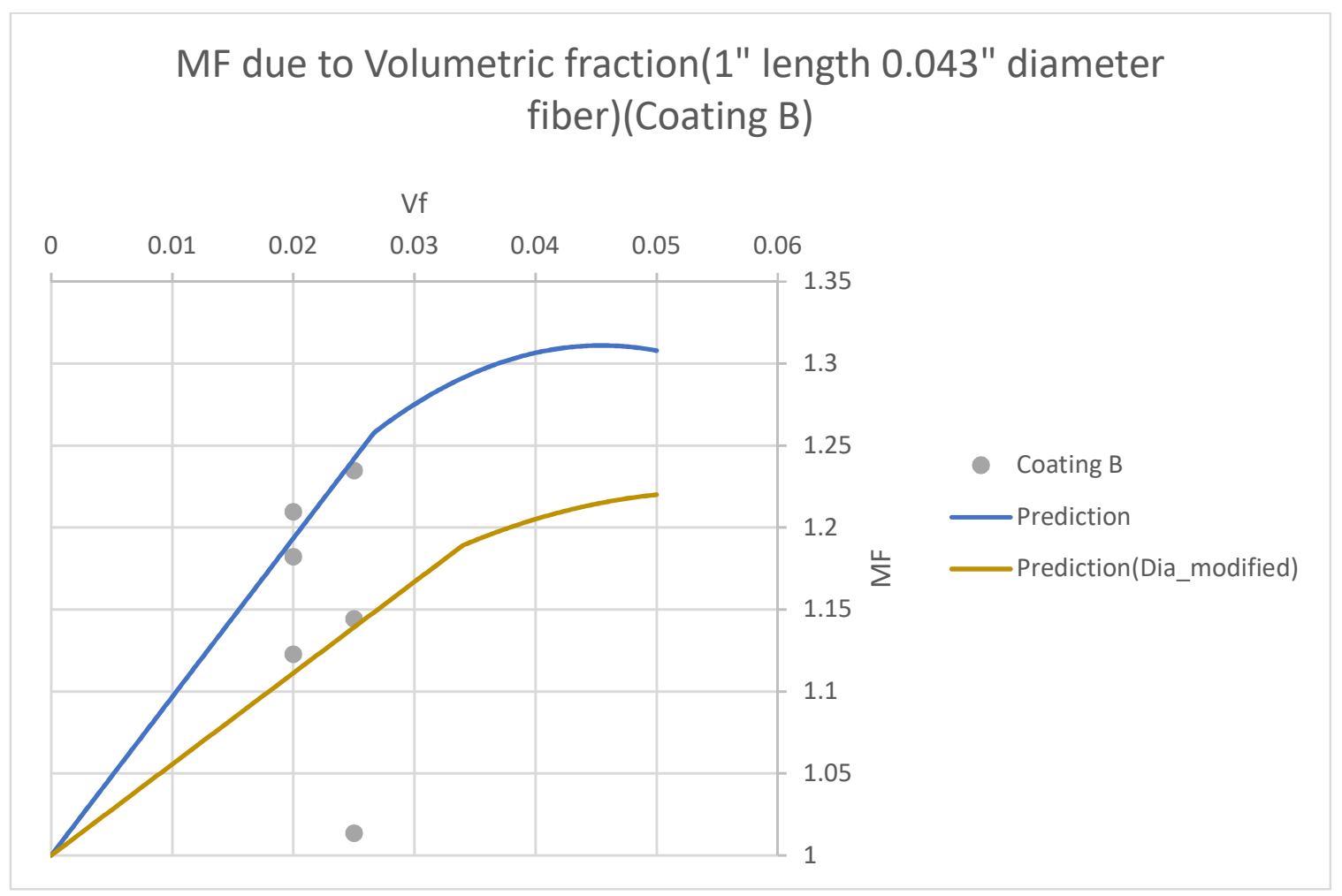

Figure 6-1 Comparison of Predicted and Measured versus Moment Factor for FRC Beams - Coating B 


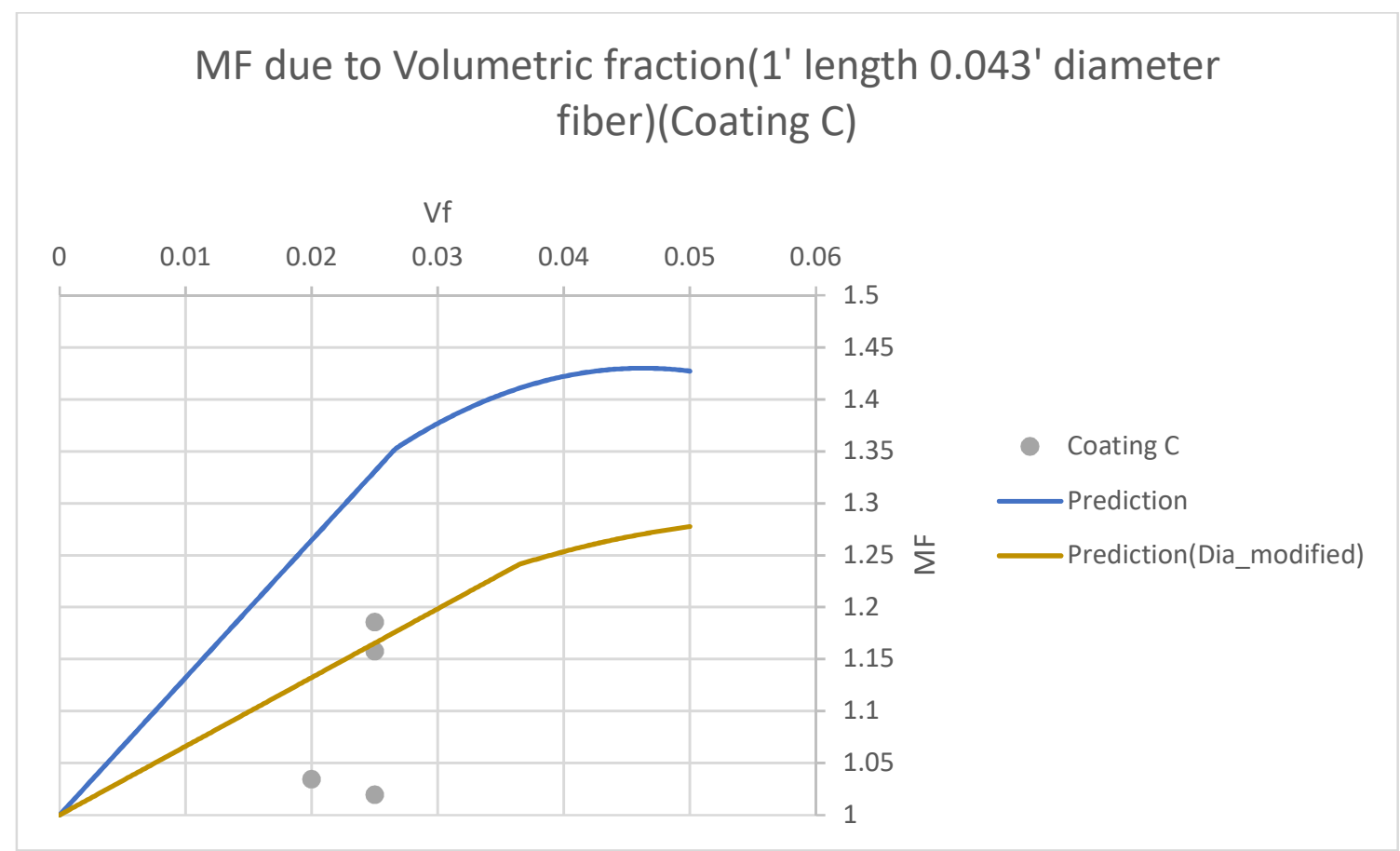

Figure 6-2 Comparison of Predicted and Measured versus Moment Factor for FRC Beams - Coating C

As can be seen from the comparisons of measured to predicted behavior, the model gives a reasonable bound for the predicted behavior of Coating $\mathrm{B}$, with the exception of one outlier. However, there is a relatively large scatter in the experimental data common to brittle cracking types of failures.

However, Figure III-4 shows that there was not as good agreement for the prediction for Coating C fiber performance. One possible reason for this poorer agreement is the fact that the modelling assumed no slip between the fiber and concrete for the Coating $\mathrm{C}$ case. This slip can significantly affect the capacity and fiber stress, and may be at least partially the cause of the larger differences between measured and predicted behavior for this coating type. 
Also, for bare fiber test, the pullout loads for 0.5 -inch embedment length fibers tested by Dr. McGinley (McGinley, 2014) are 3.33, 2.03, $9.76 \mathrm{lb}$ respectively. This large variation in fiber capacity made any prediction unreliable and these results are not presented.

It should be noted that variation in fiber diameter caused by coatings will also increase variation in measured behavior.

\subsection{Mortar Beam Tests Predicted Measured Behavior}

\subsubsection{Pre-cracked Behavior}

Using the load deflection plots of the fiber reinforced mortar listed in Appendix A, the average peak pre-crack capacity was determined for each the fiber beams configurations. In addition, using measured pullout, and material strength the predicted pre-crack capacity was predicted using the model described in Chapter III. These predicted peak stress values predictions were determined as a function of volume fraction and one of three different assumed fiber dispersion probability density functions. One of these dispersion functions assumed a uniformly dispersed density function $(2 / \pi)$, and the second assumed a density function where the probability of the fiber orientation is horizontal biased $(\cos \theta)$, the third used a density function that was biased vertically $(\sin \theta$ -as was discussed previously in Chapter III). As shown in Figures 6.6, 6.7 and 6.9, the test results generally follow the model's predicted trends for Fiber A and B, with closer agreement for predictions using the " $\cos \theta$ " fiber dispersion probability density function. One reason for the closer fit with this function was the fact that our small specimen dimensions and casting procedures made a horizontal fiber orientation more likely. This was confirmed with examination of the crack interface where exposed fibers. This was 
not found in the previous

investigations where the $\sin \theta$

function provided a better fit

(McGinley, 2016). Casting

procedures and fiber orientation

appears to have an effect on the

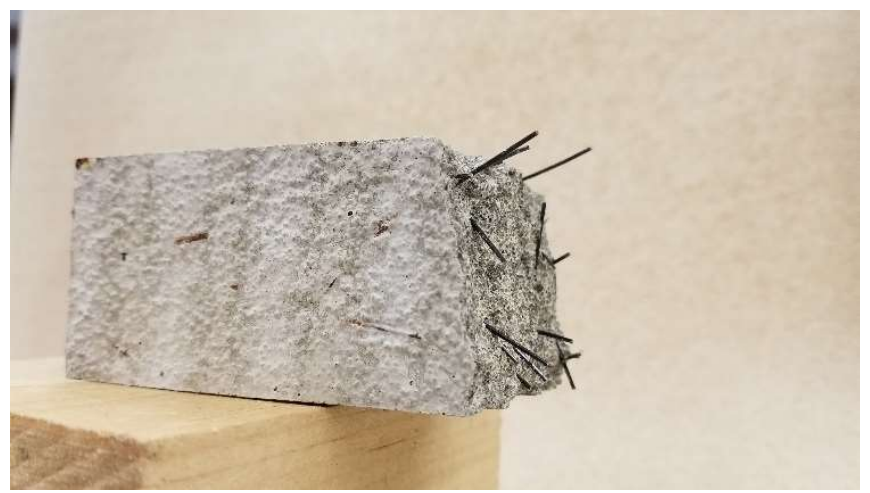

Figure 6-3 Fiber Orientation Distribution: Vertical Biased

model prediction accuracy.

It can be observed that fiber

orientation distribution varies from

specimen to specimen. Shown in

Figure 4.3, 4.4, 4.5 are different

fiber orientation conditions at the

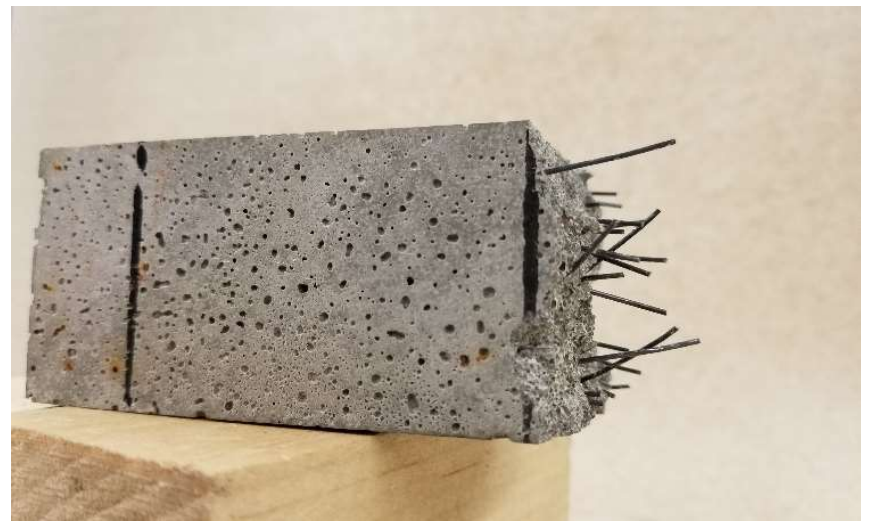

broken sections.

\section{Figure 6-4 Fiber Orientation Distribution: Uniformly}

Figure 6.8 shows that that results for

Fiber $\mathrm{C}$ do not provide good

agreement between measured and

predicted behavior. In addition,

there is an offset in all model

predictions where the impact of fiber

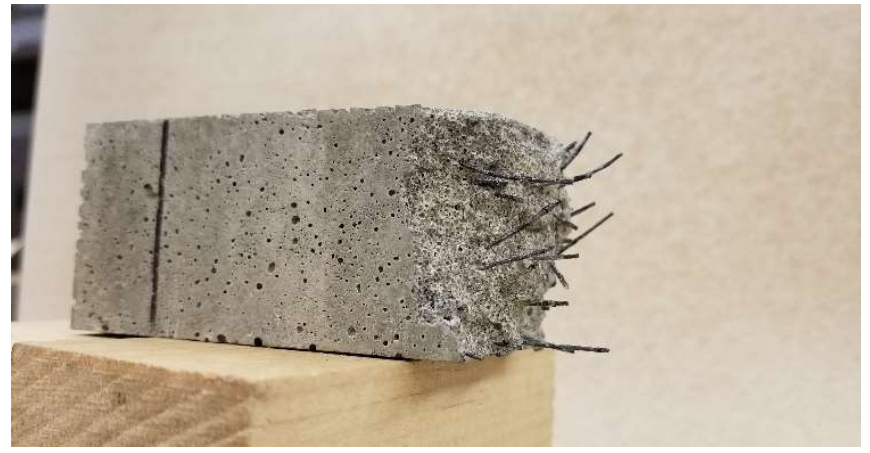

Figure 6-5 Fiber Orientation Distribution: Horizontal Biased

does not follow the model and show that, for low fiber volumes, the beam approaches the non-reinforced capacity. At low fiber volumes, the presence of fiber appears to reduces the cracking strength of the concrete. This is likely caused by the vertically oriented fiber creating planes of weakness in the concrete matrix and lower the apparent cracking 
strength. When fibers are dispersed perpendicular to the actual cracking surface, the bridging effect dominates, when parallel to the cracking surface, this weakening will dominate FRC behavior.

In all the following calibration figures, including pre-crack and post-crack, the "prediction_sin $\theta$ " used $\sin \theta$ as distribution density function, which is used by Lee, et. al. "prediction_cos $\theta$ " used $\cos \theta$ as distribution density function, "prediction_ $2 / \pi$ " used $2 / \boldsymbol{\pi}$.

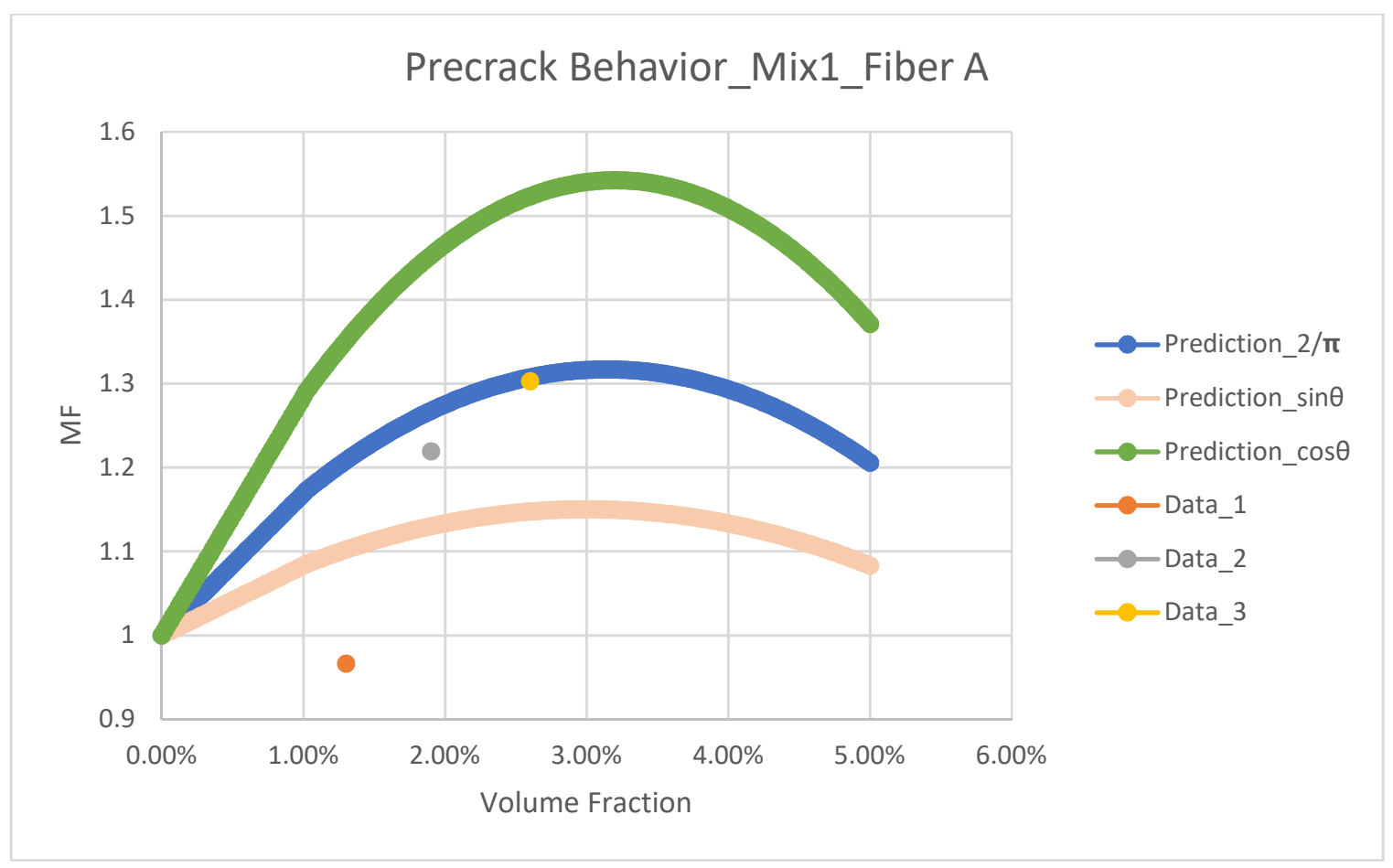

Figure 6-6 Tested Results and Predictions of Fiber A in Mix 1 


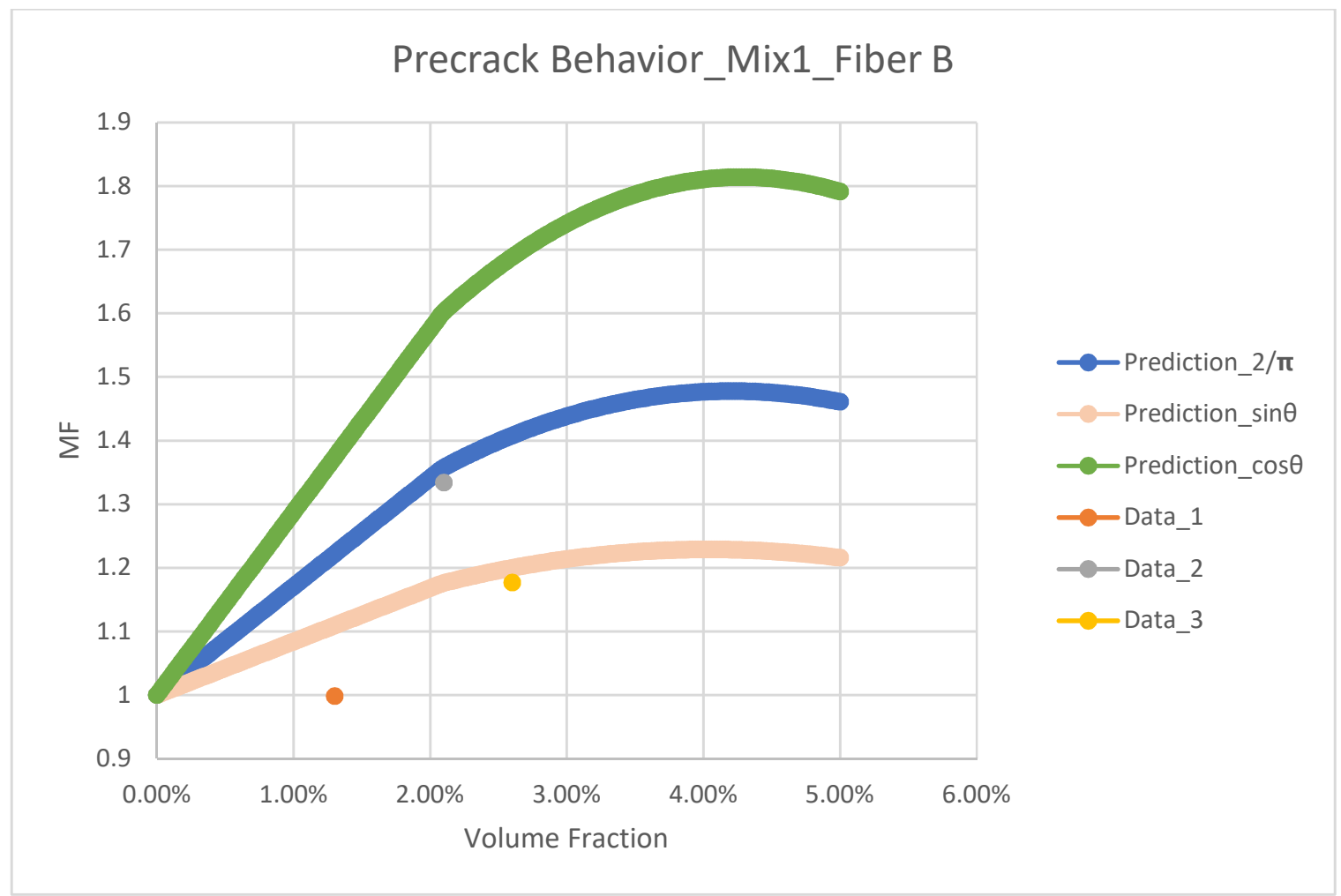

Figure 6-7 Tested Results and Predictions of Fiber B in Mix 1

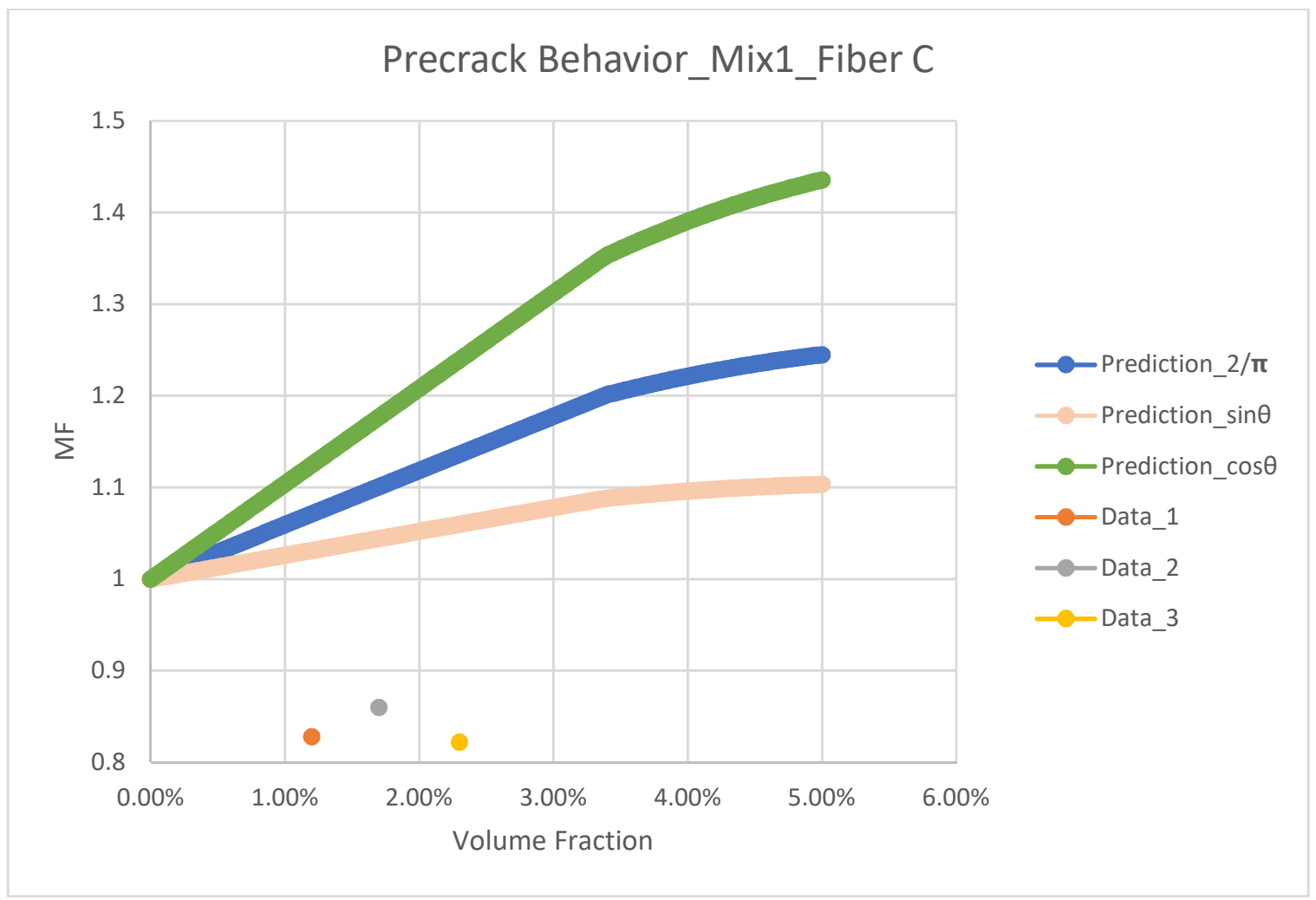

Figure 6-8 Tested Results and Predictions of Fiber C in Mix 1 
Other factors such as fiber size, fiber diameter and fiber $l / d$ ratio appear to affect the precracking behavior as well. The efficiency of the fibers, $K_{e}$ used in the model was developed based on fiber lengths and 1/d ratios higher than investigated in this program. The fiber efficiency is obviously negatively impacted by short fibers and ones with lower $l / d$ ratios. These fiber configurations have lower bond between the fiber and the concrete matrix.

In addition, very high capacities (relative to the model prediction) were measured for Fiber A in Mix 2 (see Figure 6.9). Mix 2 had a higher water cement ratio than the other mortar mix, suggesting that there are additional effects of the fiber mortar interaction. This result suggest that the higher workability of Mix 2 positively impacted the bond between the fibers and quite possibly produced a more favorable fiber dispersion for flexural strength in the more variable flexural strain gradient. This effect must be explored further before a definitive conclusion on this can be reached. 


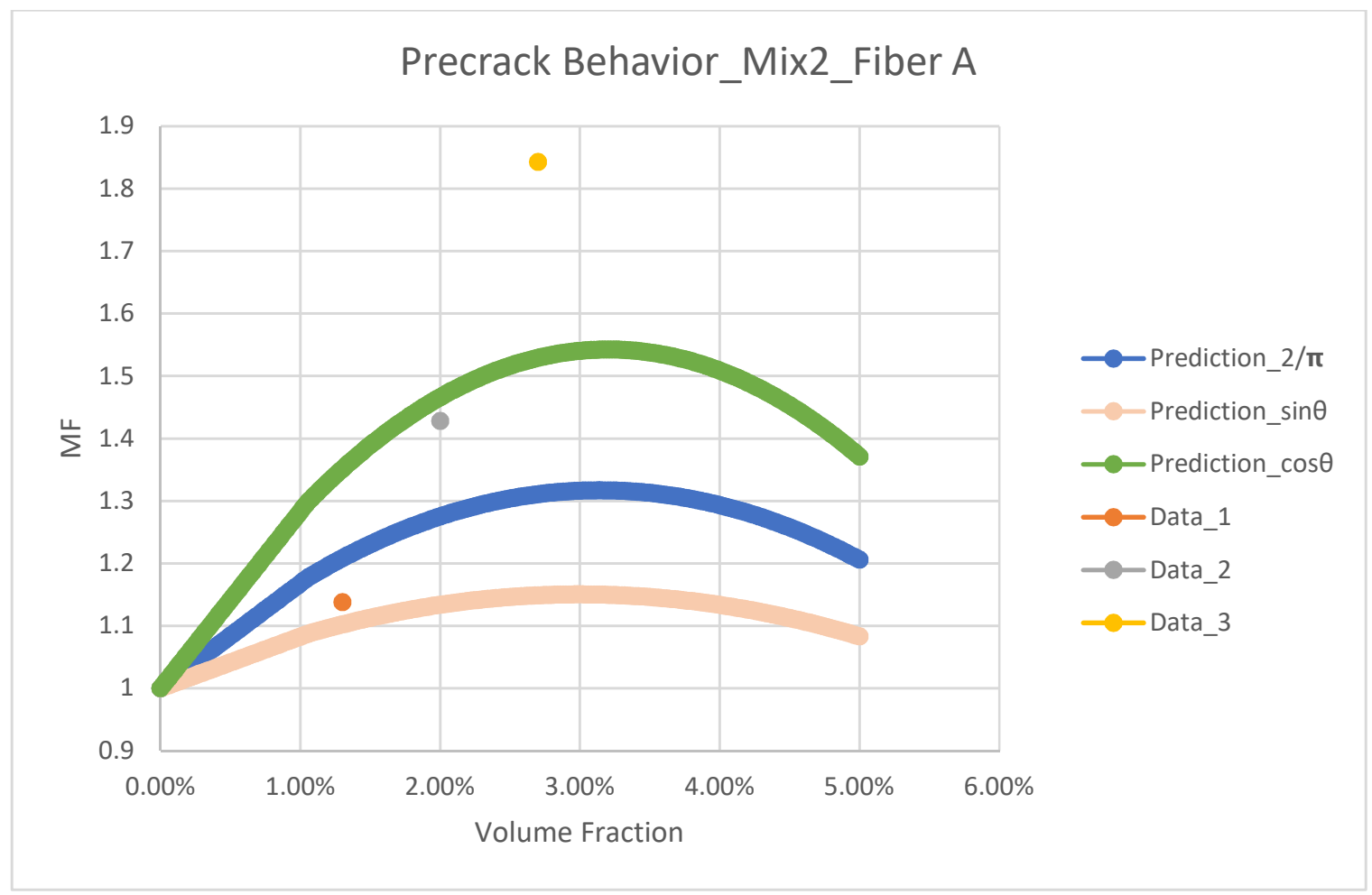

Figure 6-9 Tested Results and Predictions of Fiber A in Mix 2

\subsubsection{Post Crack Behavior}

Examination of the post cracking load deflection behavior of each FRC beam test (see Appendix A), shows similar behavior after cracking. Using the model, a post cracking moment capacity can be calculated, taking crack width and fiber volume fraction as variables. In addition, if ignoring flexural deformation as this will be very small, the relationship between deflection and crack width can be determined by geometry, as shown below. 


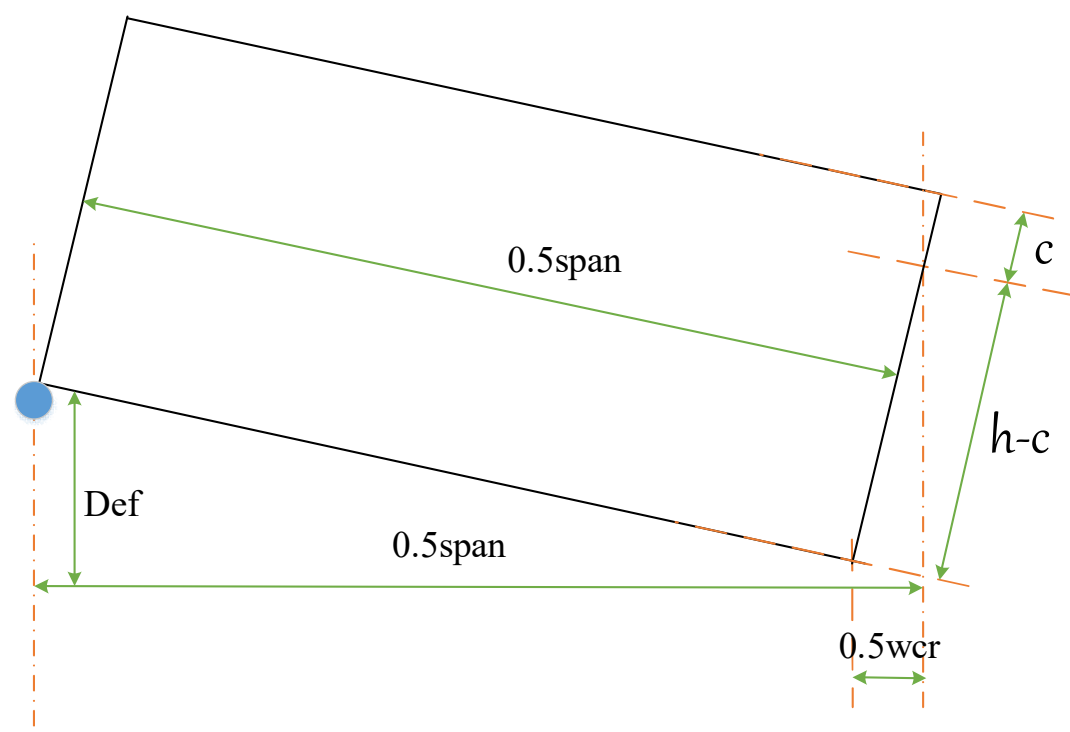

Figure 6-10 Symmetric Half of Beam Specimen in Flexural Test

From the figure above, we can figure out a relationship between deflection and crack width in the flexural test, shown below. Since $\mathrm{c}$ is a small value compared with height of specimen, we ignore it in this rough estimate. (Def is short for deflection.)

$$
\frac{\text { Def }}{0.5 \operatorname{span}} \approx \frac{0.5 w c r}{h}
$$

By inserting the span and height, we can show that $D e f \approx 0.75 \mathrm{wcr}$. Using this relationship, we are able to plot a predicted and measured Load-Deflection curve on the same figure. Then we can get a full-scale comparison, which is $0.1 \mathrm{inch}$.

Thus, for a given fiber volume fraction, a crack width vs. predicted post crack load curve can be determined, and using Equation 21, a deflection vs. predicted post crack load can be determined for each beam test. This load can be converted to an applied moment and then to a MF ratio using statics. Using the post crack model presented in Chapter III and measured fiber capacities, along with the three possible fiber distributions discussed earlier, a predicted MF ratio can be determined for each beam configuration as a function 
of the crack width. The measured and predicted behavior for each beam configuration are plotted in Figures 6.1 through 6.25.

These comparisons suggest that the post-cracking model can give reasonable, if generally conservative prediction of the strength of the FRC systems, although there appears to be other factors affecting the FRC strength that are not included in the model.

Adjustment of the fiber efficiency model for a given fiber configuration and some way to account for the workability impact of fiber dispersion may improve the model prediction accuracy.

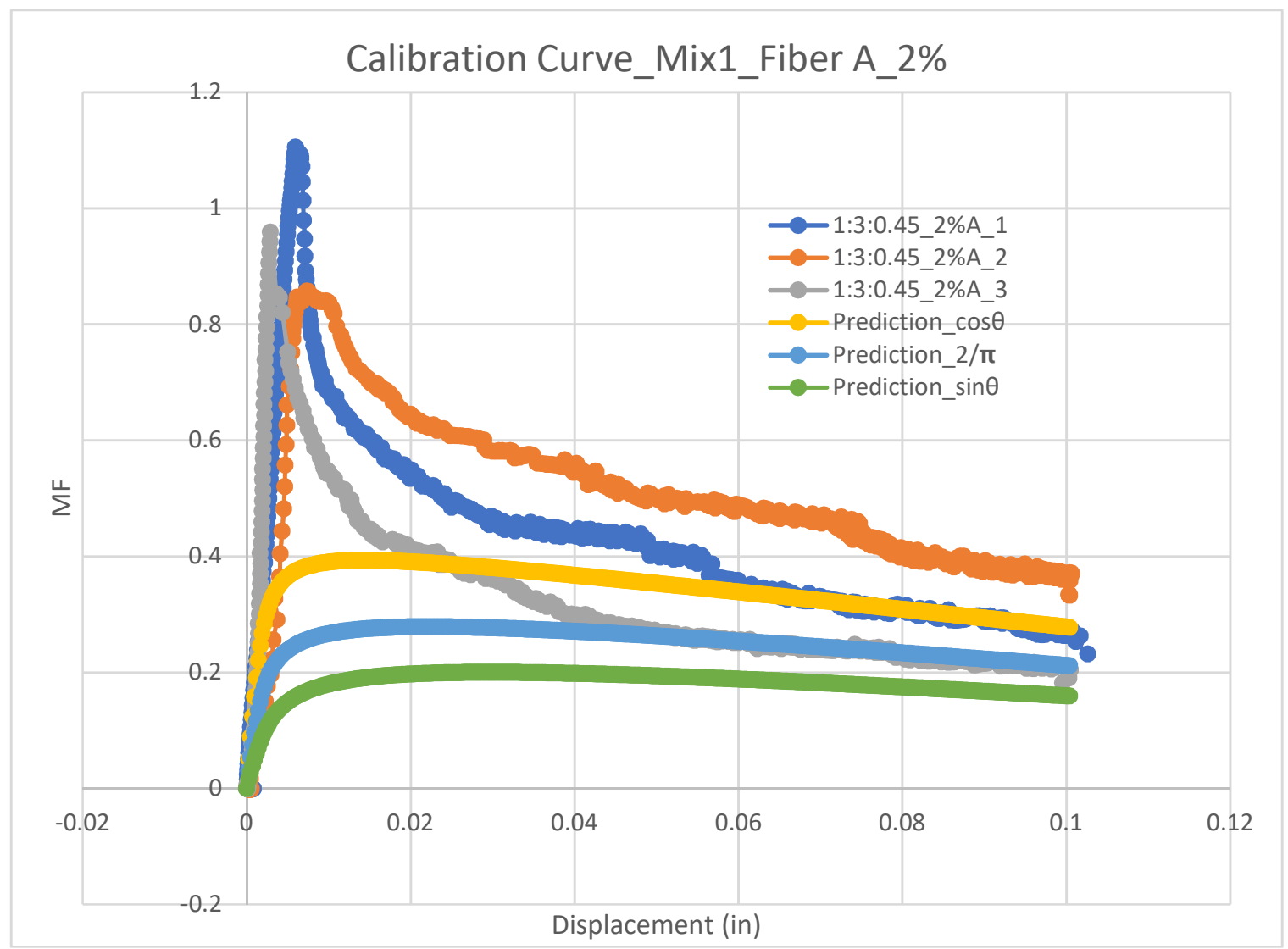

Figure 6-11 Post-crack Behavior of Fiber A in Mix 1 at 1.3\% volume fraction (2\% Nominally) 


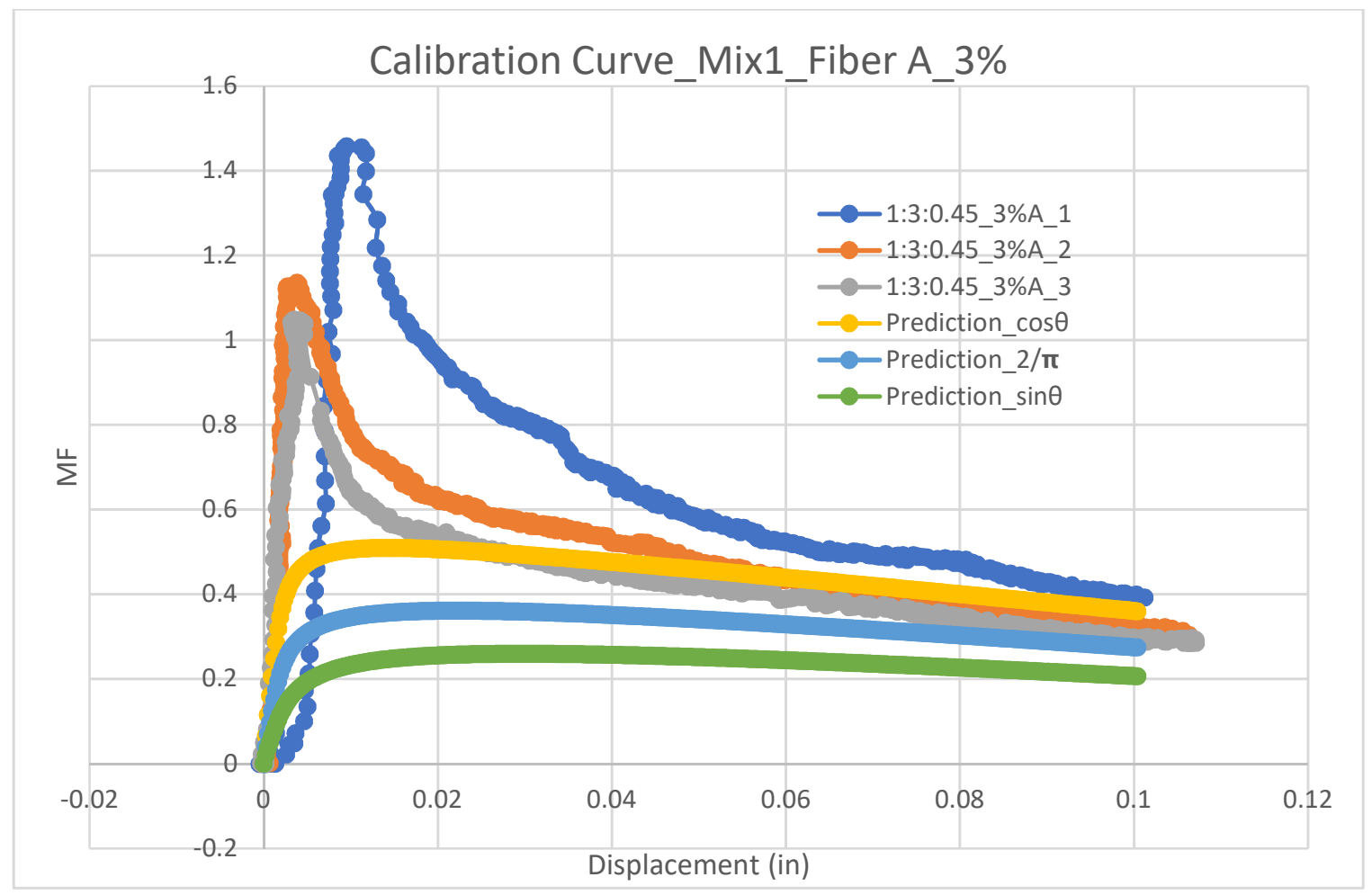

Figure 6-12 Post-crack Behavior of Fiber A in Mix 1 at 1.9\% volume fraction (3\% Nominally)

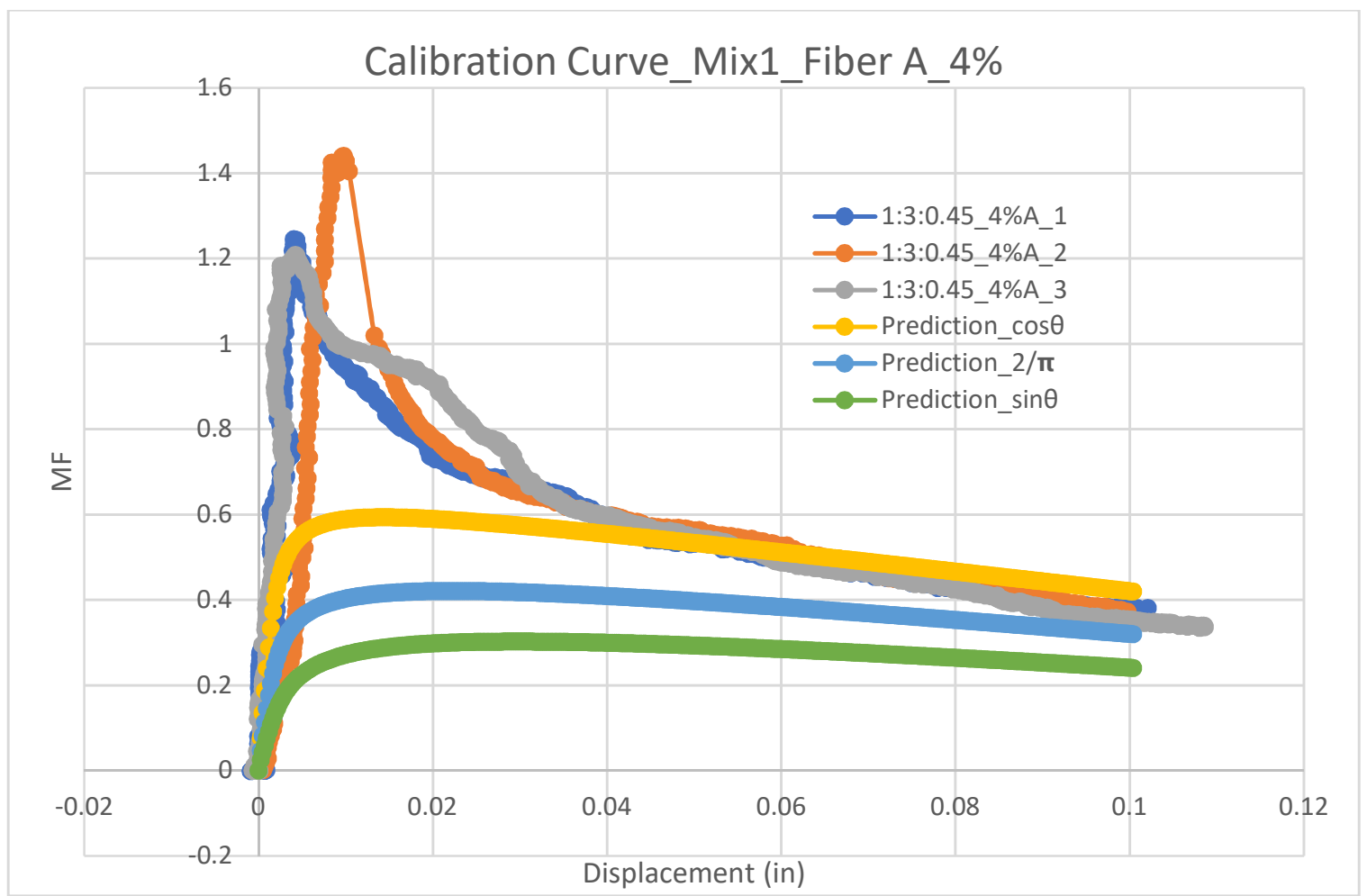

Figure 6-13 Post-crack Behavior of Fiber A in Mix 1 at 2.6\% volume fraction (4\% Nominally) 


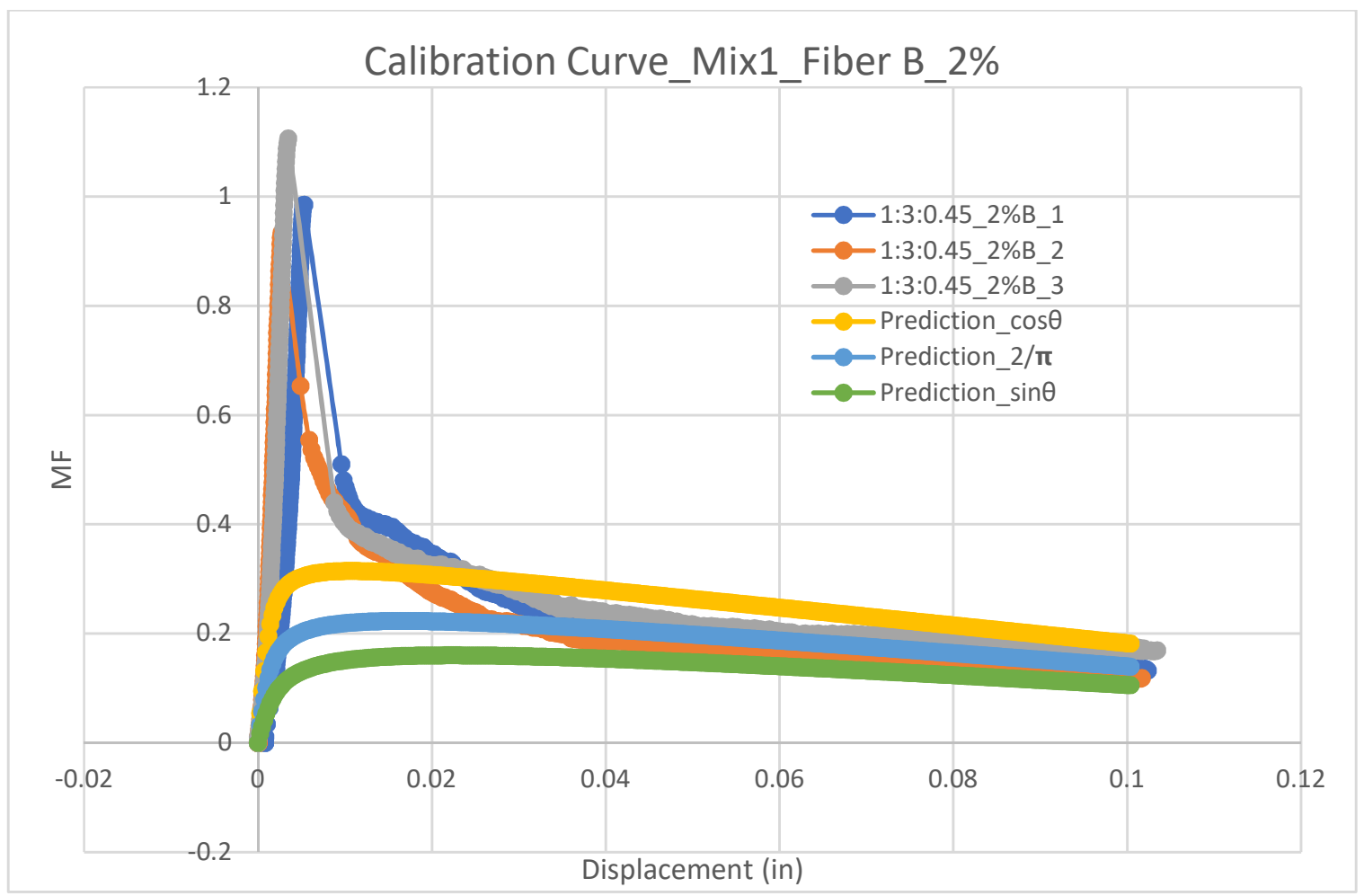

Figure 6-14 Post-crack Behavior of Fiber B in Mix 1 at 1.3\% volume fraction (2\% Nominally)

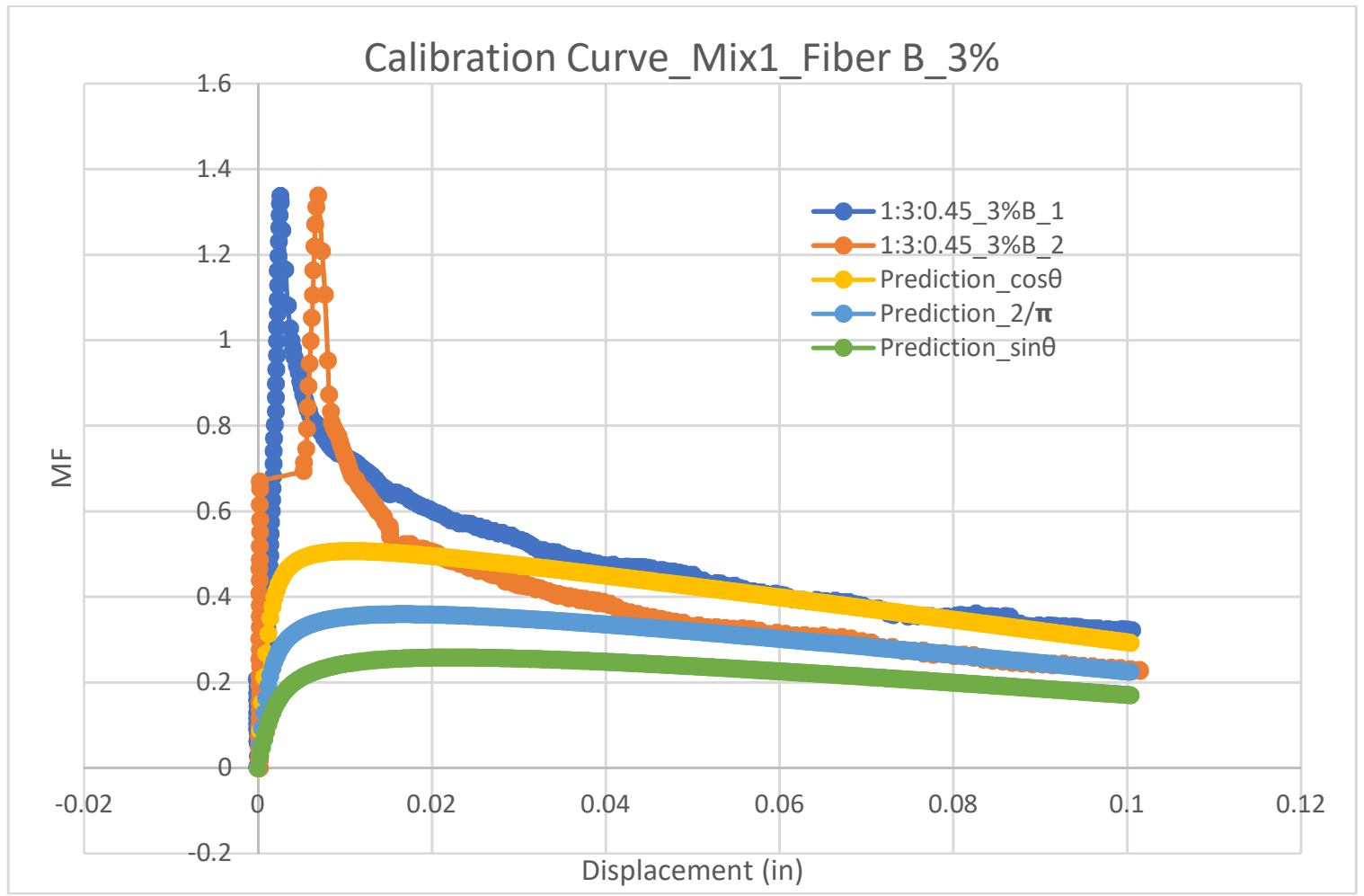

Figure 6-15 Post-crack Behavior of Fiber B in Mix 1 at 2.1\% volume fraction (3\% Nominally) 


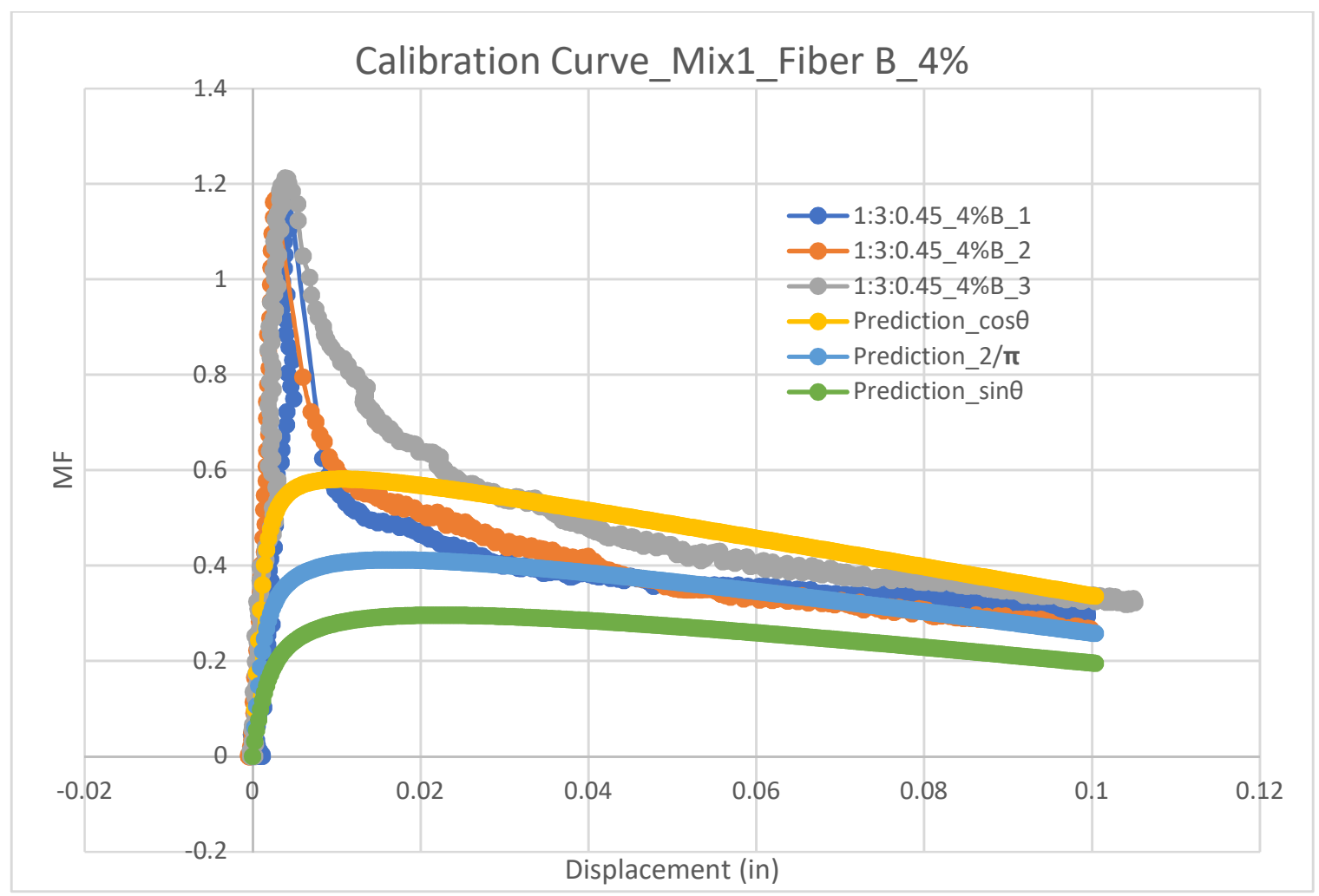

Figure 6-16 Post-crack Behavior of Fiber B in Mix 1 at 2.6\% volume fraction (4\% Nominally)

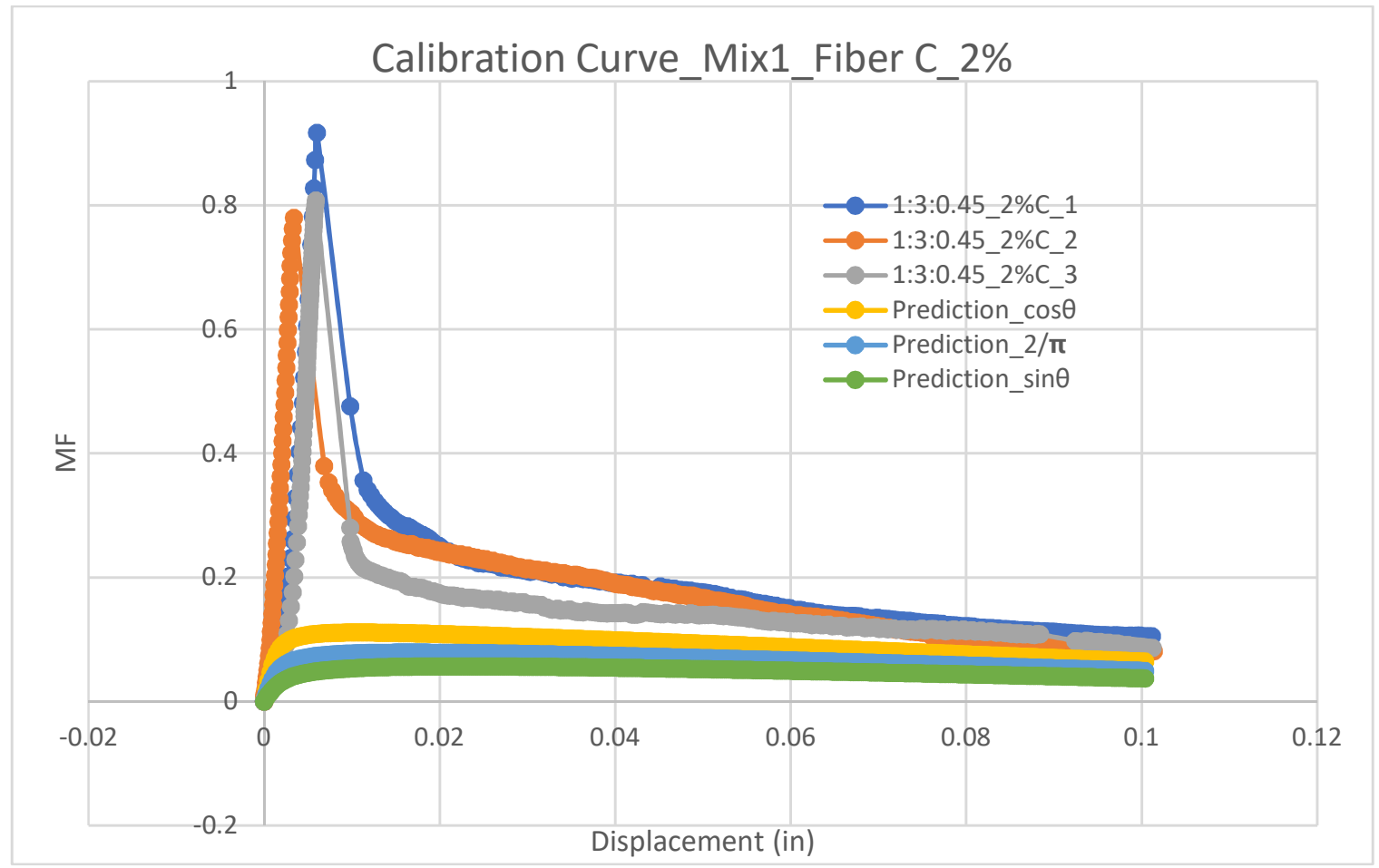

Figure 6-17 Post-crack Behavior of Fiber C in Mix 1 at 1.2\% volume fraction (2\% Nominally) 


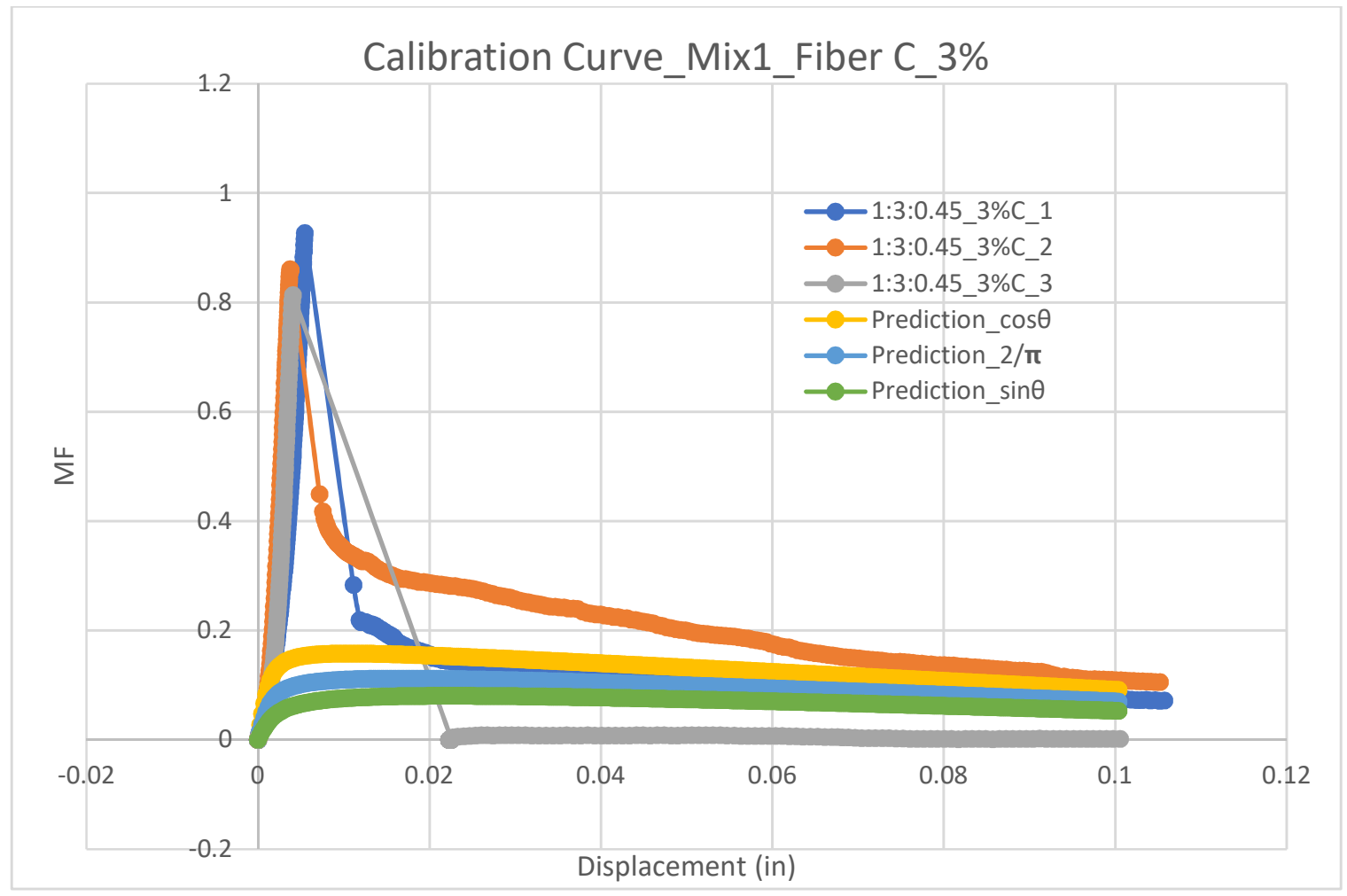

Figure 6-18 Post-crack Behavior of Fiber C in Mix 1 at 1.7\% volume fraction (3\% Nominally)

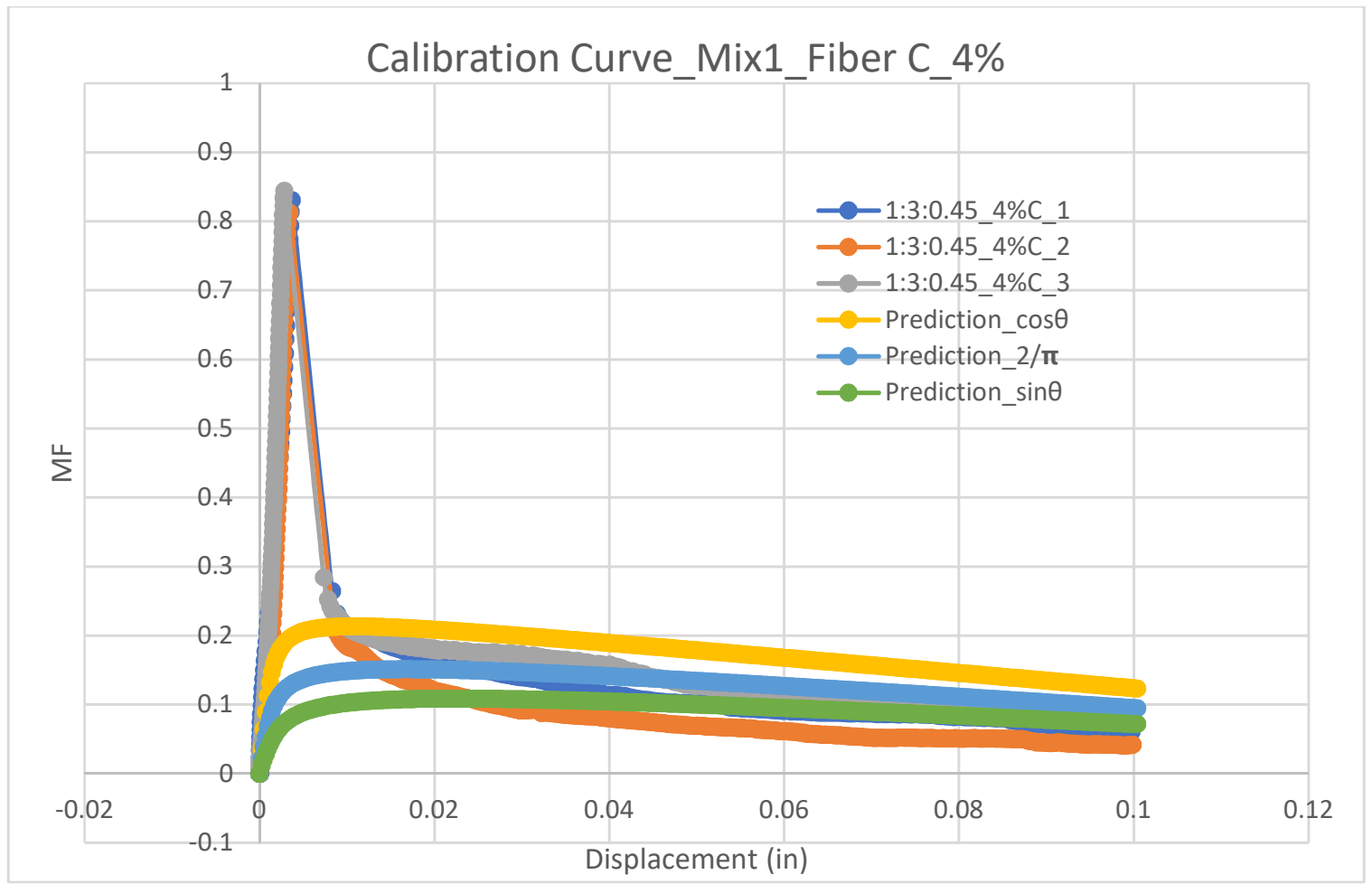

Figure 6-19 Post-crack Behavior of Fiber C in Mix 1 at 2.3\% volume fraction (4\% Nominally) 


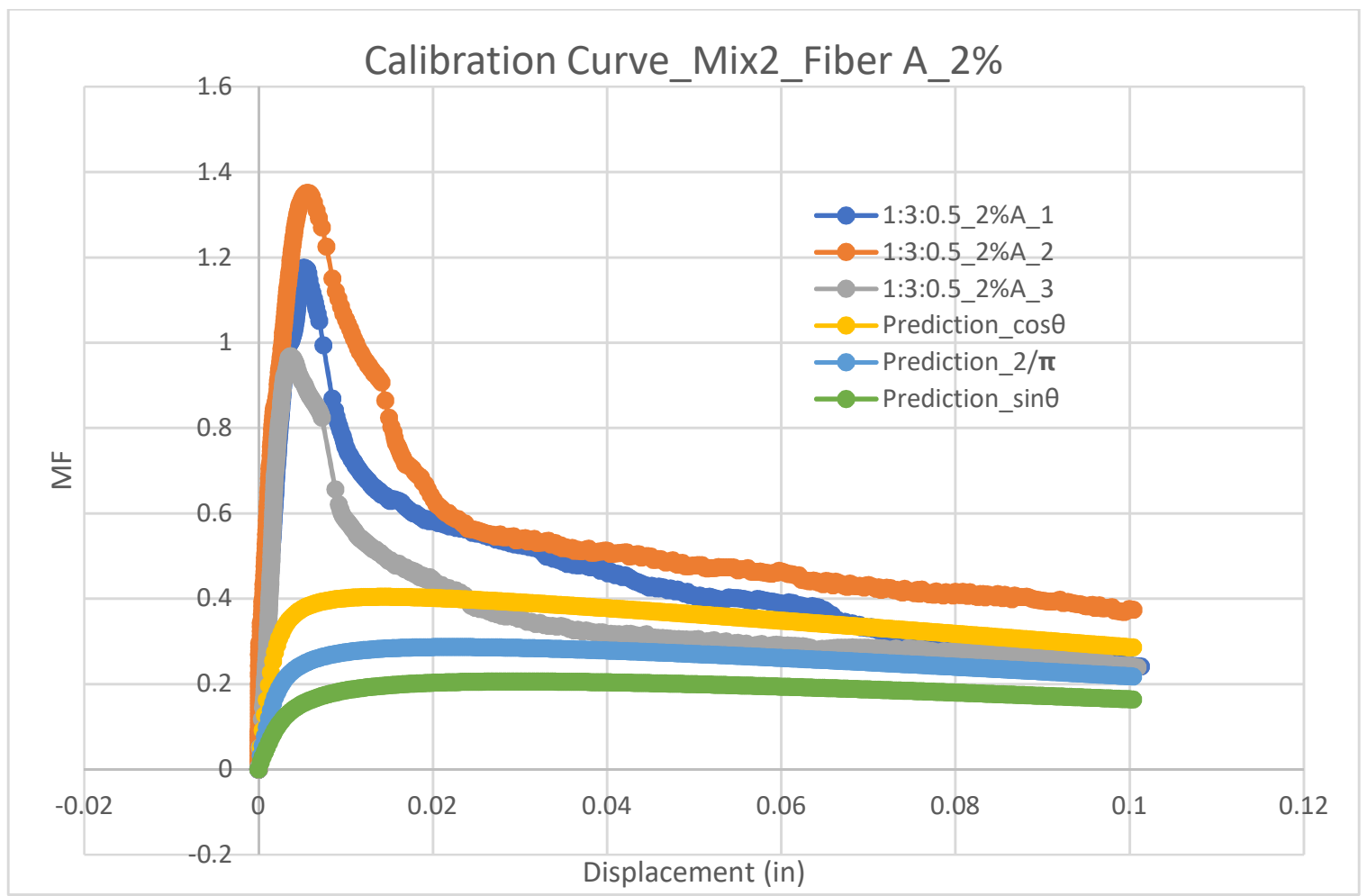

Figure 6-20 Post-crack Behavior of Fiber A in Mix 2 at 1.3\% volume fraction (2\% Nominally)

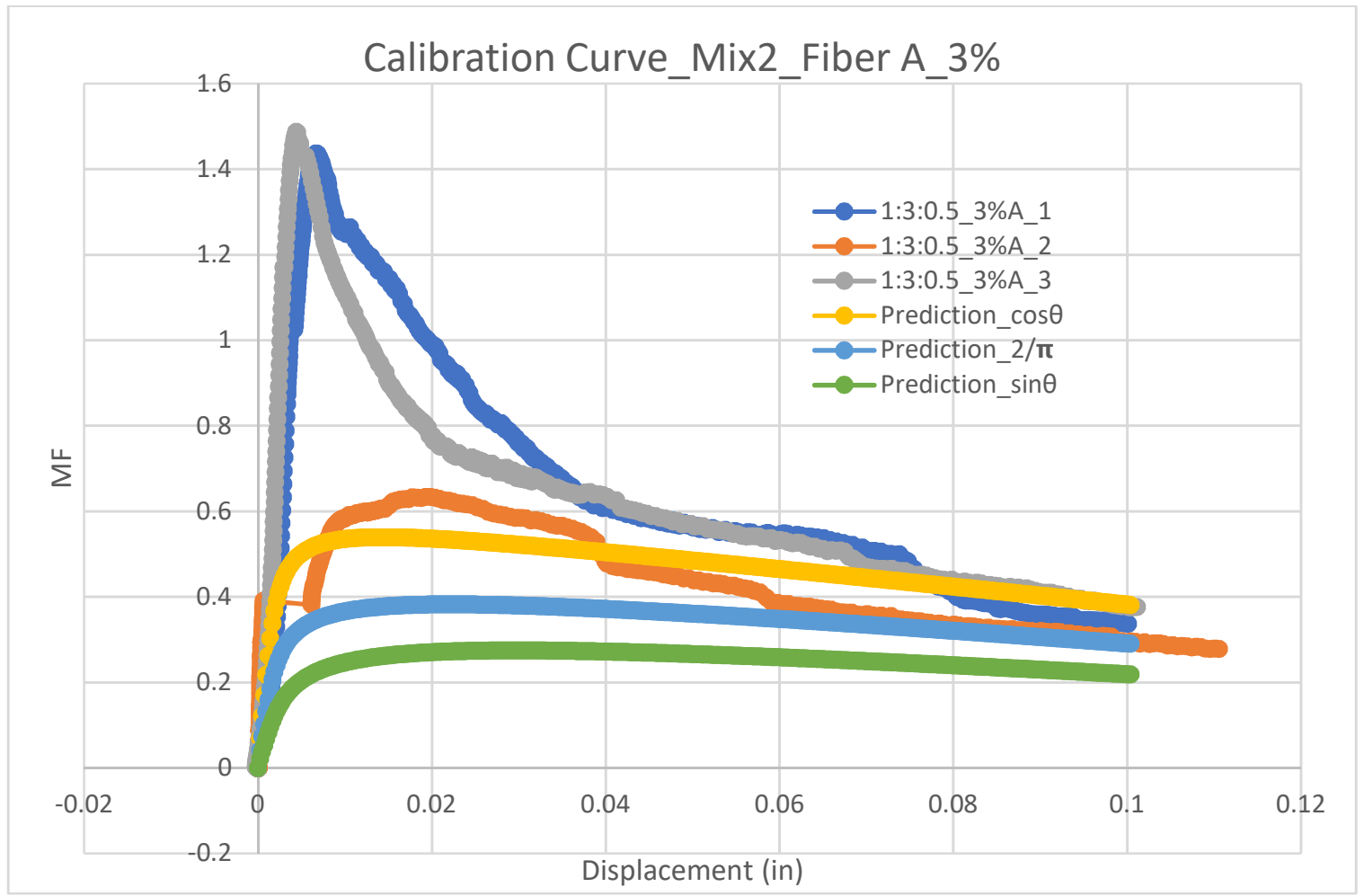

Figure 6-21 Post-crack Behavior of Fiber A in Mix 2 at 2.0\% volume fraction (3\% Nominally) 


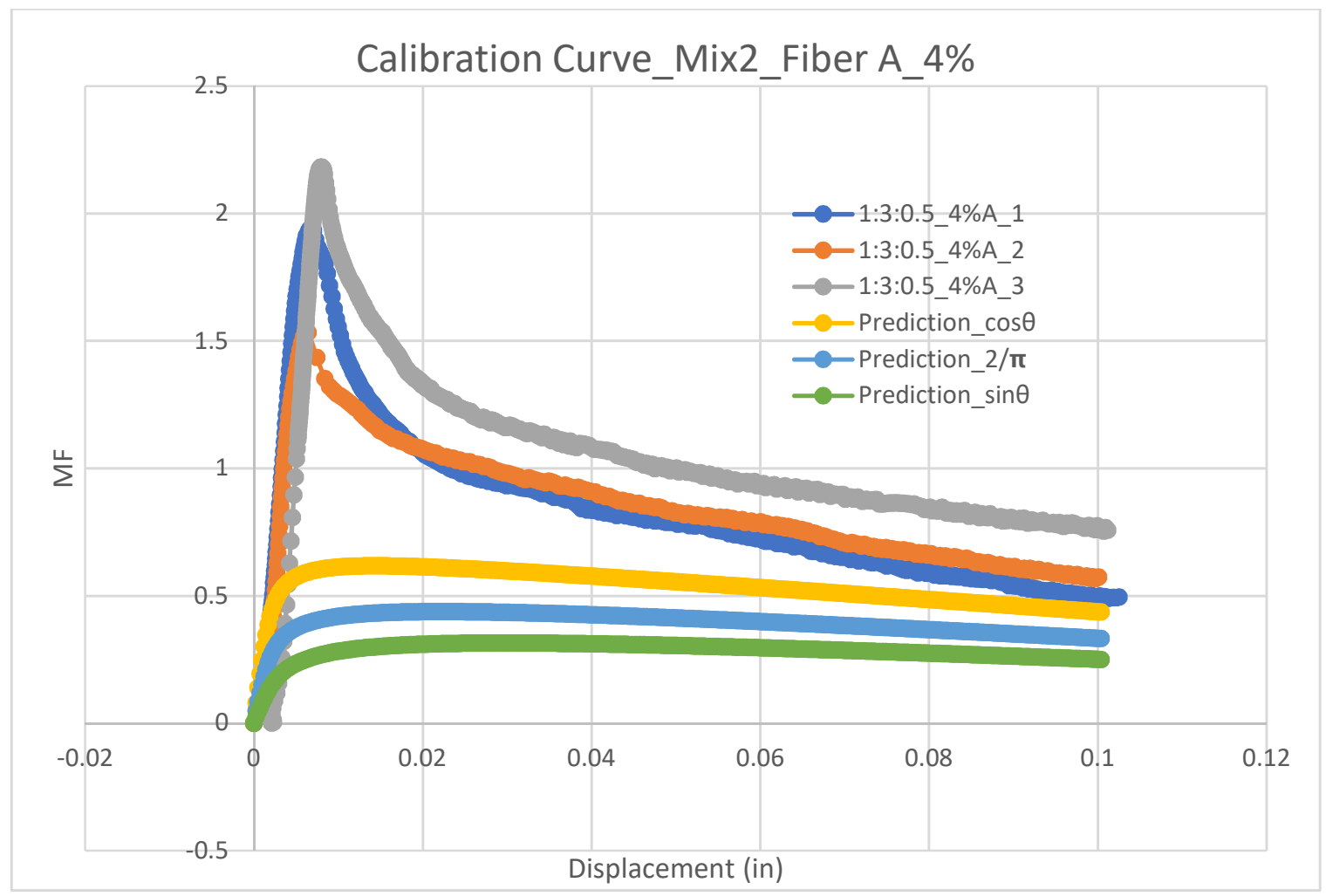

Figure 6-22 Post-crack Behavior of Fiber A in Mix 2 at 2.7\% volume fraction (4\% Nominally)

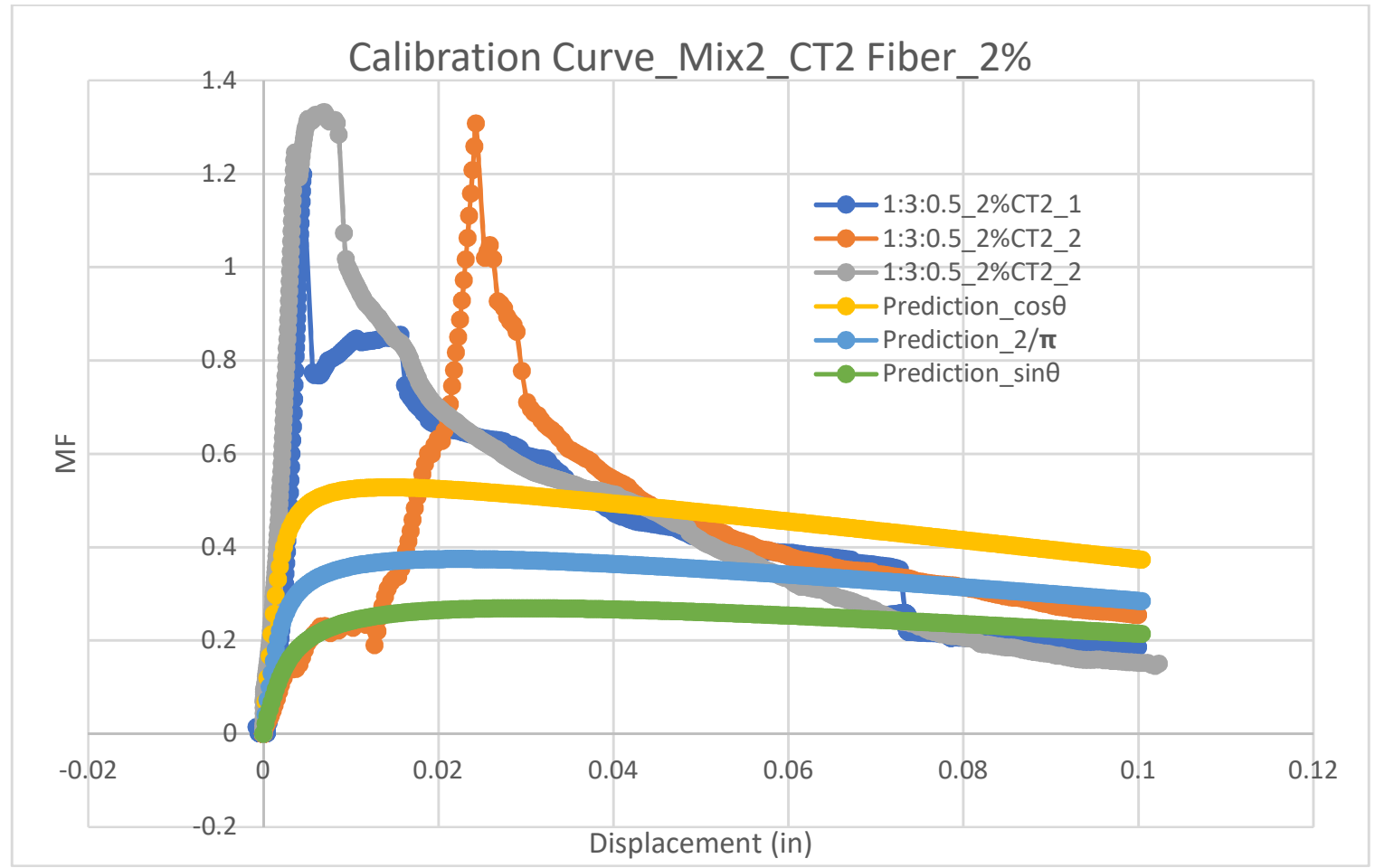

Figure 6-23 Post-crack Behavior of Coated Fiber in Mix 2 at 1.4\% volume fraction (2\% Nominally) 


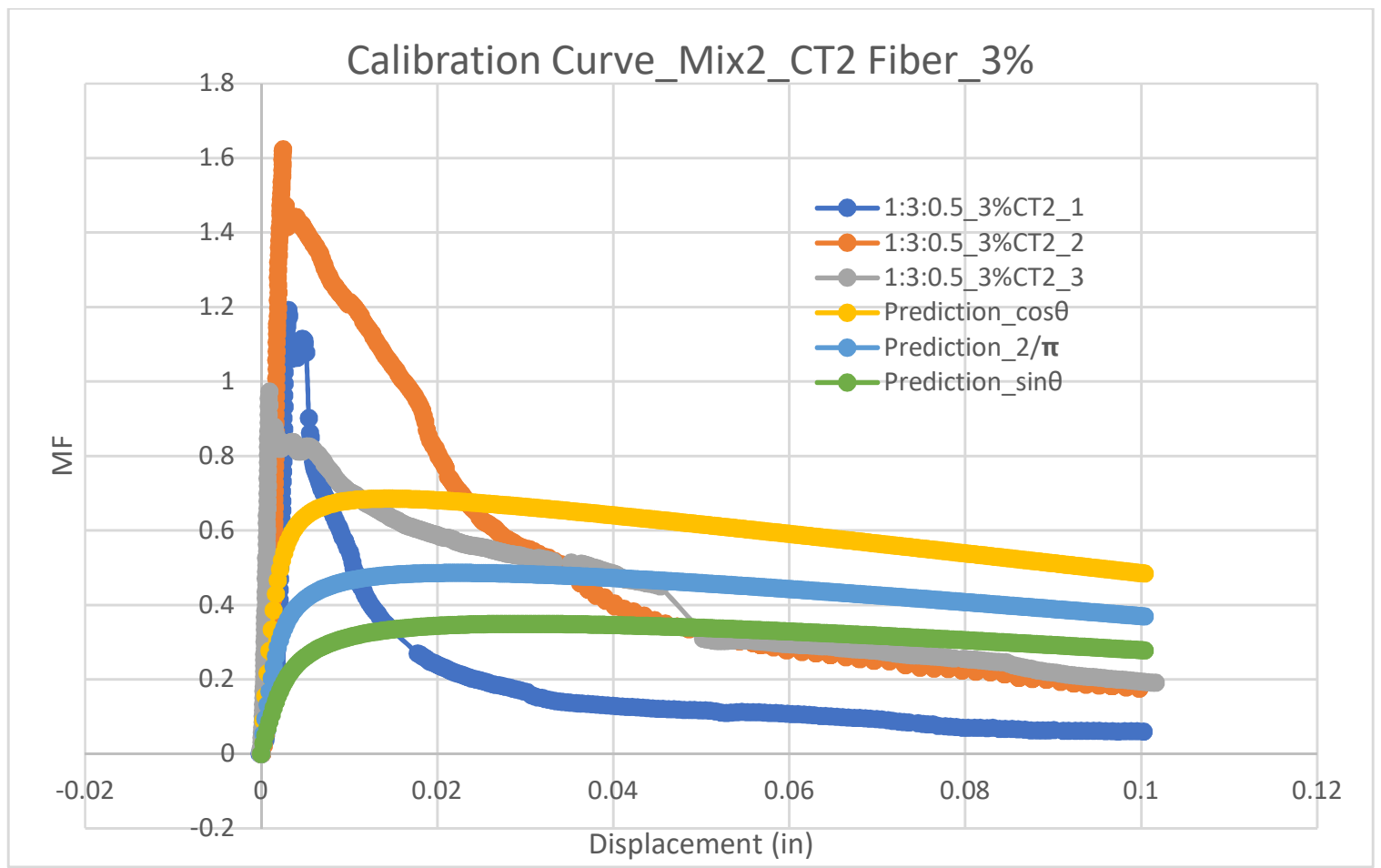

Figure 6-24 Post-crack Behavior of Coated Fiber in Mix 2 at 2.1\% volume fraction (3\% Nominally)

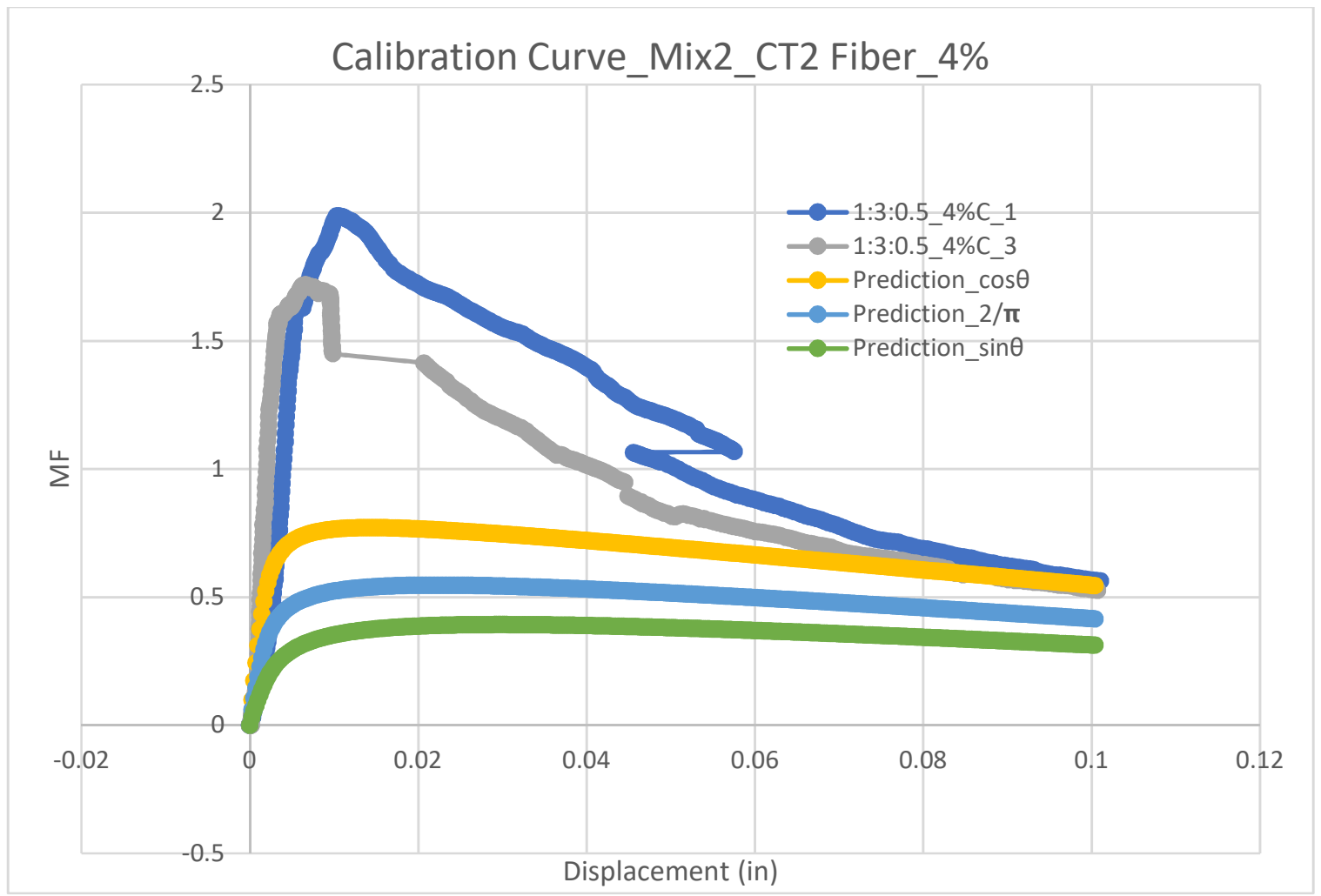

Figure 6-25 Post-crack Behavior of Coated Fiber in Mix 2 at 2.8\% volume fraction (4\% Nominally) 


\subsection{Model Parametric Study and Optimization}

The previously described fiber models can be used to optimize the flexural cracking strength of coated fiber and concrete composites. The coated steel fiber used in previous experiments, can be used to increase the cracking strength of FRC. As was discussed in earlier chapters, different fiber lengths, fiber diameters and fiber volumes have different impacts on cracking strength. The fiber model can be used to estimate the effects of each of these parameters and determine the optimum fiber length and volume for a given expected cracking strength. Although the model does predict the flexural capacity of FRC beams in in all cases, the model was able to describe general trends of how these fiber characteristics can impact the relative flexural strength of the composite.

In the following analysis, the strengthening effect of different fiber lengths ( 1 ", 0.75 ", $0.5 ", 0.25$ ”) for a fiber diameter of 0.1 " is shown in Figure 6.26. Note that the vertical axis is MF, the horizontal axis is variable fiber volumes. A $\tau_{f, \max }=453.68 \mathrm{psi}$, was assumed for the analysis as this was the approximate value obtained from tests on Coating B fiber. The figure shows that effect that fiber length on the flexural capacity of FRC beams and for this diameter shorter fibers give the highest capacities. The lower the fiber length, the greater the fiber volumes needed to achieve a significant increase in cracking moment. The figure also the long the fiber, the lower the fiber volume needed to achieve optimum cracking moment. 


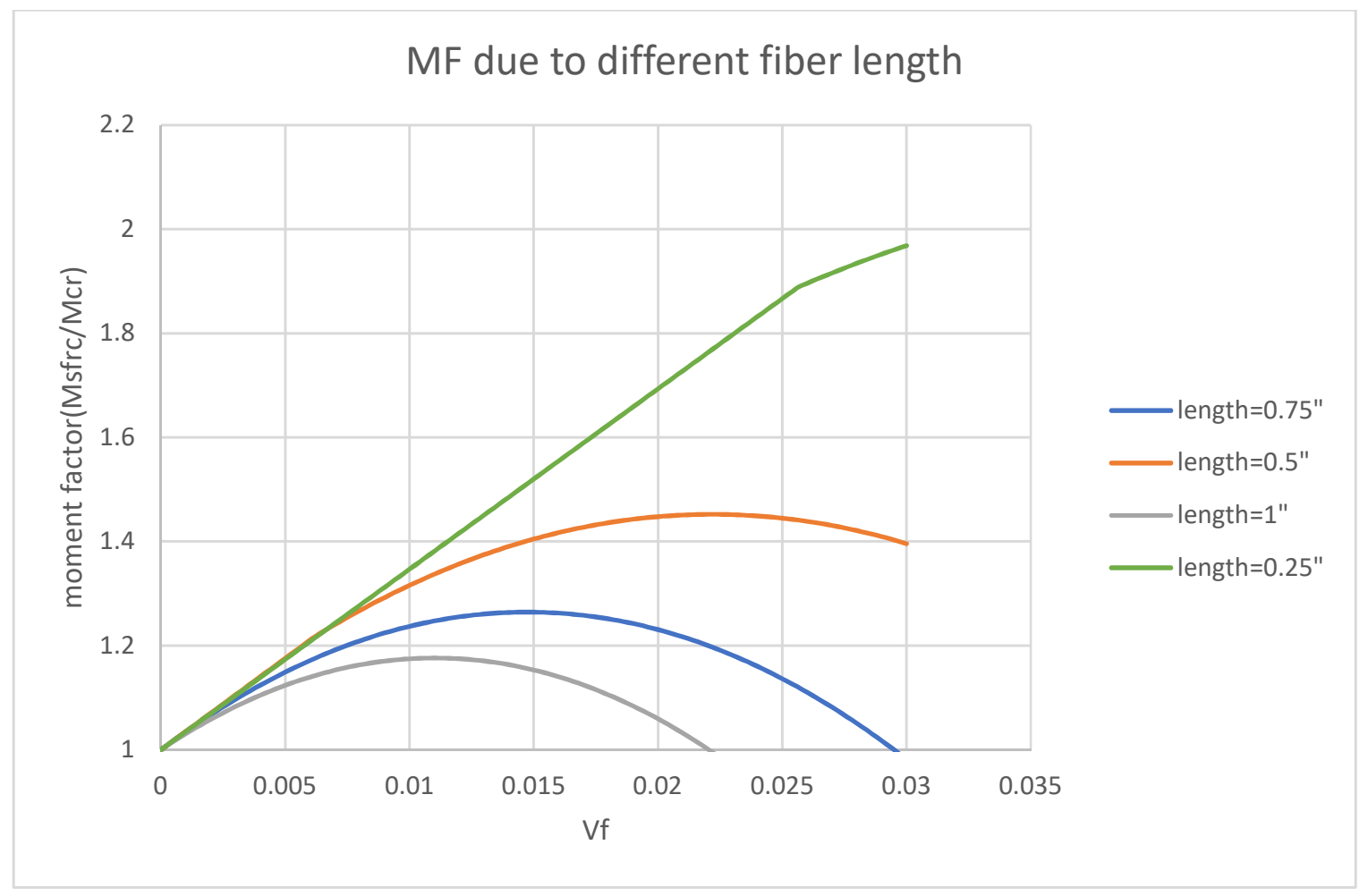

Figure 6-26 Variation of Cracking Moment with Fiber length \& variable volumes for $d_{f}=0.1$ " fiber 
For a fiber length of $0.75 "$, and $\tau_{f, \max }=453.68 \mathrm{psi}$, the variation in cracking moment for various fiber diameters and volumes is shown in Figure 6.27.

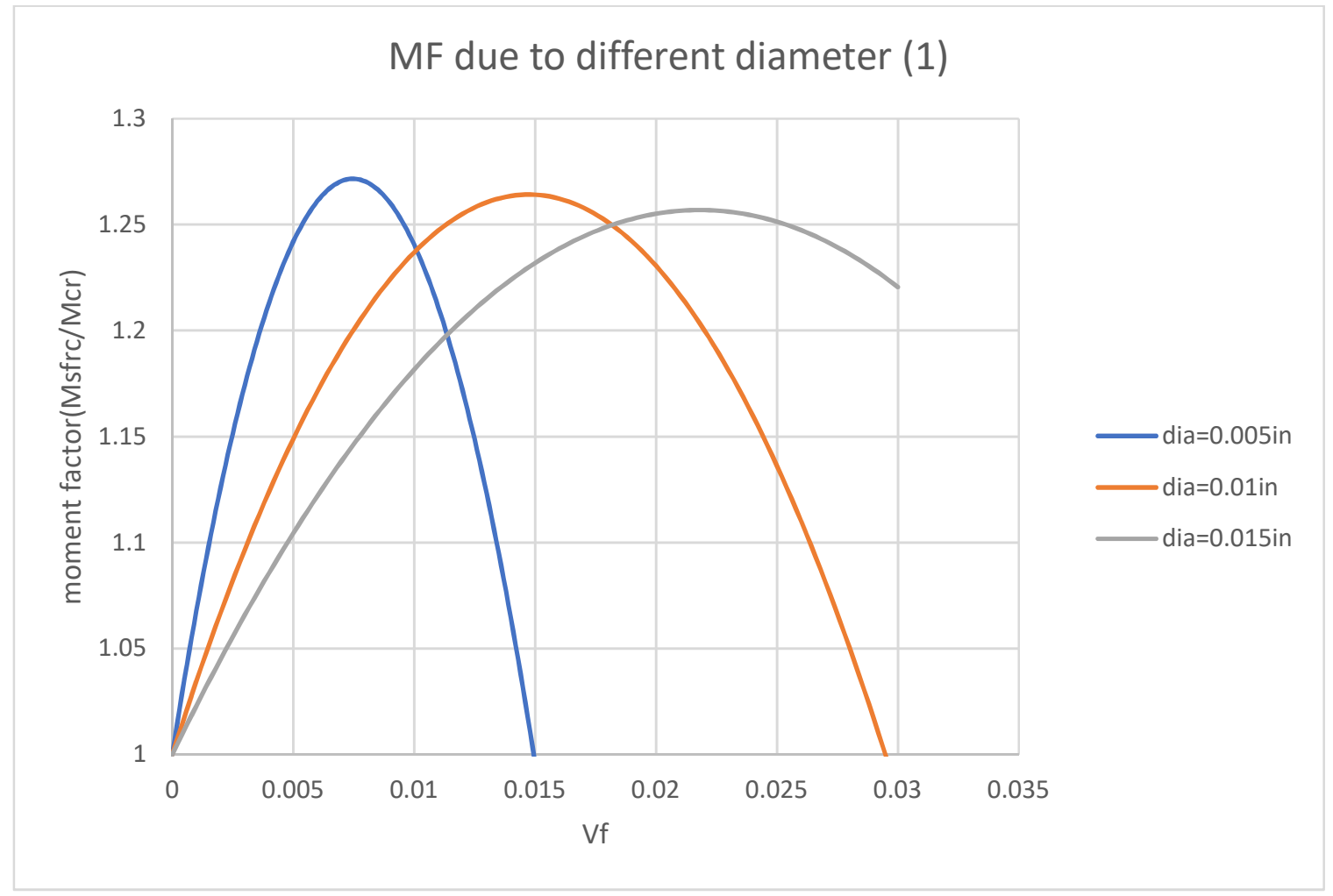

Figure 6-27 Variation of Cracking Moment with Fiber diameter \& variable volumes for $l_{f}=0.75$ " fiber For a fiber length of 0.5 ", and $\tau_{f, \max }=453.68 \mathrm{psi}$, the variation in cracking moment for various fiber diameters and volumes is shown in Figure 6.28. 


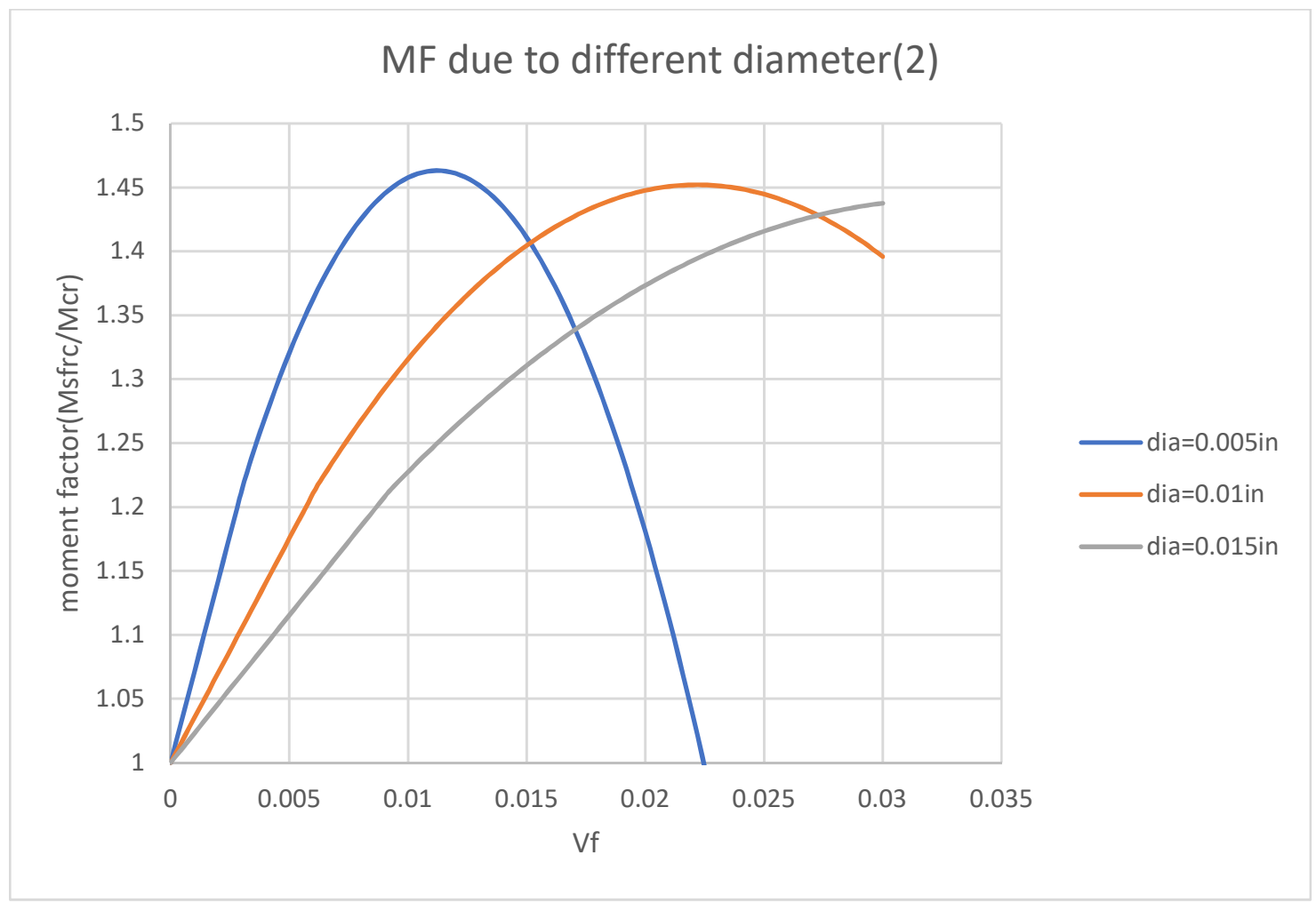

Figure 6-28 Variation of Cracking Moment with Fiber diameter \& variable volumes for $l_{f}=0.5$ " fiber

For a fiber length of $0.25 "$, and $\tau_{f, \max }=453.68 \mathrm{psi}$, the variation in cracking moment for various fiber diameters and volumes is shown in Figure 6.29. 


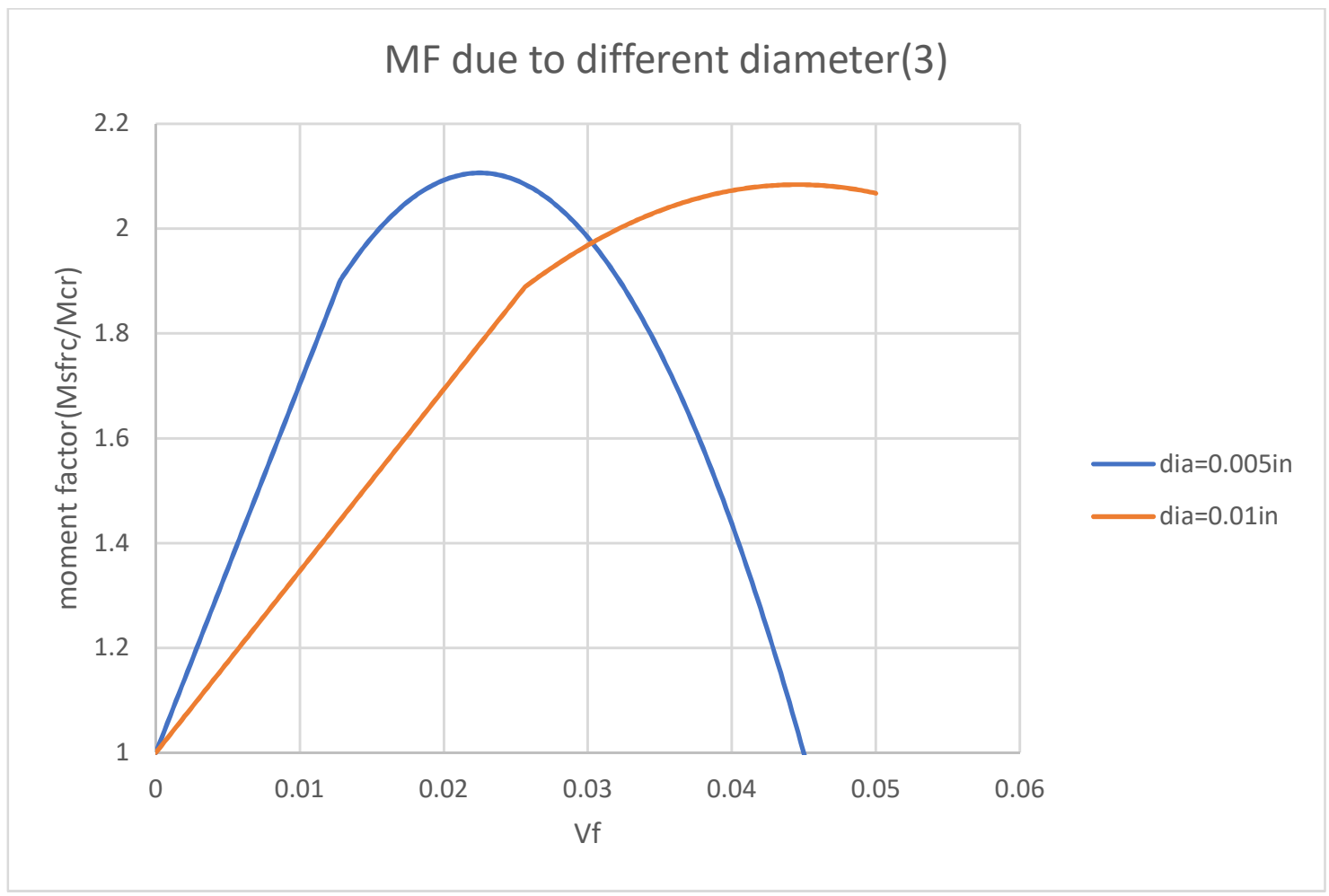

Figure 6-29 Variation of Cracking Moment with Fiber diameter \& variable volumes for $l_{f}=0.25$ " fiber

Examining Figure 6.27 through 6.29, shows that for a given fiber diameter there is a fiber volume that provides the maximum cracking moment capacity for the flexural element, and the smaller the diameter of the fiber the lower this percentage is.

These parametric analyses and the test results suggest that that fibers with about 0.5 -inch length and 0.02-inch diameter will provide optimum cracking moment. Similar configurations of fiber were used in previous studies by different researchers. In 2008, John Wuest et al. published the results of an investigation of the tensile hardening response of Ultra High Performances Fiber Reinforced Concretes (UHP-FRCs) (Wuest, Denarié, \& Brühwiler, 2008). In their paper, $10 \mathrm{~mm} \sim 13 \mathrm{~mm}$ length steel fiber were used with fiber diameters of $0.2 \mathrm{~mm}$ were used. As shown in their research, the tensile strength of 2 SFRC testing groups reached peak tensile strength with volume fractions of $4 \%$ and 
$6 \%$, respectively. In 2012, Seung Hun Park et al. stated that the addition of micro-fibers in Ultra High Performances Hybrid Fiber Reinforced Concretes (UHP-HFRCs) favorably affects both strain hardening and multiple micro-cracking behavior (Park, Kim, Ryu, \& Koh, 2012). Their investigation also showed that the volume increases of micro fiber didn't affect the first cracking strength, but did effect the post cracking strength. Similarly, R.S. Olivito and F.A. Zuccarello observed that increases of fiber content increases ductility, first crack strength and flexural strength, but did not increase compressive strength (Olivito \& Zuccarello, 2010). At the same time, testing results from R.S. Olivito et al. showed that shorter fiber $(22 \mathrm{~mm})$ with same aspect ratio (50) reached its maximum tensile capacity at around $4 \%$ fiber volume, while longer fibers $(30 \mathrm{~mm}, 44$ $\mathrm{mm})$ at peaked at $3 \%$ fiber volumes in their tests. 


\section{CHAPTER 7}

\section{CONCLUSION AND RECOMMENDATIONS}

The results of this investigation allow the following conclusion to be made:

1. The results of the pullout tests and the mortar beam test have confirmed that the proposed fiber model generally predicts pre-cracked and post cracked flexural capacity of fiber reinforced concrete, for both bare and coated steel fibers over the range of fiber configurations evaluate in this investigation. These models do indicated that fiber length, diameter, orientation, and bond between the fibers and the concrete are very important and can affect the accuracy of the model prediction.

2. Pullout results also shows that fiber with small diameter or embedment length will lead to a generally a more consistent and constant pullout capacity. It was further found that concrete mix strength and aggregate size did not have a large effect on this strength and doesn't change much between mortar and concrete we used in this study.

3. This research showed that $\mathrm{w} / \mathrm{c}$ ratio may have an impact on the strengthening effect of fibers. However, the results are unclear on how much this impacts the strength and as the results of the investigation showed larger impact on fiber performance that would be predicted by the change concrete strength (and higher water cement ratios produced better fiber performance contrary to the model prediction). This effect must be studies further. 
4. Modeling and testing fiber with small $l / d$ ratios showed that these fiber configurations may not improve the composite flexural tensile nor compressive strengths. Fibers in low volume fractions with low lengths or lower $l / d$ ratios can produce weakening planes that reduce these strengths. This effect must be investigated further and the models need to be adjusted to address this effect.

5. Thin fiber with reasonable lengths, will probably give a satisfactory strengthen in both pre and post crack behavior. 


\section{REFERENCES}

McGinley, W. , Mark, "Active Enamel Coatings and Applications to Civil Engineering Infrastructure - Coated Fibers, Proceedings of the Porcelain Enamel Institute - Tech Forum 2016, Louisville KY , 2016

ASTM A307-14e1, Standard Specification for Carbon Steel Bolts, Studs, and Threaded Rod 60000 PSI Tensile Strength, ASTM International, West Conshohocken, PA, 2014, www.astm.org

ASTM C348-14, Standard Test Method for Flexural Strength of Hydraulic-Cement Mortars, ASTM International, West Conshohocken, PA, 2014, www.astm.org

ASTM C109 / C109M-16a, Standard Test Method for Compressive Strength of Hydraulic Cement Mortars (Using 2-in. or [50-mm] Cube Specimens), ASTM International, West Conshohocken, PA, 2016, www.astm.org

ACICommittee318. (2014). Building Code Requirements for Structural Concrete (ACI 318-14).

Aveston, J., \& Kelly, A. (1973). Theory of multiple fracture of fibrous composites. Journal of Materials Science, 8(3), 352-362. doi:10.1007/bf00550155

Banthia, N., \& Sappakittipakorn, M. (2007). Toughness enhancement in steel fiber reinforced concrete through fiber hybridization. Cement and Concrete Research, 37(9), 1366-1372. doi:10.1016/j.cemconres.2007.05.005

Bayasi, M. Z., Pa, \& Soroushian. (July-August 1992). Effect of Steel Fiber Reinforcement on Fresh Mix Properties of Concrete. ACI Materials, 89, No. 4.

Boulekbache, B., Hamrat, M., Chemrouk, M., \& Amziane, S. (2014). Failure mechanism of fibre reinforced concrete under splitting test using digital image correlation. Materials and Structures, 48(8), 2713-2726. doi:10.1617/s11527-014-0348-X

Boulekbache, B., Hamrat, M., Chemrouk, M., \& Amziane, S. (2016). Flexural behaviour of steel fibre-reinforced concrete under cyclic loading. Construction and Building Materials, 126, 253-262. doi:http://dx.doi.org/10.1016/j.conbuildmat.2016.09.035

Brandt, A. M. (2008). Fibre reinforced cement-based (FRC) composites after over 40 years of development in building and civil engineering. Composite Structures, 86(1-3), 3-9. doi:10.1016/j.compstruct.2008.03.006 
Foster, S. J. (2001). On Behavior of High-Strength Concrete Columns: Cover Spalling, Steel Fibers, and Ductility. ACI structural journal., 98(4), 583.

Iqbal, S., Ali, A., Holschemacher, K., \& Bier, T. A. (2015). Effect of Change in Micro Steel Fiber Content on Properties of High Strength Steel Fiber Reinforced Lightweight Self-Compacting Concrete (HSLSCC). Procedia Engineering, 122, 88-94. doi:10.1016/j.proeng.2015.10.011

Iskhakov, I., Ribakov, Y., Holschemacher, K., \& Mueller, T. (2014). Experimental Investigation of Full Scale Two-Layer Reinforced Concrete Beams. Mechanics of Advanced Materials and Structures, 21(4), 273-283. doi:10.1080/15376494.2012.680673

Lee, S.-C., Cho, J.-Y., \& Vecchio, F. J. (2011). Diverse Embedment Model for Steel Fiber-Reinforced. ACI materials journal.

Lee, S.-C., Oh, J.-H., \& Cho, J.-Y. (2016). Fiber efficiency in SFRC members subjected to uniaxial tension. Construction and Building Materials, 113, 479-487. doi:10.1016/j.conbuildmat.2016.03.076

Marti, P., Pfyl, T., Sigrist, V., \& Ulaga, T. (1999). Harmonized Test Procedures for Steel Fiber-Reinforced Concrete. ACI materials journal., 96(6), 676.

Olivito, R. S., \& Zuccarello, F. A. (2010). An experimental study on the tensile strength of steel fiber reinforced concrete. Composites Part B: Engineering, 41(3), 246255. doi:10.1016/j.compositesb.2009.12.003

Park, S. H., Kim, D. J., Ryu, G. S., \& Koh, K. T. (2012). Tensile behavior of Ultra High Performance Hybrid Fiber Reinforced Concrete. Cement and Concrete Composites, 34(2), 172-184. doi:10.1016/j.cemconcomp.2011.09.009

Vellore S. Gopalaratnam, A. M. A., \& Surendra P. Shah, M. A. (1987). TENSILE FAILURE OF STEEL FIBER-REINFORCED MORTAR. J. Eng. Mech., 113(5), 635-652.

Voo, J. Y. L., \& Foster, S. J. (2003). Variable Engagement Model for the Design of Fibre Reinforced Concrete Structures. ECI Digital Archives.

Wuest, J., Denarié, E., \& Brühwiler, E. (2008). Model for predicting the UHPFRC tensile hardening response. Second International Symposium on Ultra High Performance Concrete, Heft 10(num. 10), 153-160.

Zhao, S., Du, H., Qian, X., \& Li, C. (2008). Study on direct mix design method for steel fiber reinforced high-strength concrete. Tumu Gongcheng Xuebao/China Civil Engineering Journal, 41(7), 1-6. 


\section{APPENDIX A. BEAM FLEXURAL TEST PLOTS:}

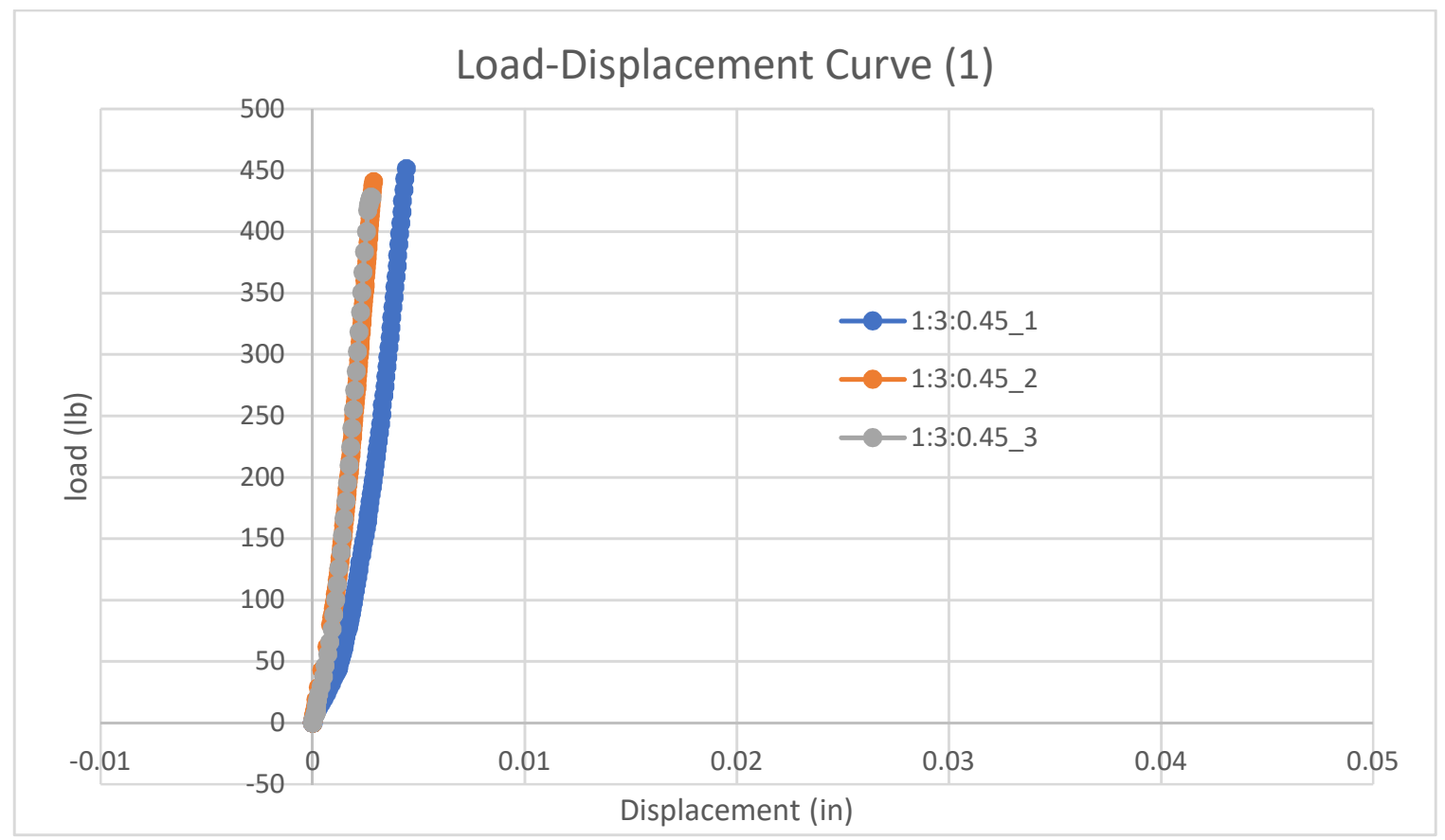

Figure 1 Load-Displacement Curve of Plain Mortar Mix 1

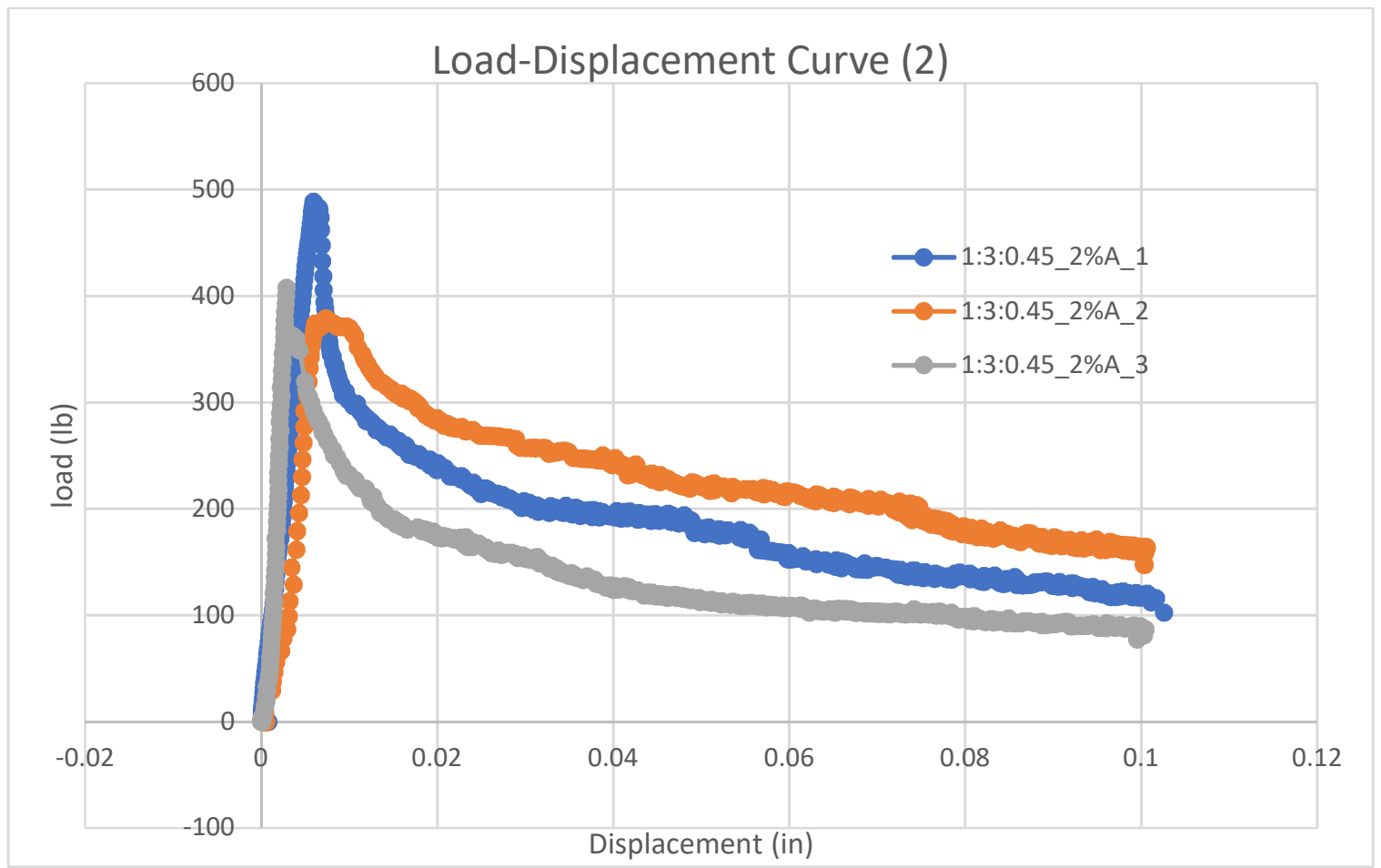

Figure 2 Load-Displacement Curve of 2\% Fiber A in Mortar Mix 1 


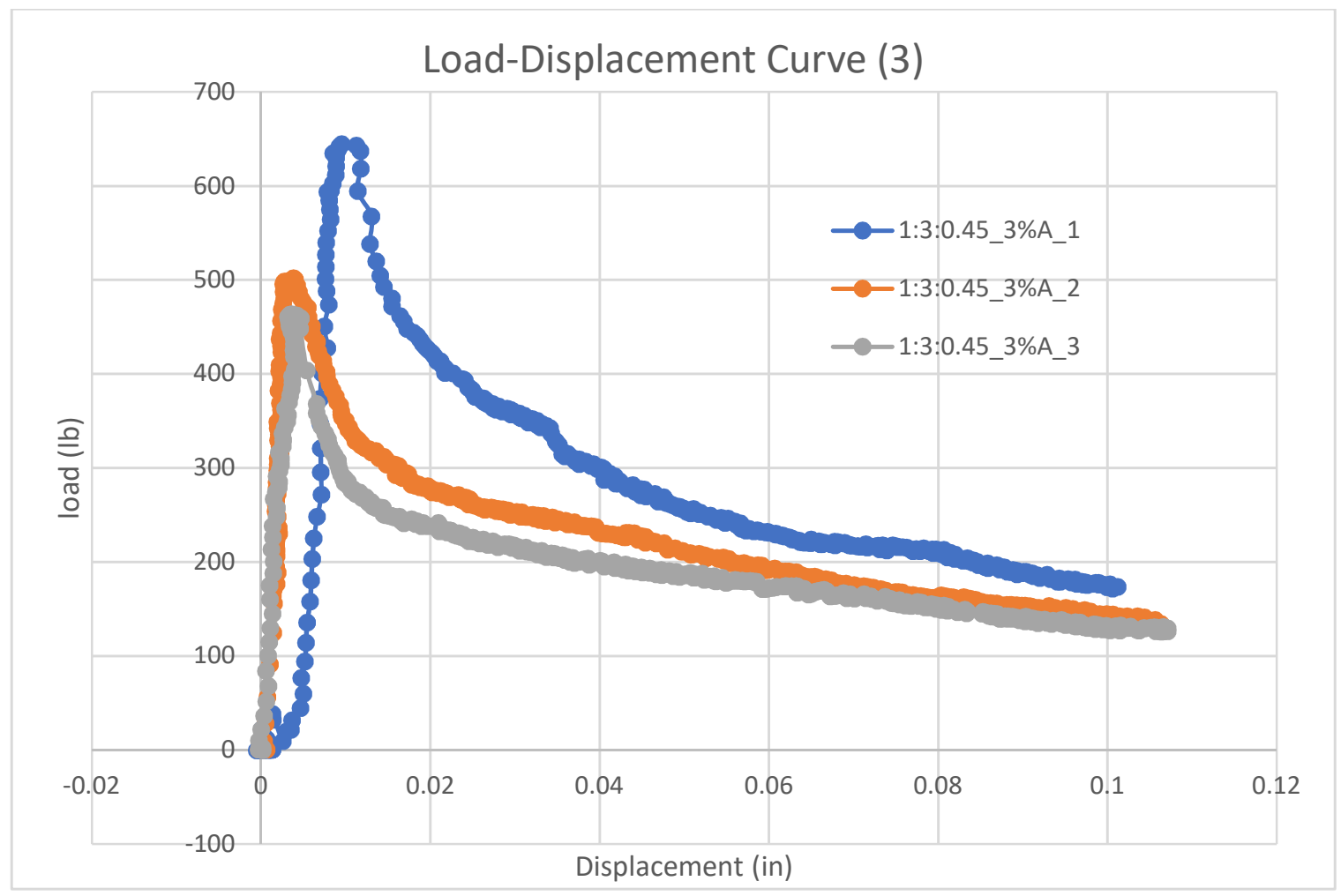

Figure 3 Load-Displacement Curve of 3\% Fiber A in Mortar Mix 1

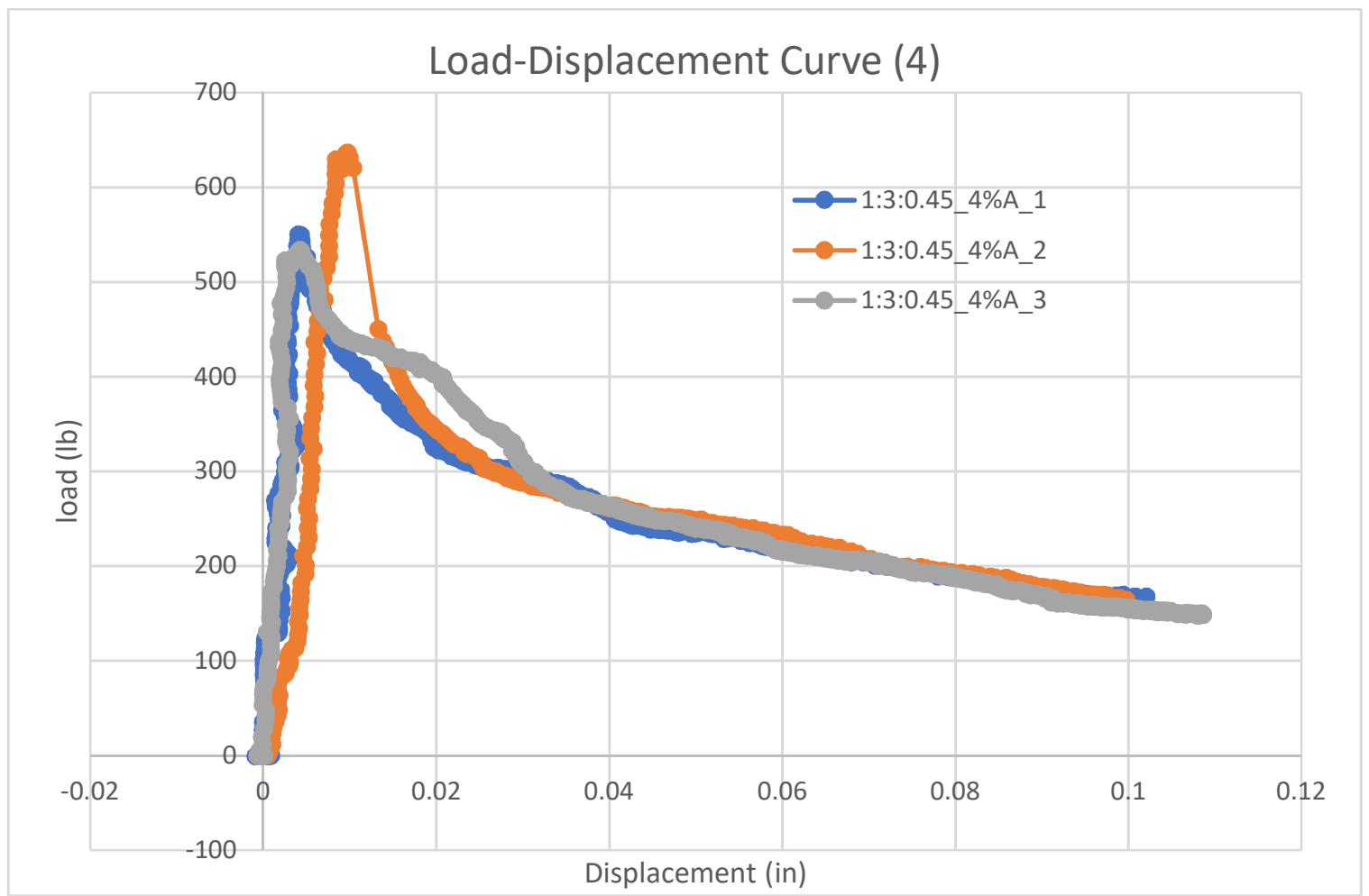

Figure 4 Load-Displacement Curve of 4\% Fiber A in Mortar Mix 1 


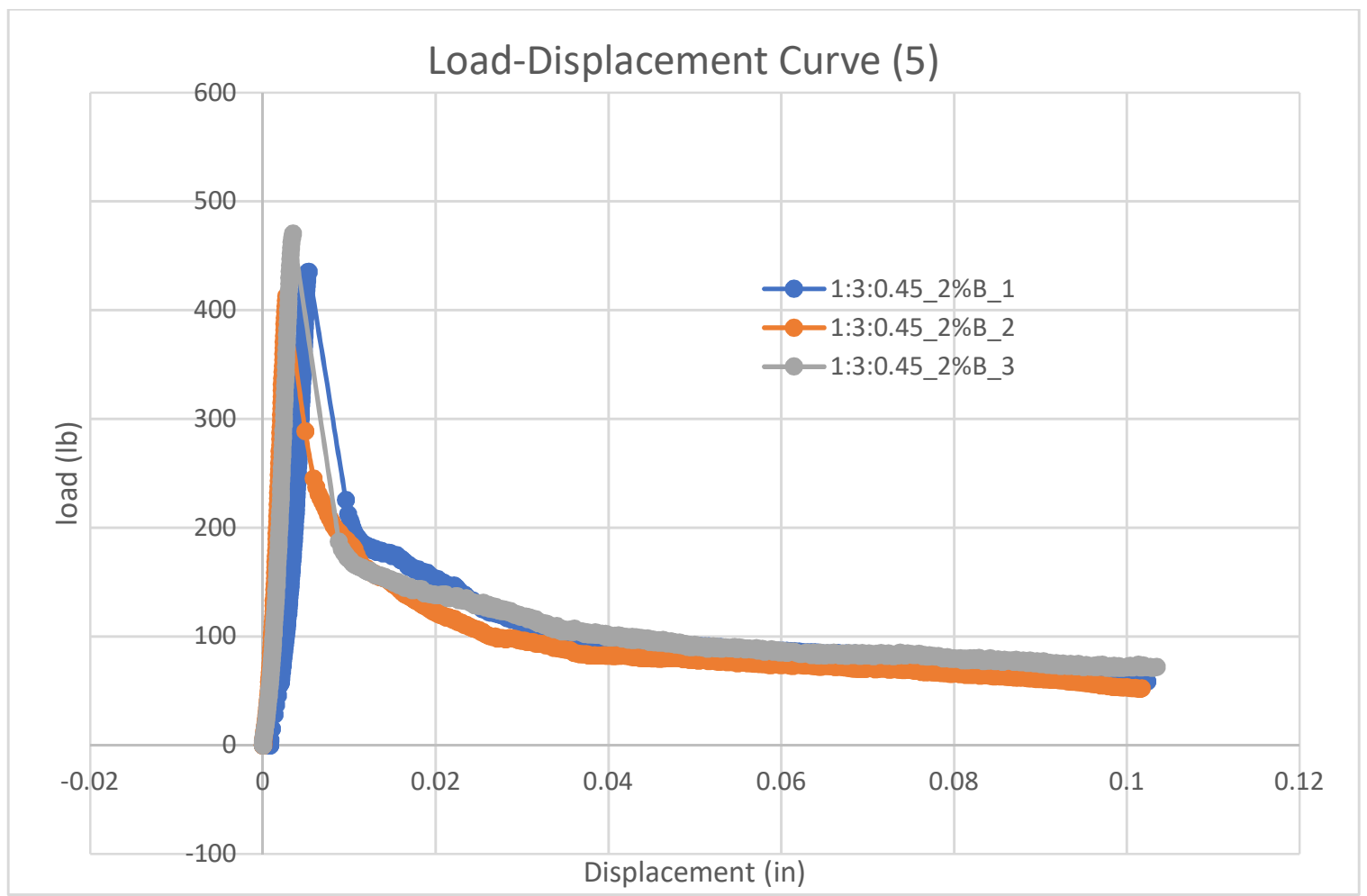

Figure 5 Load-Displacement Curve of 2\% Fiber B in Mortar Mix 1

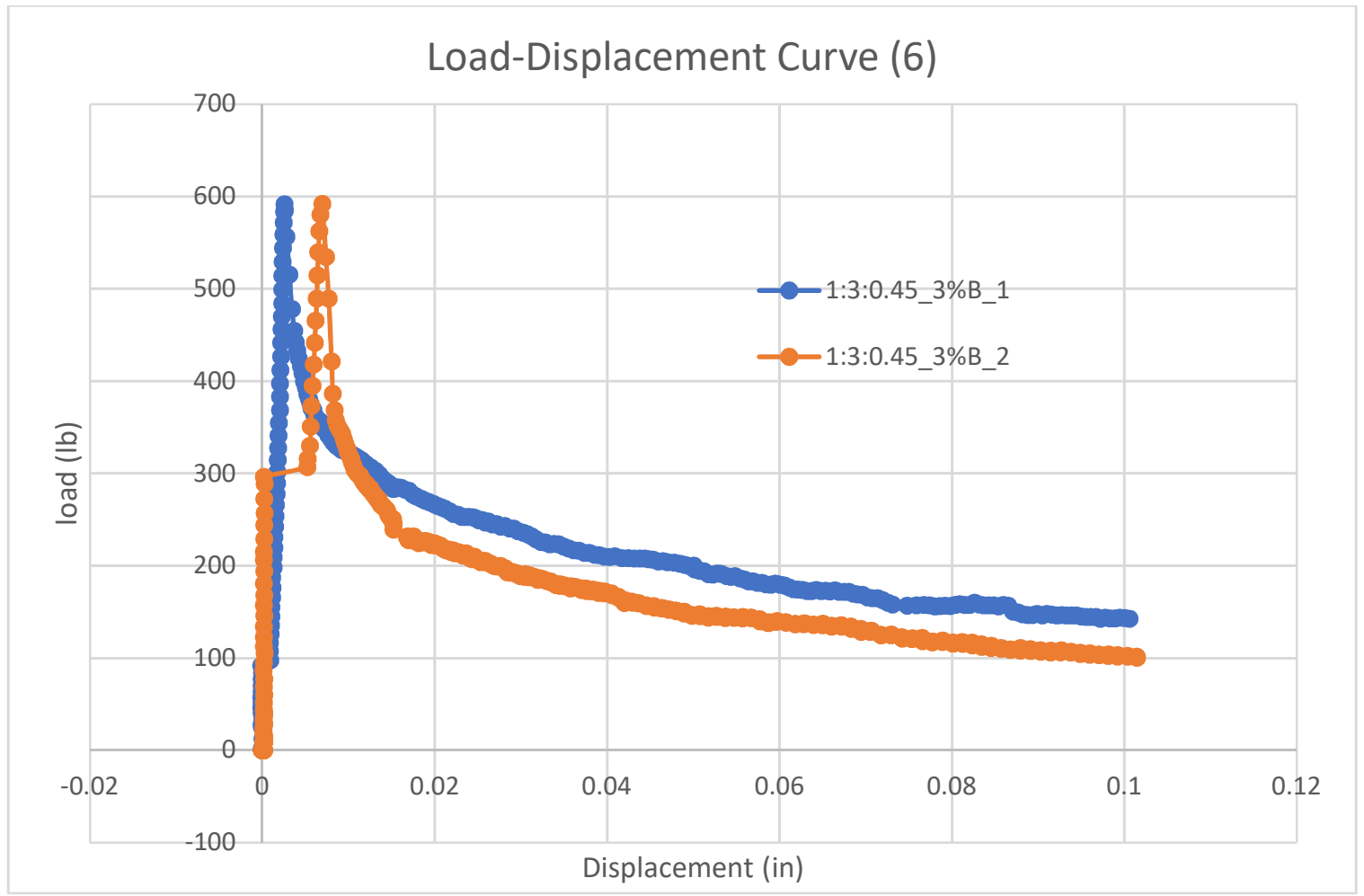

Figure 6 Load-Displacement Curve of 3\% Fiber B in Mortar Mix 1 


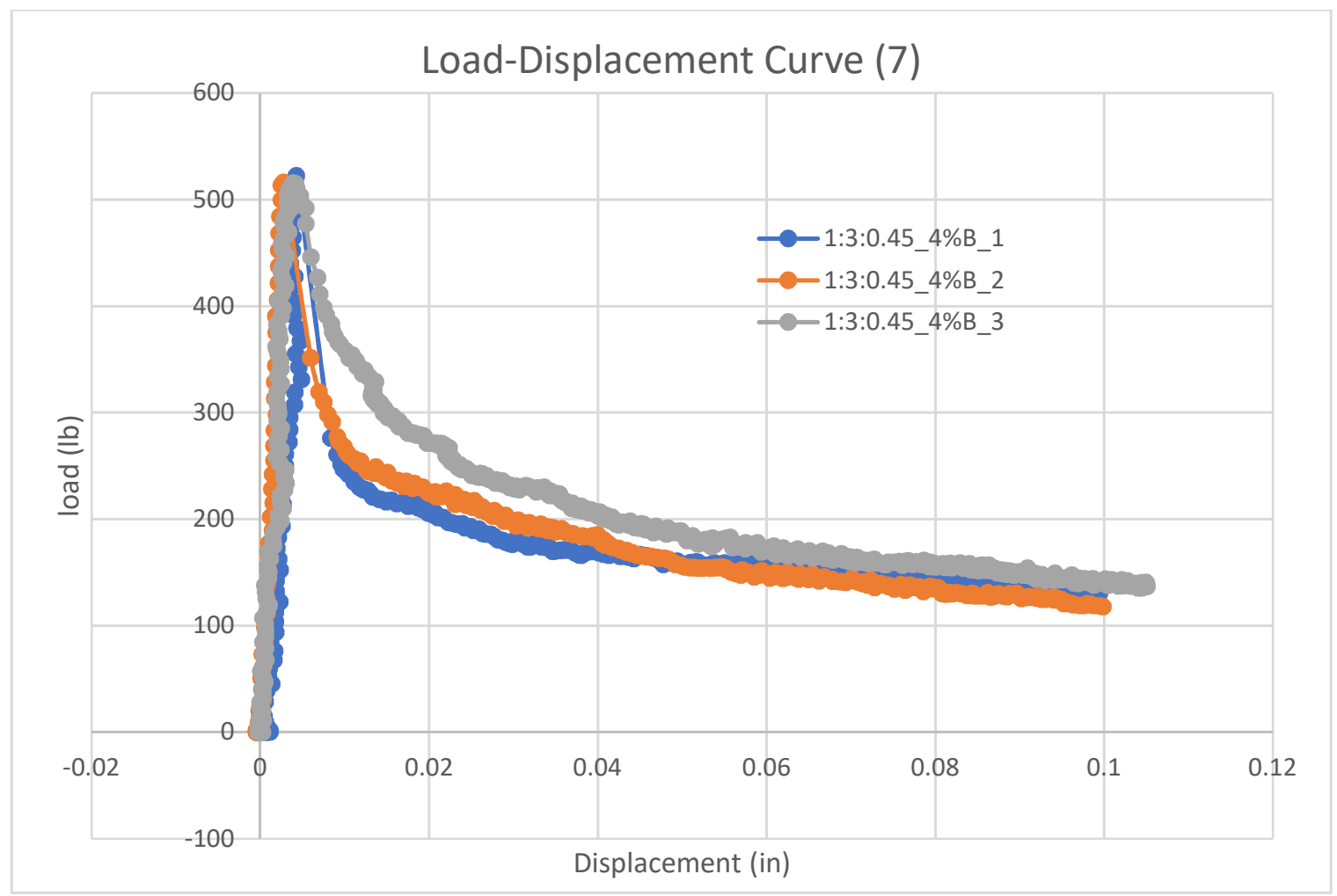

Figure 7 Load-Displacement Curve of 4\% Fiber B in Mortar Mix 1

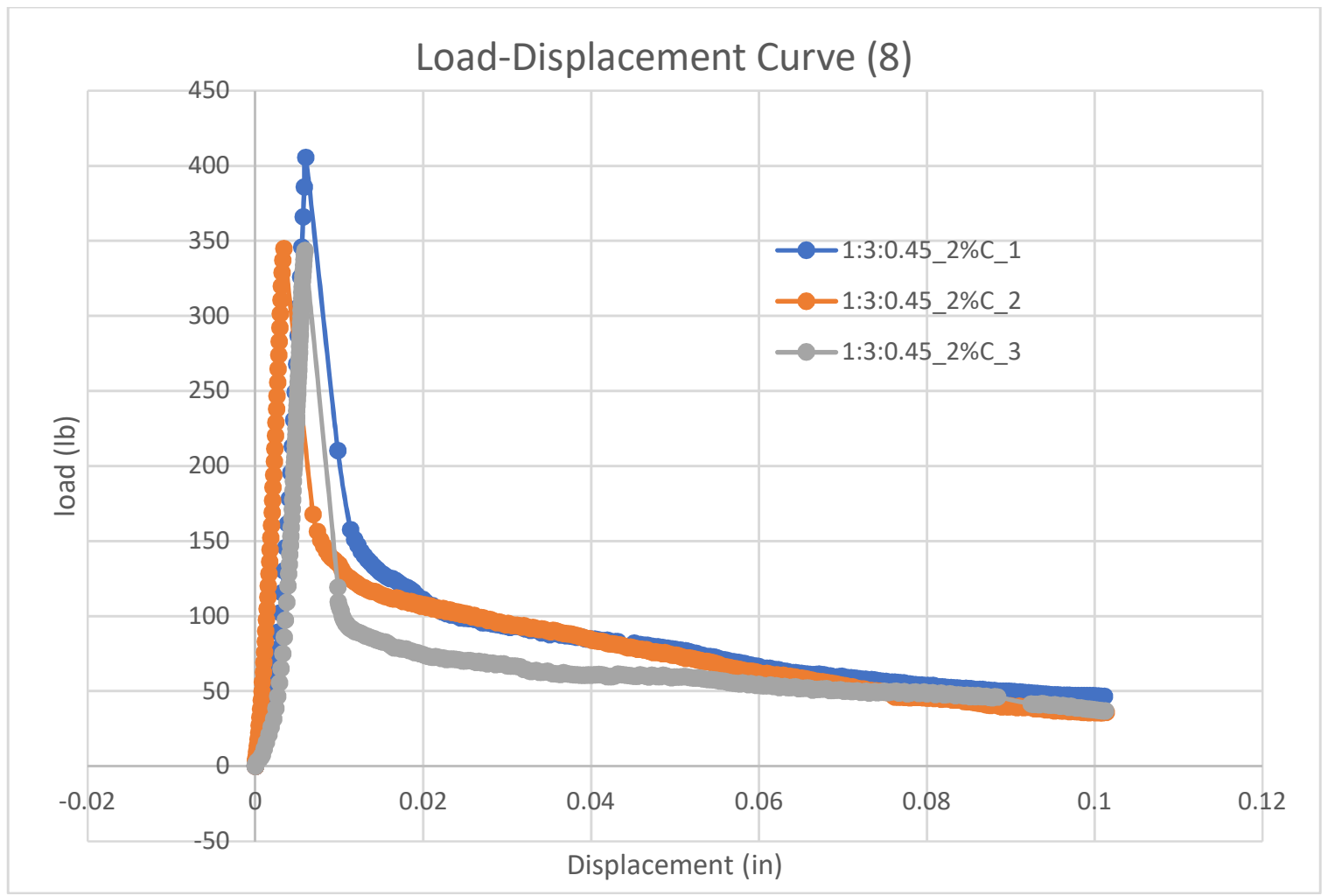

Figure 8 Load-Displacement Curve of 2\% Fiber C in Mortar Mix 1 


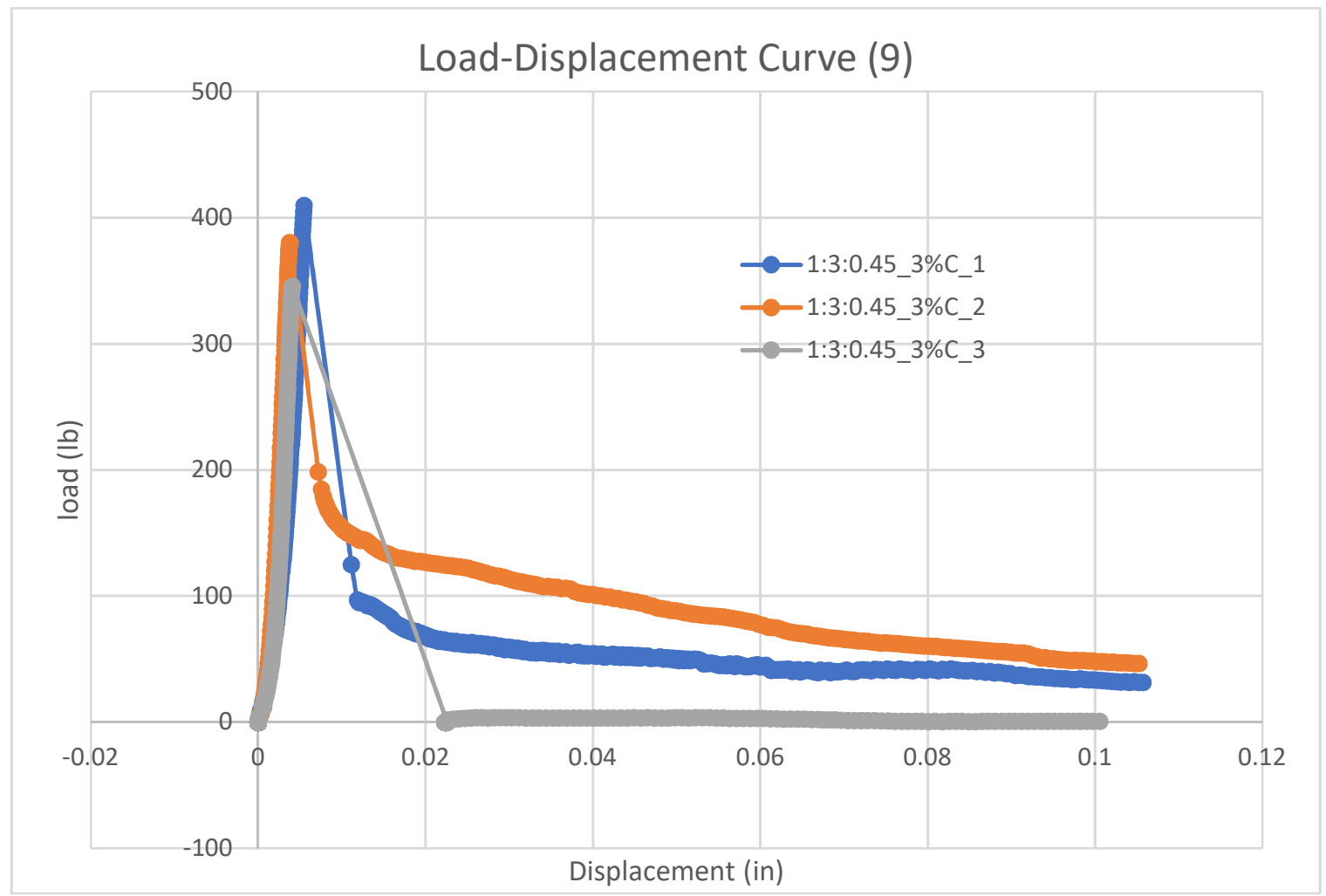

Figure 9 Load-Displacement Curve of 3\% Fiber C in Mortar Mix 1

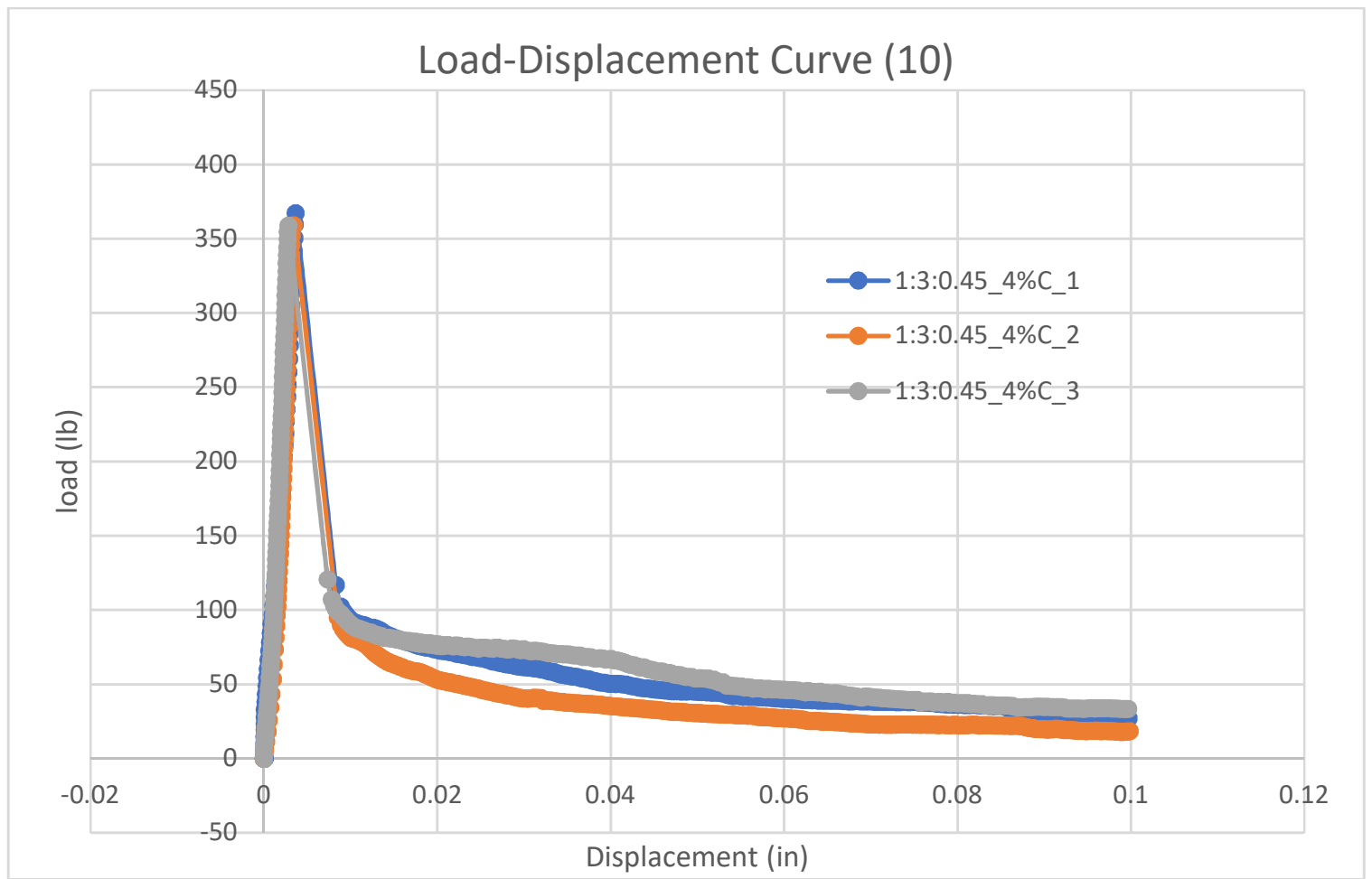

Figure 10 Load-Displacement Curve of 4\% Fiber C in Mortar Mix 1 


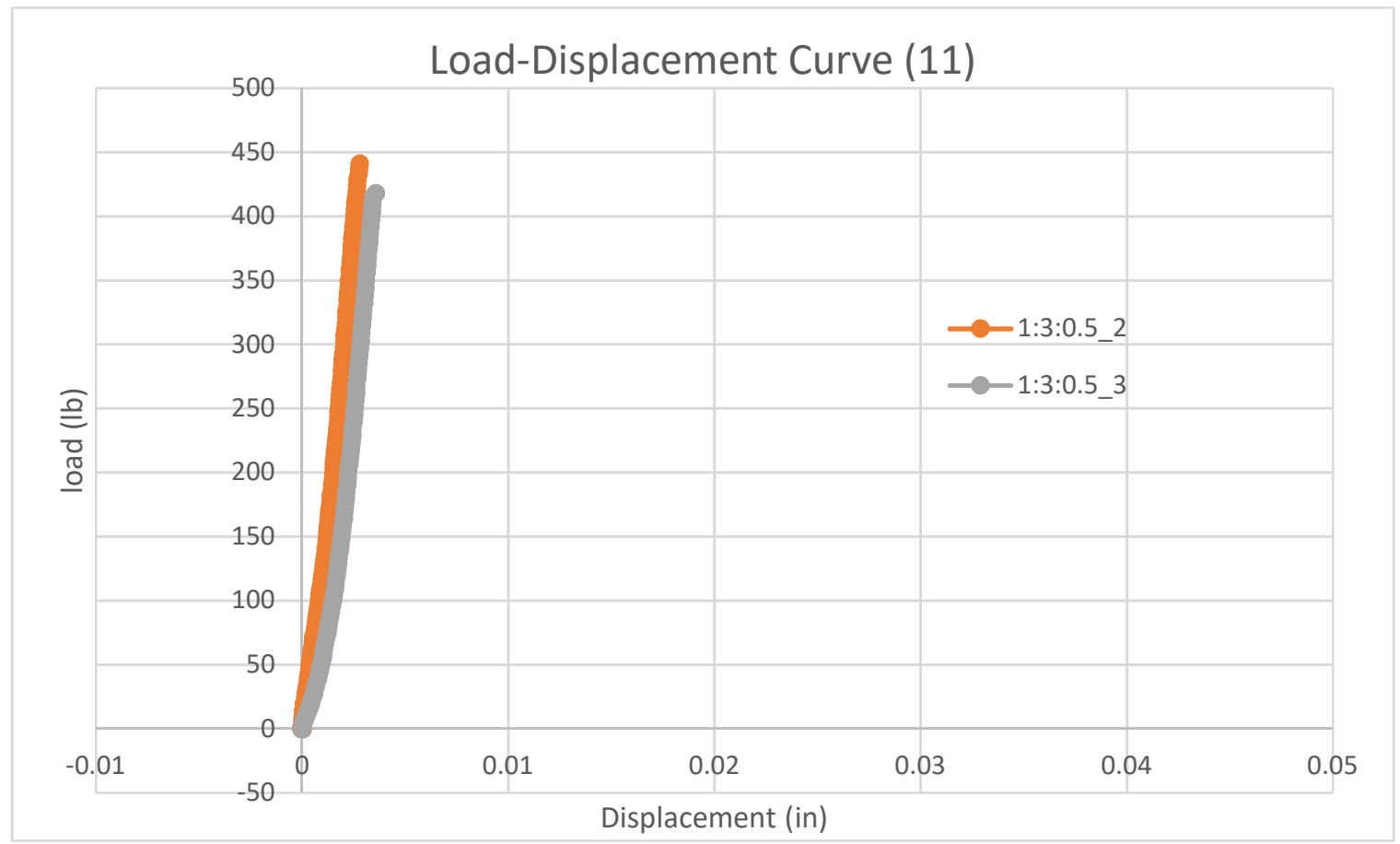

Figure 11 Load-Displacement Curve of Plain Mortar Mix 2

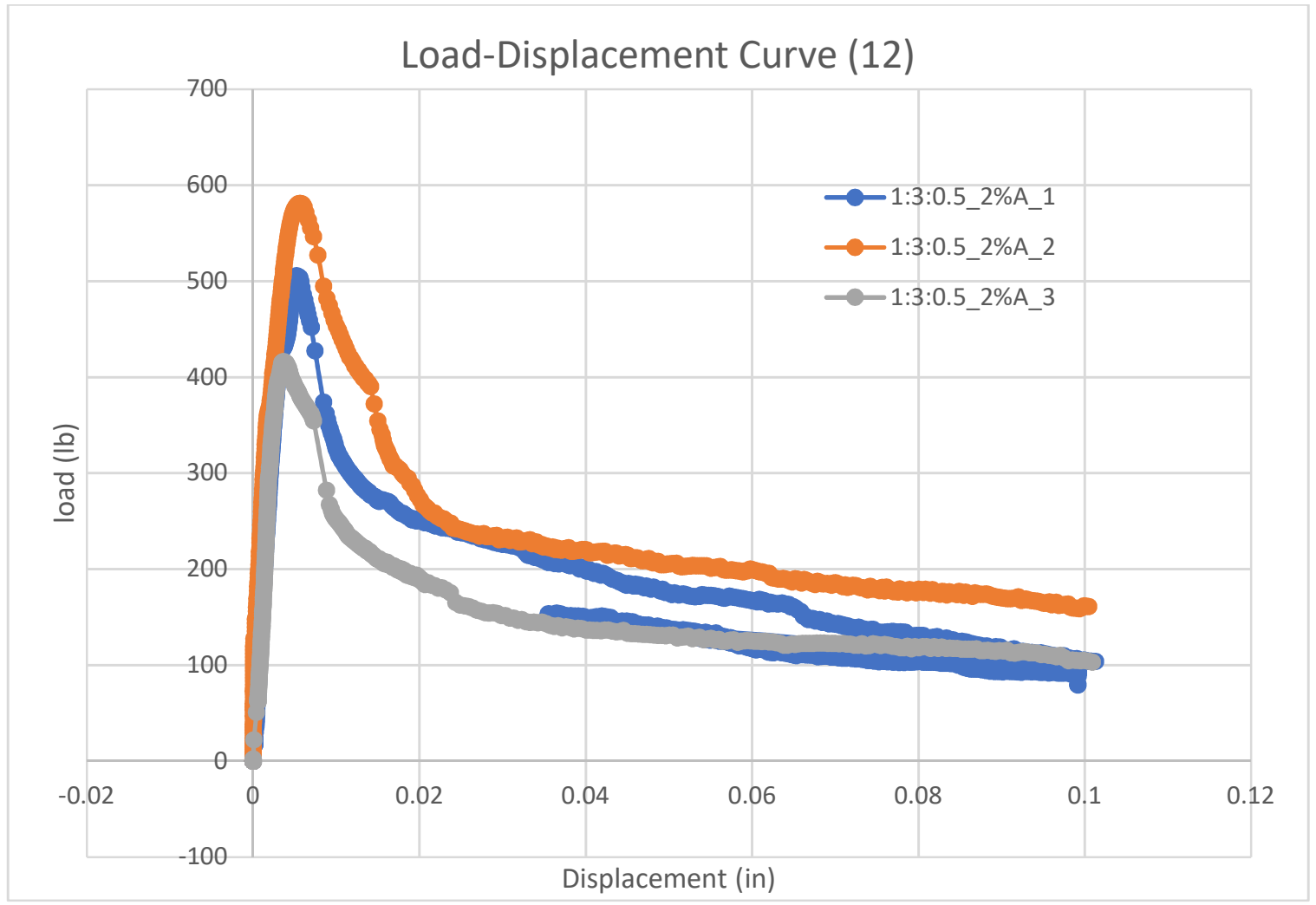

Figure 12 Load-Displacement Curve of 2\% Fiber A in Mortar Mix 2 


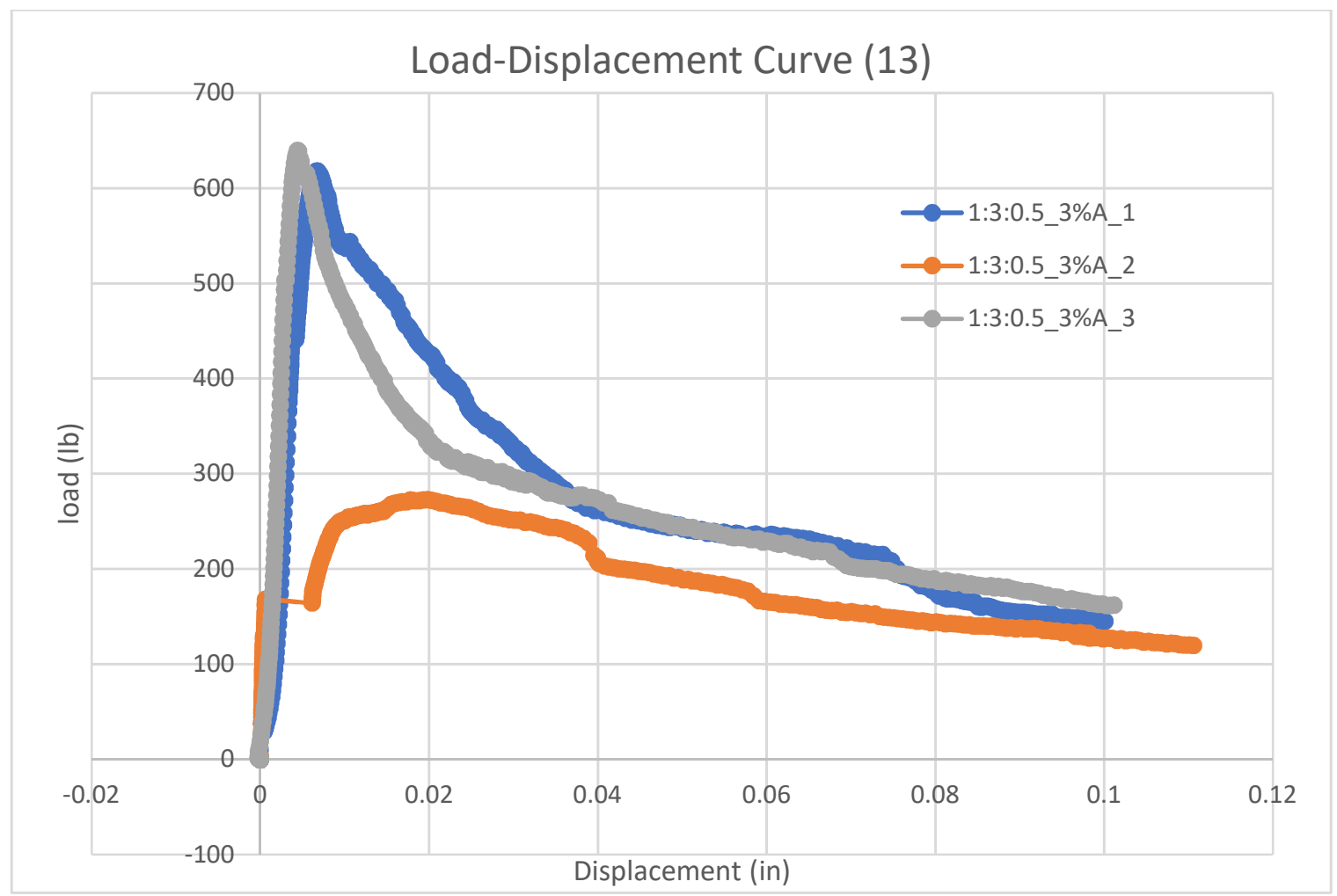

Figure 13 Load-Displacement Curve of 3\% Fiber A in Mortar Mix 2

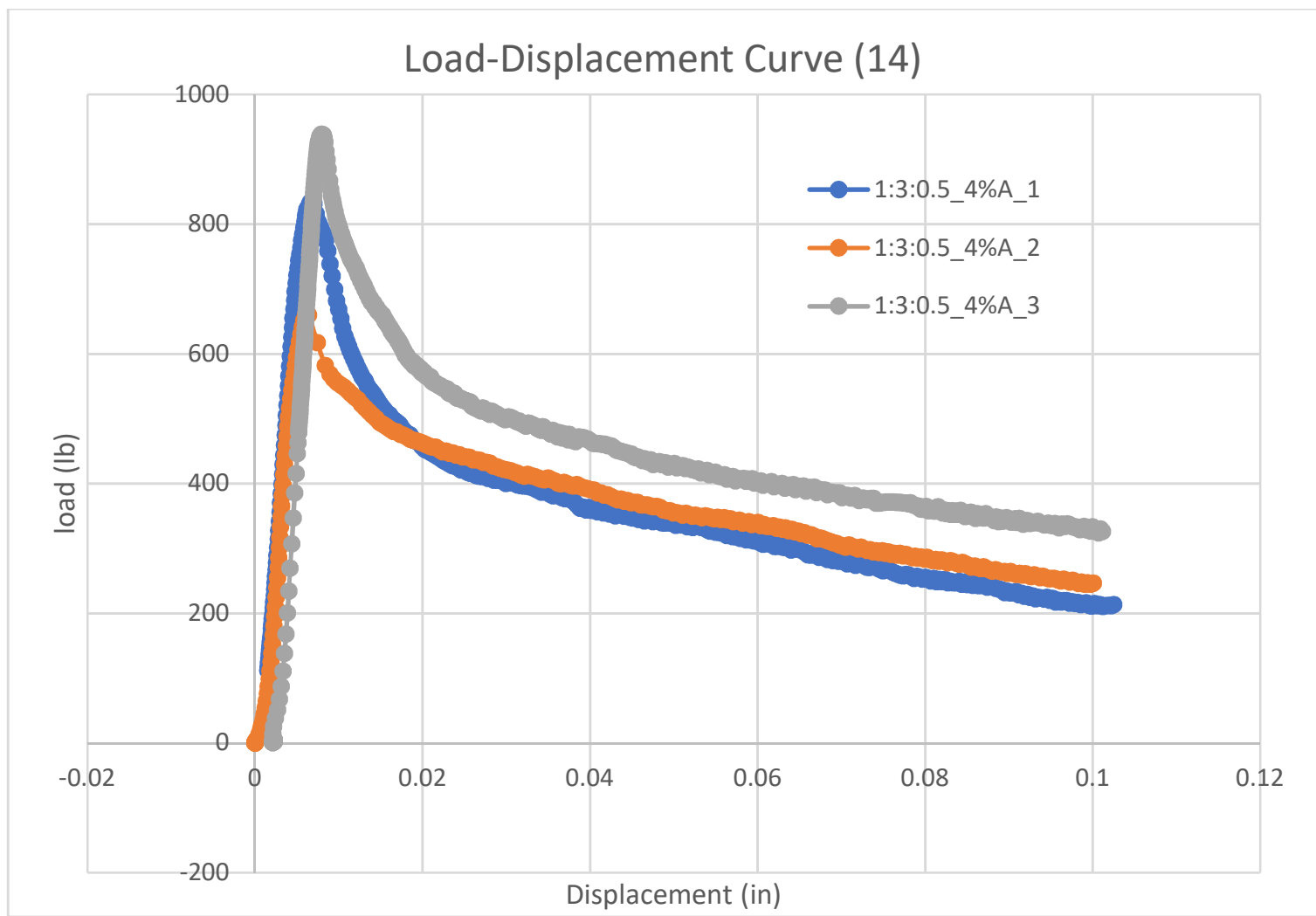

Figure 14 Load-Displacement Curve of 4\% Fiber A in Mortar Mix 2 


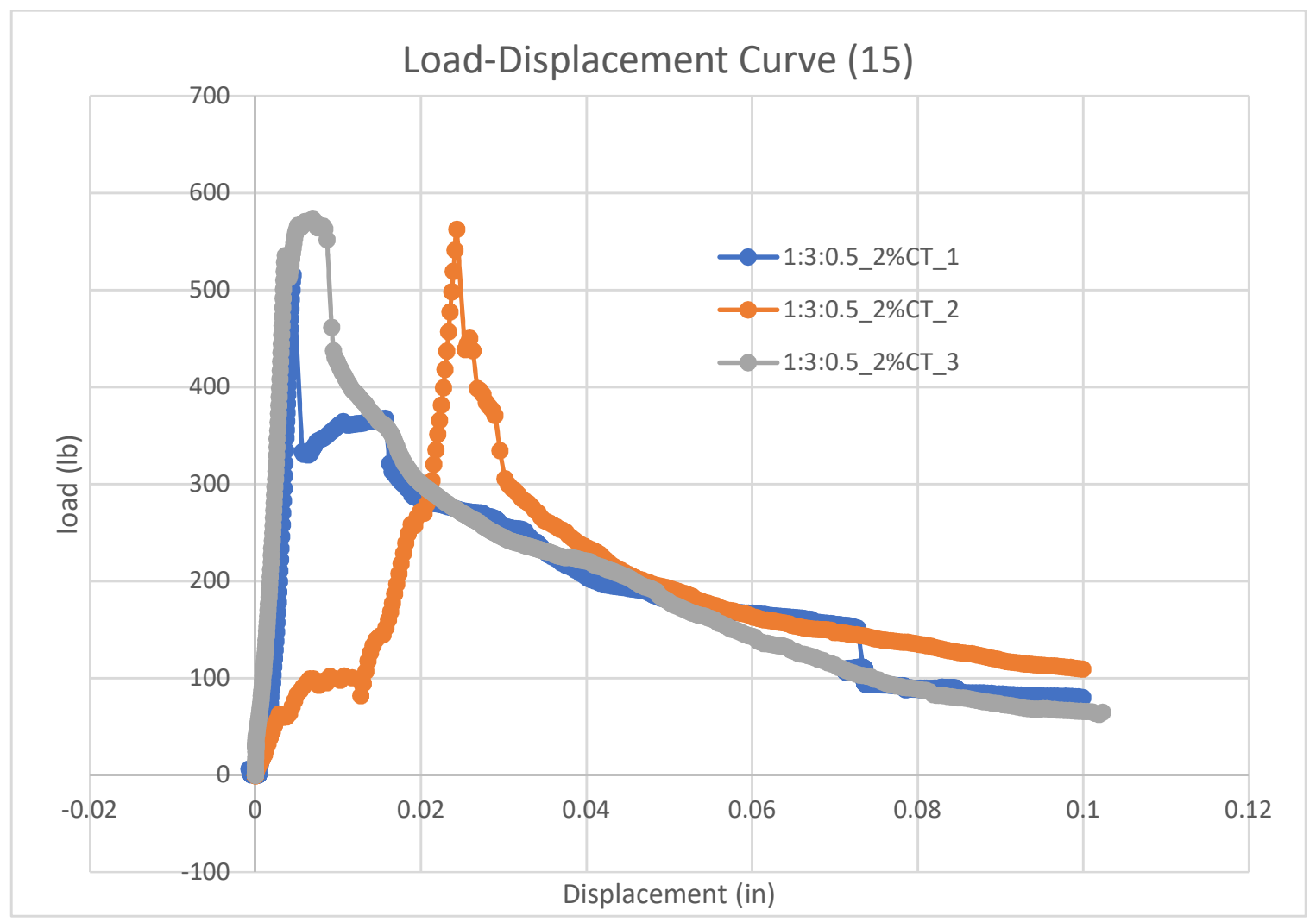

Figure 15 Load-Displacement Curve of 2\% Fiber CT2 in Mortar Mix 2

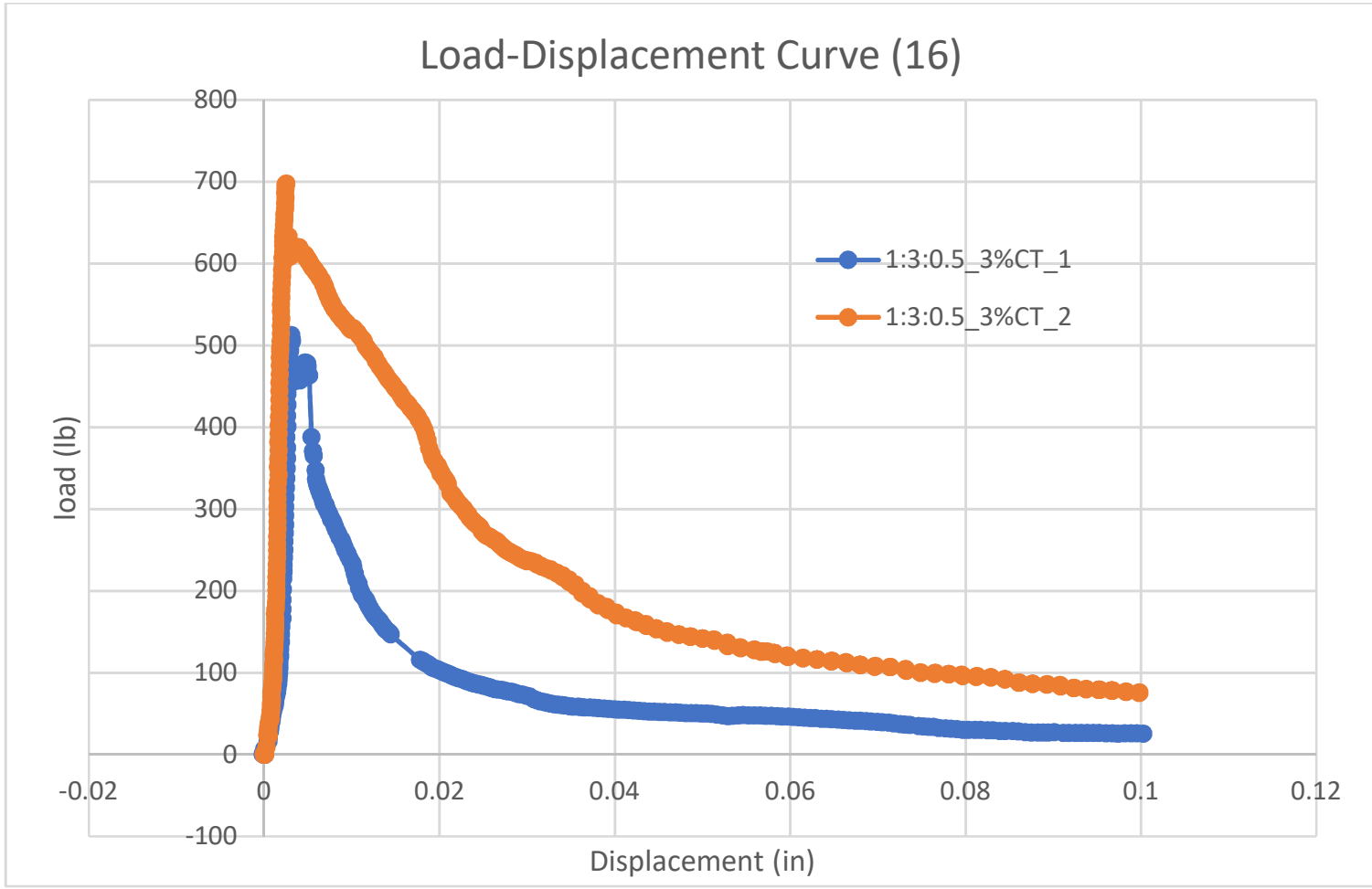

Figure 16 Load-Displacement Curve of 3\% Fiber CT2 in Mortar Mix 2 


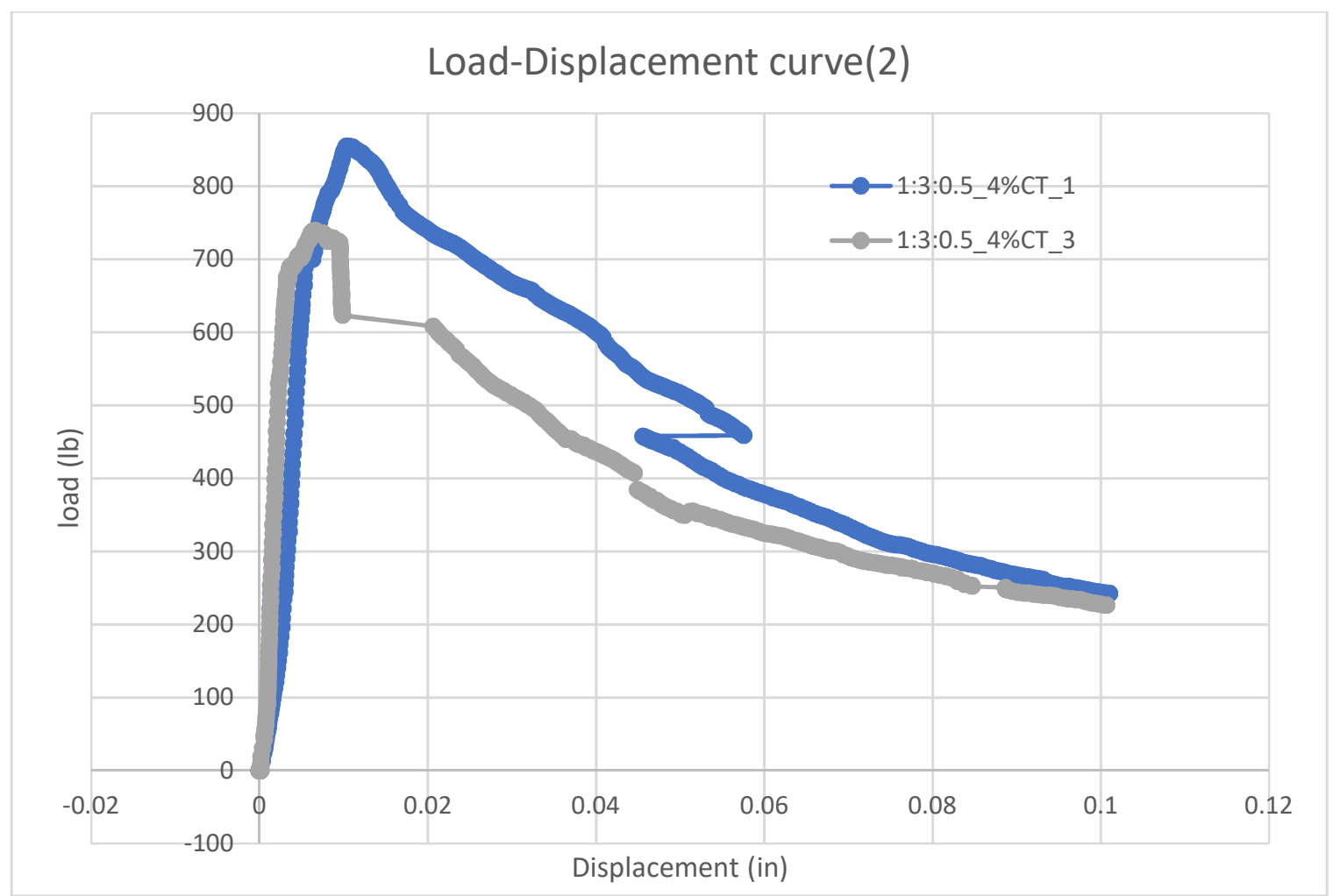

Figure 17 Load-Displacement Curve of 4\% Fiber CT2 in Mortar Mix 2 


\section{APPENDIX B. MATLAB CODE}

The pre-crack code is an typical example of all the pre-crack codes, developed for precrack behavior of Fiber A in mortar mix 1. If fiber or mortar type changes, change the related parameter to adjust the actual situation.

a). Pre-crack code:

clear all

clc

\%fiber feature, unit: $\mathrm{mm} \mathrm{MPa}$

lf $=25.4 * 1.0 ; \mathrm{df}=0.029 * 25.4 ; \mathrm{sf}=0.0025 * 1 \mathrm{f} / 2 ;$

taofmax $=2.395 ; \%$ Due to pull out test

\%specimen feature, unit: $\mathrm{mm} \mathrm{MPa}$

width $=40 ;$ height $=40 ; \mathrm{fc}=46 ; \mathrm{fr}=5.507 ; \mathrm{Ec}=4730^{*} \mathrm{fc}^{\wedge} 0.5^{*} 10^{\wedge} 6 ; \% \mathrm{Ec}=5.32 * 10^{\wedge} 9 ; \%$

$\%$ calculate accuracy \& upper limit

step $1=0.01 ; \operatorname{limit} 1=6 / 6 * \mathrm{pi} / 2 ;$ num $1=$ floor $(\operatorname{limit} 1 / \mathrm{step} 1)+1 ; \%$ sita

step2 $=0.1 ; \operatorname{limit} 2=1 \mathrm{f} / 2 ;$ num2 $=$ floor(limit $2 /$ step 2$)+1 ; \%$ la

step3 $=0.002 ; \operatorname{limit} 3=2 ;$ num3 $=$ floor $(\operatorname{limit} 3 /$ step3 $)+1 ; \%$ wcr

step4=0.0002; limit4=0.05; num4=floor(limit4/step4) $+1 ; \% \mathrm{Vf}$

oarfaf=0.5; \% if sin, distribution density function

\%arfaf $=0.6366 ; \quad \%$ if $2 / \mathrm{pi}$

$\operatorname{arfaf}=0.7854 ; \quad$ 의 $\cos$

$\%$ sita

for $\mathrm{i}=1$ :num 1

$\operatorname{sita}(i)=\operatorname{step} 1 *(i-1) ;$

end

$\%$ la

for $\mathrm{j}=1$ :num 2

la $(\mathrm{j})=\operatorname{step} 2 *(\mathrm{j}-1)$;

end

$\%$ wer

for $\mathrm{k}=1$ :num3

$\mathrm{wcr}(\mathrm{k})=\operatorname{step} 3 *(\mathrm{k}-1) ;$ 


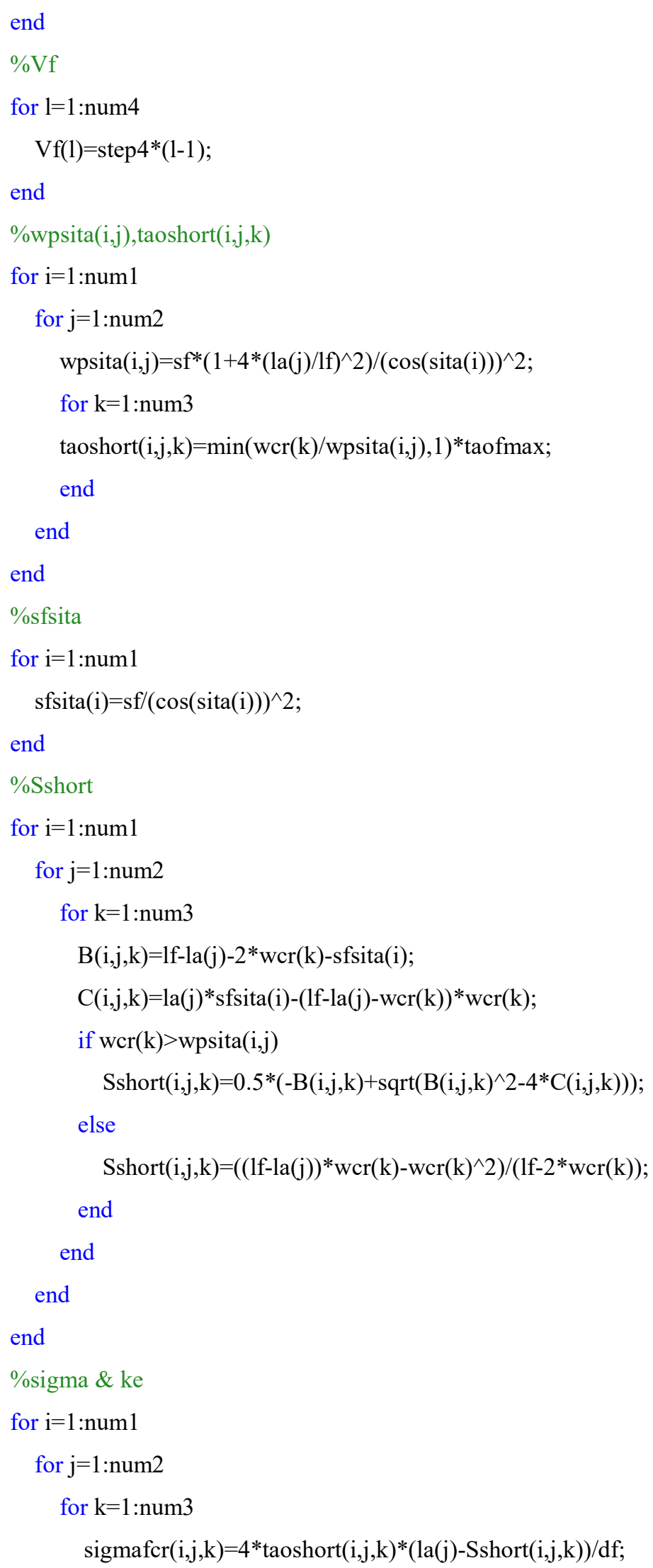




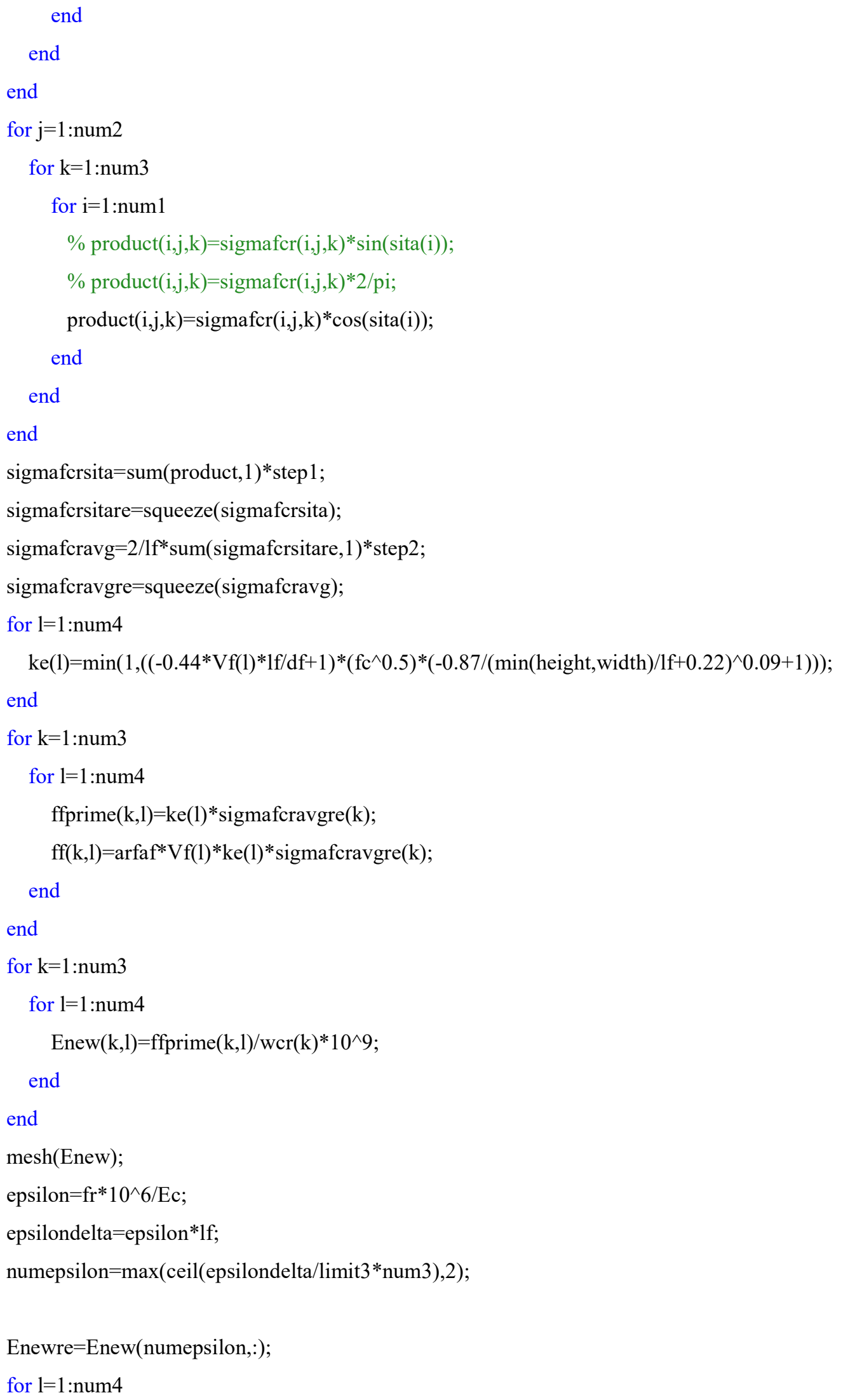


ffnew $(1)=(1-V f(1)) * f r+$ Enewre(l)*epsilon*arfaf*Vf(1)/(10^6);

end

$\mathrm{MF}=\mathrm{ffnew} / \mathrm{fr}$;

$\operatorname{plot}(\mathrm{MF})$

The post-crack code is an typical example of all the post-crack codes, developed for postcrack behavior of Fiber A in mortar mix 1. If fiber or mortar type changes, change the related parameter to adjust the actual situation.

\section{b). Post-crack code:}

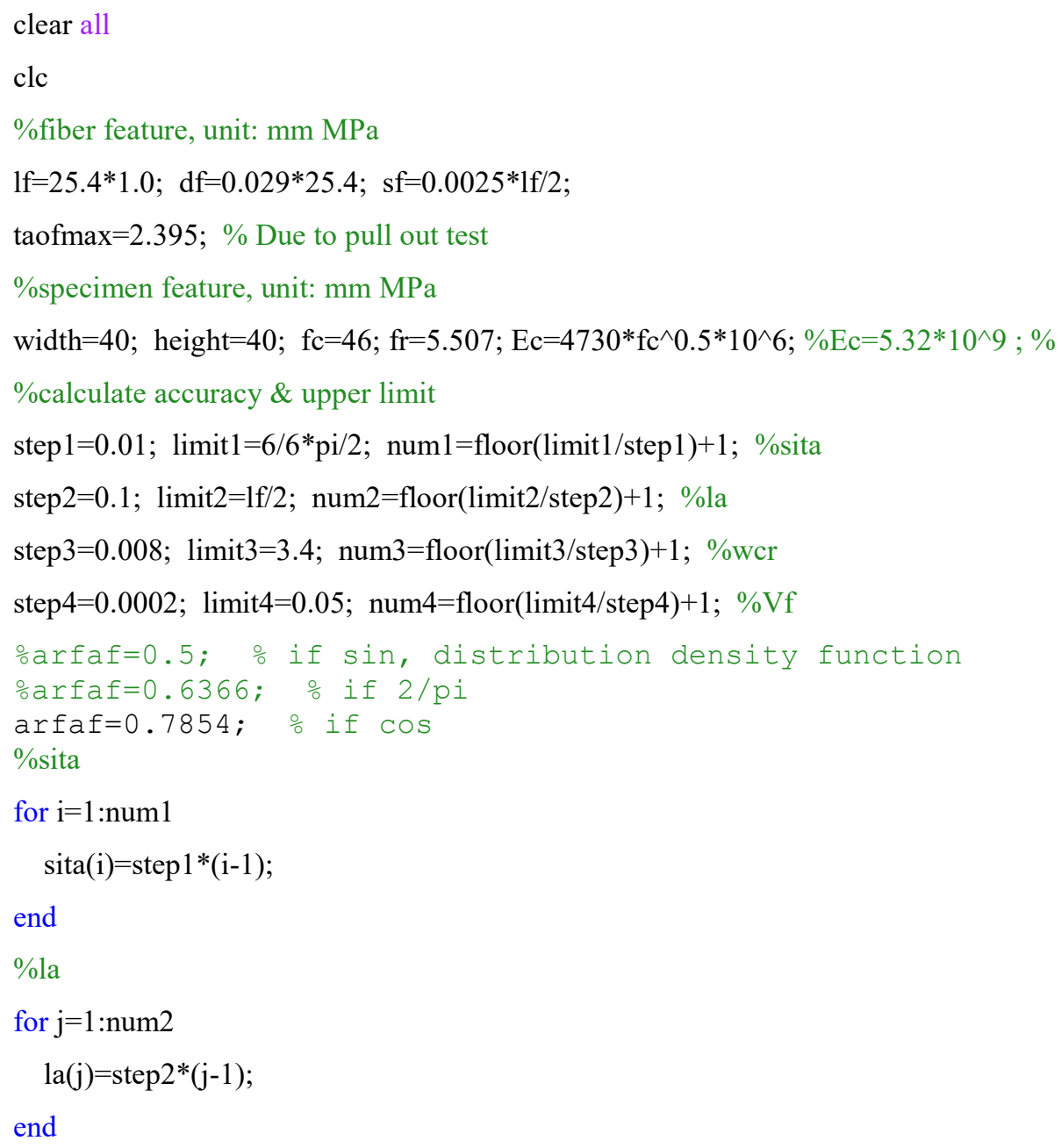




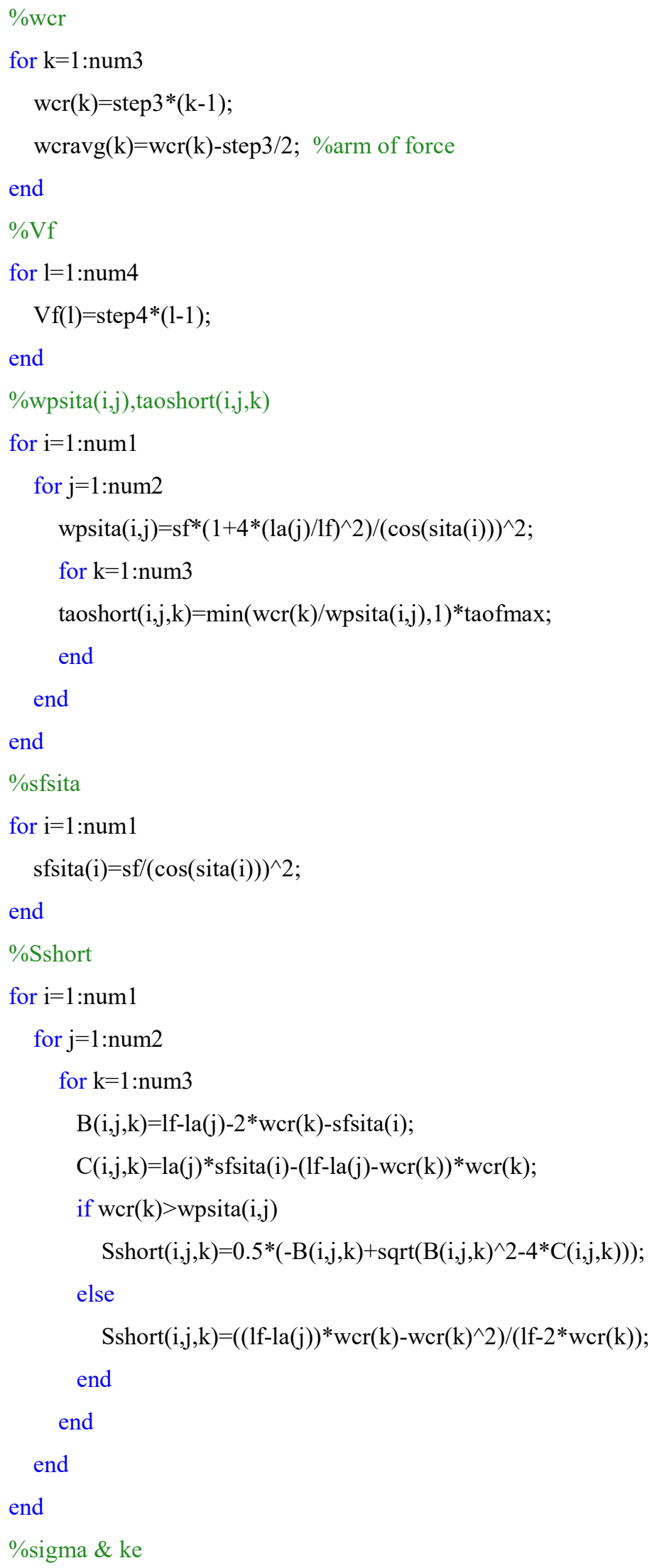




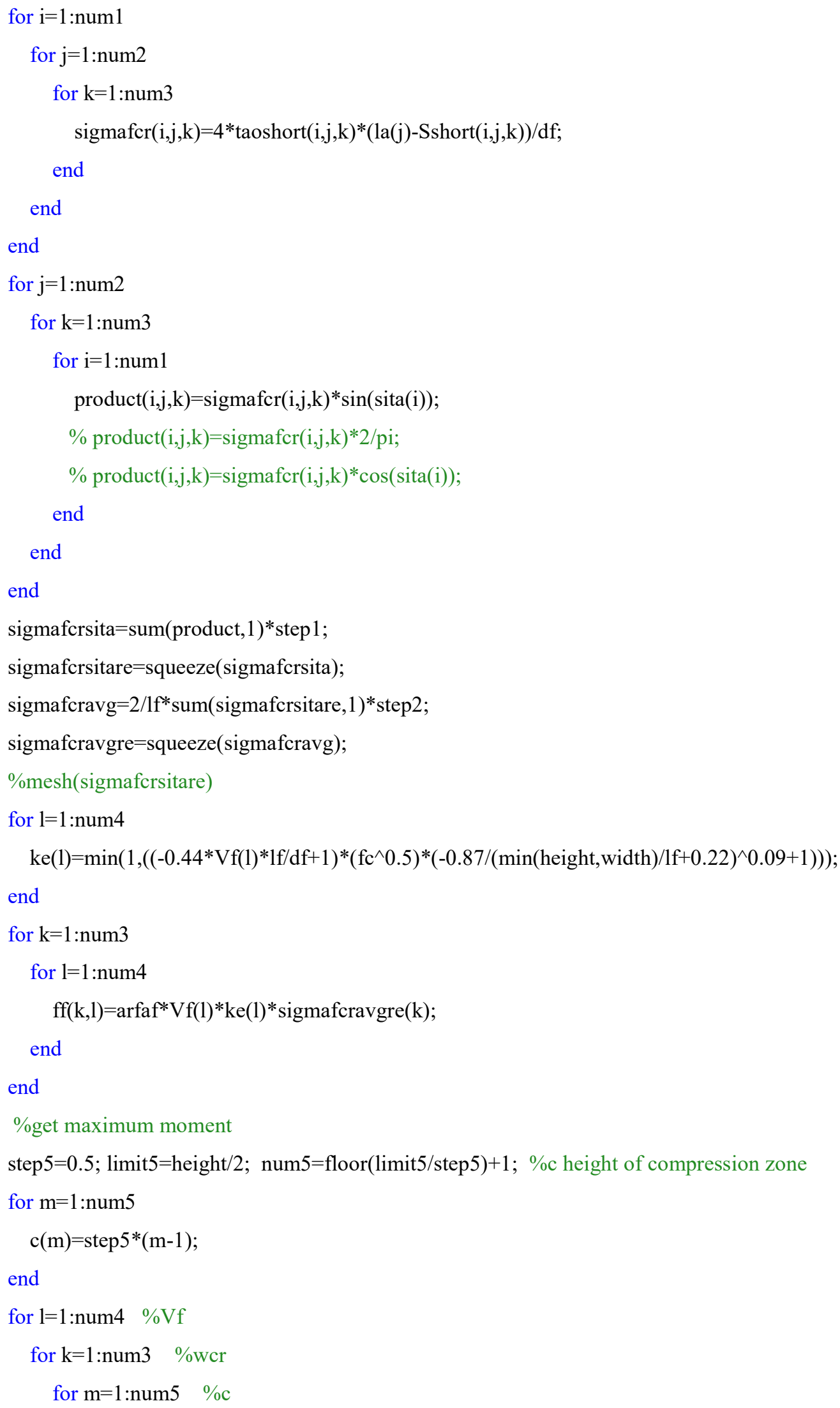




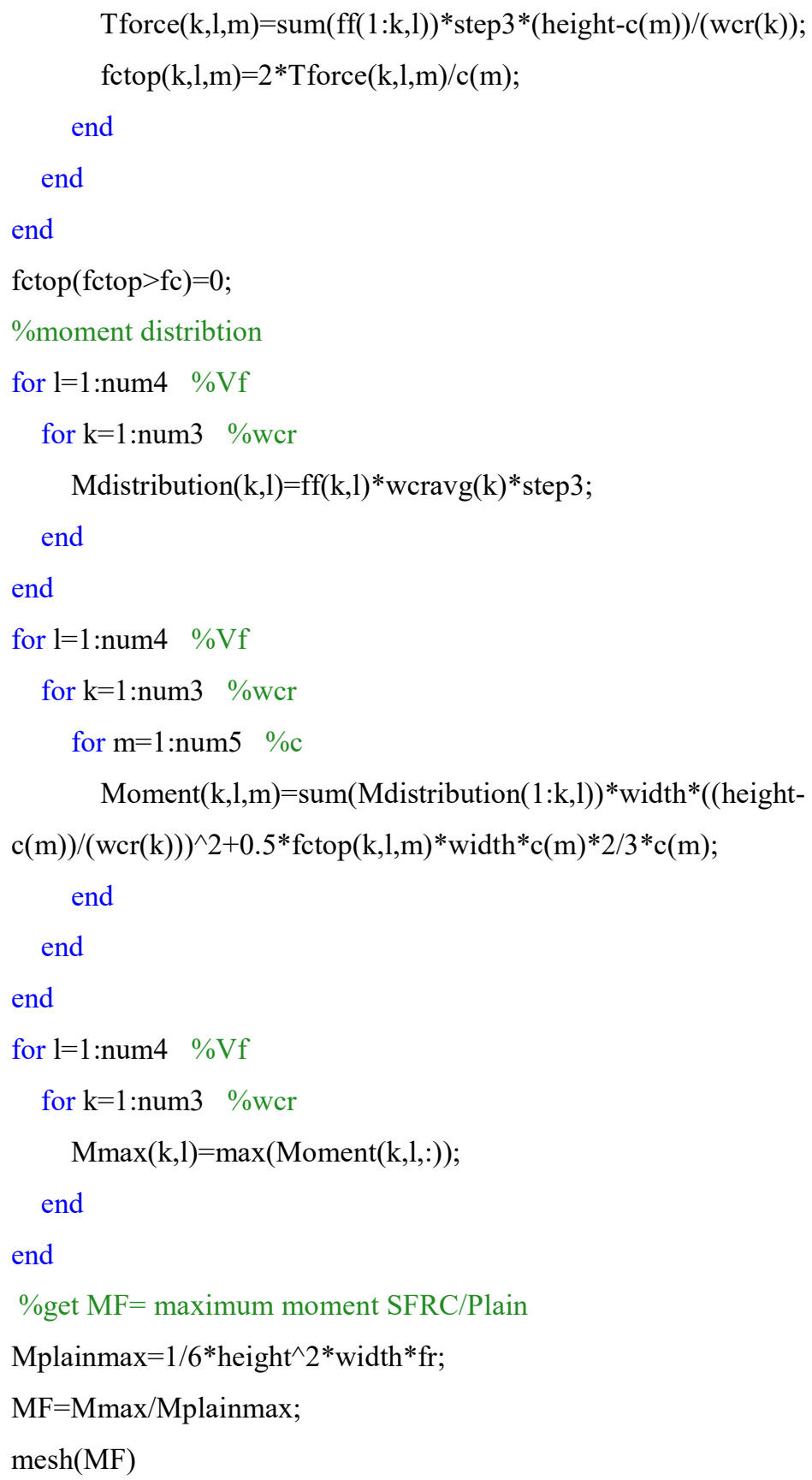




\section{CURRICULUM VITA}

NAME: Li Liu

ADDRESS: Department of Civil and Environmental Engineering

132 Eastern Parkway

University of Louisville

Louisville, KY 40292

DOB: $\quad$ Wuhan, Hubei, China- May 3, 1990

EDUCATION \& TRAINING:

B.S., Civil Engineering

Huazhong University of Science \& Technology

2008-2012

M.S., Civil Engineering

University of Louisville

2016-2017 